Pontifícia Universidade C Católica

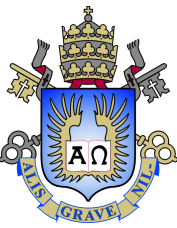

Otavio Hiroaki Morisita Fujisima

\title{
Banking Spread Decomposition through a Structural Macroeconomic Model
}

Dissertation presented to the Programa de Pós-graduação em Economia da PUC-Rio in partial fulfillment of the requirements for the degree of Mestre em Economia .

Advisor : Prof. Carlos Viana de Carvalho Co-advisor: $\quad$ Prof. Eduardo Zilberman 


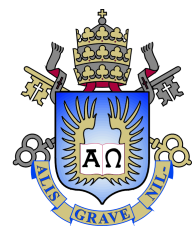

\section{Otavio Hiroaki Morisita Fujisima}

\section{Banking Spread Decomposition through a Structural Macroeconomic Model}

Dissertation presented to the Programa de Pós-graduação em Economia da PUC-Rio in partial fulfillment of the requirements for the degree of Mestre em Economia. Approved by the Examination Committee.

Prof. Carlos Viana de Carvalho Advisor

Departamento de Economia - PUC-Rio

Prof. Eduardo Zilberman

Co-advisor

Departamento de Economia - PUC-Rio

Prof. André Minella

Banco Central do Brasil - BCB

Prof. Yvan Becard

Departamento de Economia - PUC-Rio

Rio de Janeiro, July the 29th, 2021 
All rights reserved.

\section{Otavio Hiroaki Morisita Fujisima}

B.A. in Economics, Instituto de Ensino e Pesquisa (Insper), 2016.

Bibliographic data

Morisita Fujisima, Otavio Hiroaki

Banking Spread Decomposition through a Structural Macroeconomic Model / Otavio Hiroaki Morisita Fujisima; advisor: Carlos Viana de Carvalho; co-advisor: Eduardo Zilberman. - Rio de janeiro: PUC-Rio, Departamento de Economia, 2021.

v., 77 f: il. color. ; $30 \mathrm{~cm}$

Dissertação (mestrado) - Pontifícia Universidade Católica do Rio de Janeiro, Departamento de Economia.

Inclui bibliografia

1. Economia - Teses. 2. Macroeconomia - Teses. 3. Fricção Financeira;. 4. DSGE;. 5. Spread Bancário;. 6. Decomposição;. 7. Inadimplência;. I. Carvalho, Carlos Viana de. II. Zilberman, Eduardo. III. Pontifícia Universidade Católica do Rio de Janeiro. Departamento de Economia. IV. Título. 


\section{Acknowledgments}

I thank the Universe for everyday new opportunity and the self consciousness that I can always try again.

I thank my advisors Carlos Viana and Eduardo Zilberman for guidance through this whole journey and the lessons beyond academic perspective.

I thank my friend Raffael Russo for the support during the darkest moments of this process.

I thank my classmates and friends for the support and the friendship during this process with special acknowledgements to Luiz Sacramento, Mateus Morais, Raphael Ludwig, Rafael Fonseca, and Gilberto Boaretto.

I thank my family and my girlfriend Maria Carla for the support, knowledge and understanding.

I thank PUC-Rio and Economics Department for this opportunity and for every person that touched my life.

Financial support from Vinci Partners and CAPES is gratefully acknowledged. This study was financed in part by the Coordenação de Aperfeiçoamento de Pessoal de Nível Superior - Brasil (CAPES) - Código de Financiamento 001 


\section{Abstract}

Morisita Fujisima, Otavio Hiroaki; Carvalho, Carlos Viana de (Advisor); Zilberman, Eduardo (Co-Advisor). Banking Spread Decomposition through a Structural Macroeconomic Model. Rio de Janeiro, 2021. 77p. Dissertação de mestrado - Departamento de Economia, Pontifícia Universidade Católica do Rio de Janeiro.

This paper aims to decompose the banking spread using a structural macroeconomic model. We embedded a general equilibrium framework with loans to households and entrepreneurs that may be in default, a banking sector in monopolistic competition and subject to administrative costs, and we also added a tax structure related to bank intermediation. These characteristics for the composition of the spread are in line with the empirical literature on banking spread determinants in Brazil and with the accounting decomposition of the spread made by the Banco Central do Brasil (BCB). Our quantitative findings reveal that household spread reduction is greater when we increase competition in the banking sector (3.77 p.p. quarterly or $54 \%$ decrease compared to baseline calibration). Furthermore, reducing administrative cost is the most effective way of diminishing entrepreneur spread (1.35 p.p. quarterly or $46 \%$ decrease compared to baseline) and it is also capable of diminishing household spread (2.5 p.p. quarterly or $36 \%$ decrease compared to baseline). Results also suggest some careful actions by policy makers only supported by BCB accounting decomposition without an economic model underpinning the analysis. This dissertation also reveals some challenges regarding the inclusion of credit default with a banking sector in imperfect competition and its contribution to the spread formation.

\section{Keywords}

Financial Friction; DSGE; Banking Spread; Decomposition; Default; 


\section{Resumo}

Morisita Fujisima, Otavio Hiroaki; Carvalho, Carlos Viana de; Zilberman, Eduardo. Decomposição do Spread Bancário através de um modelo Macroeconômico Estrutural. Rio de Janeiro, 2021. 77p. Dissertação de Mestrado - Departamento de Economia, Pontifícia Universidade Católica do Rio de Janeiro.

Este artigo objetiva decompor o spread bancário utilizando um modelo macroeconômico estrutural. Nós enriquecemos um arcabouço de equilíbrio geral com empréstimos para indivíduos e firmas que podem inadimplir, um setor bancário em competição monopolística e sujeito a custos administrativos e também acrescentamos uma estrutura de impostos relacionadas a intermediação bancária. Essas características da composição do spread estão em linha com a literatura empírica dos determinantes do spread bancário e com a decomposição contábil do spread realizada pelo Banco Central do Brasil (BCB). Nossa análise quantitativa revela que a redução do spread para indivíduos é maior quando aumentamos a competição no mercado bancário (3.77 p.p. trimestral ou 54\% comparado a calibração baseline). Ademais, redução do custo administrativo é a maneira mais eficaz para reduzir o spread para firmas (1.35 p.p. trimestral ou $46 \%$ comparado a calibração baseline) e também é capaz de reduzir o spread para indivíduos (2.5 p.p. trimestral ou $36 \%$ comparado a calibração baseline). Resultados também sugerem cuidado na formulação de políticas econômicas somente baseadas na decomposição contábil realizada pelo BCB e sem um modelo econômico fundamentando a análise. Esta dissertação também revela alguns desafios relacionados à inclusão da inadimplência juntamente com um mercado bancário em competição imperfeita e sua contribuição para formação do spread.

\section{Palavras-chave}

Friç̧ão Financeira; DSGE; Spread Bancário; Decomposição; Inadimplência; 


\section{Table of contents}

1 Introduction $\quad 12$

2 Brief Literature Review $\quad 15$

3 The Analytical Framework $\quad 17$

$\begin{array}{lll}3.1 & \text { Patient Households } & 17\end{array}$

$\begin{array}{lll}3.2 & \text { Impatient Households } & 19\end{array}$

3.3 Entrepreneurs 21

3.4 Loan and Deposit Demand 22

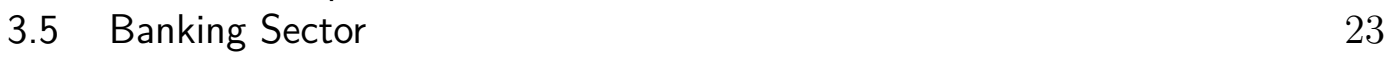

3.5.1 Wholesale Branch 24

3.5.2 Loan Branch 25

3.5.3 Deposit Branch 26

$\begin{array}{lll}3.6 & \text { Recycling Firms } & 27\end{array}$

$\begin{array}{lll}3.7 & \text { Capital Producers } & 27\end{array}$

3.8 Durable Goods Producers 28

3.9 Retail Firms and Final Goods Producers 28

$\begin{array}{ll}3.10 \text { Government } & 29\end{array}$

3.11 Market Clearing 30

3.12 Steady State $\quad 30$

$4 \quad$ Steady State Quantitative Analysis $\quad 33$

4.1 Calibration 33

4.2 ICC Accounting Spread Decomposition 37

$\begin{array}{lll}4.3 & \text { Counterfactual Analysis } & 38\end{array}$

5 Conclusion $\quad 43$

$\begin{array}{lll}\text { A Economic Spread Decomposition } & 46\end{array}$

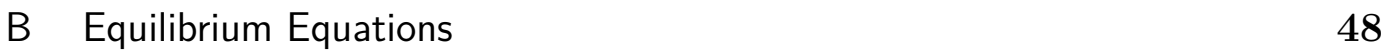

B.1 Patient Households 48

B.2 Impatient Households 48

$\begin{array}{lll}\text { B.3 Entrepreneur } & 49\end{array}$

B.4 Banking Sector 50

B.5 Capital and Durable Good Producer 51

B.6 Retail Firms 51

B.7 Government $\quad 51$

B.8 Recycling Firms $\quad 52$

B.9 Market Clearing and Exogenous Process 52

C Steady State $\quad 53$

D BCB Accounting Decomposition - Adapted $\quad 57$ 
$\begin{array}{ll}\text { E Counterfactual Analysis - Combinations } & 58\end{array}$

F Propagation of Shocks $\quad 61$

F.1 Monetary Policy Shock $\quad 61$

F.2 Technology Shock 63

G Steps of debt payment from the Representative Entrepreneur $\quad 65$

H $\quad$ Default Modelling Approaches - Alternative Model $1 \quad 66$

H.1 Banking Sector - Alternative Model 1

H.1.1 Wholesale Branch - Alternative Model $1 \quad 67$

$\begin{array}{ll}\text { H.1.2 Funding Loan Branch } & 67\end{array}$

H.1.3 Deposit Branch - Alternative Model $1 \quad 68$

H.2 Commercial banks - impatient households 68

H.3 Impatient households - Alternative Model $1 \quad 69$

H.4 Entrepreneurs - Alternative Model 1

H.5 Government - Alternative Model 1

H.6 Steady State - Alternative Model $1 \quad 70$

H.7 Counterfactual Analysis - Alternative Model 1

I Model with Banking Technology - Alternative Model 2

$\begin{array}{ll}\text { J Data Sources } & \mathbf{7 5}\end{array}$

J.1 Nonearmarked credit operations outstanding - Total 75

J.2 Nonearmarked credit operations outstanding - Non-financial corporations - Total $\quad 75$

J.3 Nonearmarked credit operations outstanding - Households - Total 75

J.4 Percent of 90 days past due loans of nonearmarked credit operations outstanding - Non-financial corporations - Total 75

J.5 90 days past due loans - Nonearmarked credit outstanding - Households - Total $\quad 76$

J.6 Regulatory Capital to Risk-Weighted Assets 76

J.7 ICC Spread - Nonearmarked - Non-financial corporations - Total 76

J.8 ICC Spread - Nonearmarked - Households - Total 76

J.9 GDP at current prices in R\$ 76

J.10 GDP - investment rate - current prices $\quad 77$

$\begin{array}{ll}\text { J.11 Payout } & 77\end{array}$

$\begin{array}{ll}\text { J.12 IPCA } & 77\end{array}$

$\begin{array}{lll}\text { J.13 CDB } & 77\end{array}$ 


\section{List of figures}

Figure 1.1 Banco Central do Brasil (2019b) - nonearmarked credit 12

$\begin{array}{lll}\text { Figure 3.1 The Model - main connections } & 18\end{array}$

$\begin{array}{lll}\text { Figure } 4.1 & \text { Model } & 38\end{array}$

Figure 4.2 Banco Central do Brasil (2019b) - nonearmarked credit 38

Figure A.1 Impatient household $\quad 47$

$\begin{array}{lll}\text { Figure A.2 Entrepreneur } & 47\end{array}$

$\begin{array}{lll}\text { Figure A.3 Total } & 47\end{array}$

Figure F.1 Monetary Policy Shock $\quad 62$

Figure F.2 Technology Shock 64

Figure H.1 Model with strategic default - main connections 66 


\section{List of tables}

Table 4.1 Calibration $\quad 35$

Table 4.2 Steady State Properties - Model vs Data 37

Table 4.3 Counterfactual Analysis - $1 \quad 40$

Table 4.4 Accounting vs Counterfactual 41

Table E.1 Counterfactual Analysis - 2 58

Table E.2 Counterfactual Analysis - $3 \quad 59$

Table H.1 Counterfactual Analysis 1 - Alternative Model 1

Table H.2 Counterfactual Analysis 2 - Alternative Model 1 


\section{List of Abreviations}

BCB - Banco Central do Brasil

CB - Central Bank

CDB - Certificado de Depósito Bancário

COFINS - Contribuição para o Financiamento da Seguridade Social

CSLL - Contribuição Social Sobre o Lucro Líquido

DSGE - Dynamic Stochastic General Equilibrium

FF - Financial Friction

FGC - Fundo Garantidor de Crédito

GDP - Gross Domestic Product

ICC - Índice de Custo de Crédito

IOF - Imposto sobre Operações Financeiras

IPCA - Índice Nacional de Preços ao Consumidor Amplo

IRPJ - Imposto de Renda das Pessoas Jurídicas

OECD - Organisation for Economic Co-operation and Development

PIS - Programa de Integração Social

RDB - Recibos de Depósitos bancários

REB - Relatório de Economia Bancária

SELIC - Sistema Especial de Liquidação e Custódia 


\section{Introduction}

Banking spread is an important variable for economic growth and the Brazilian economy is an international outlier in terms of high banking spread, ${ }^{1}$ even controlling for the credit-to-GDP (World Bank (2018)). Reducing banking spread as an official objective of Banco Central do Brasil (BCB) dates back at least to 1999 with the project Juros e Spread Bancário no Brasil. Recently, the Agenda $B C+$ reinforced the idea and not only did it aim to reduce the credit cost to final borrowers, but also diminish default rate, and foster competition in credit markets as a pillar for that agenda. One particular study under this initiative is the Índice de Custo de Crédito (ICC) spread decomposition which estimates component shares of an average banking spread. Figure 1.1 reports ICC main components and shares calculated in Banco Central do Brasil $(2019 b) .^{2}$

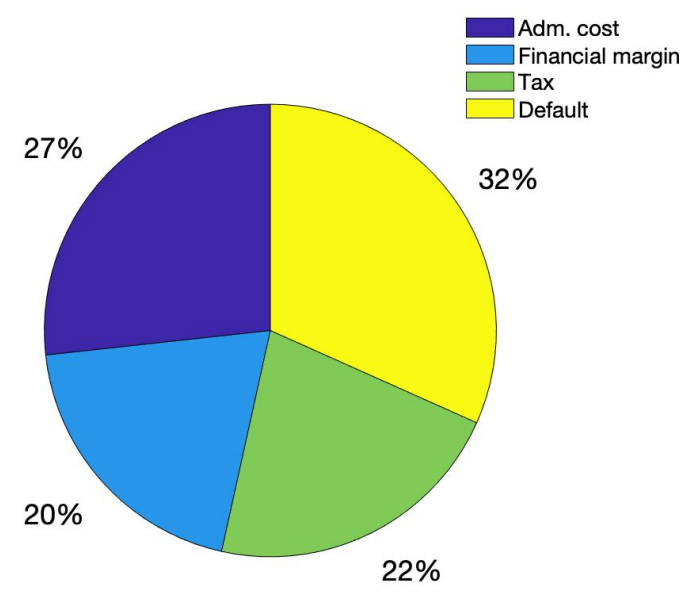

Figure 1.1: Banco Central do Brasil (2019b) - nonearmarked credit

\footnotetext{
${ }^{1}$ Banco Central do Brasil (BCB) estimates wedges of $7.7 \%$ quarterly faced by households and $2.91 \%$ faced by non-financial firms. Only non-earmarked credit (i.e., financing and loans in which rates and destination are negotiated freely between financial institutions and borrowers). Monthly average between 2013-2019.

${ }^{2}$ Administrative cost embrace general cost like employee training, payroll, and marketing. Tax share captures expenditures related to banking intermediation of funds taxation and contributions to Fundo Garantidor de Crédito (FGC). Unpaid debts and interest rates compose default share. Lastly, financial margin is a residual account and captures bank profits and other factors not mapped by the methodology.
} 
In this dissertation we study and decompose the banking spread according to ICC decomposition with the support of a structural macroeconomic model. We utilize a DSGE with financial friction characterized by endogenous default, administrative cost, tax, and a banking sector in monopolistic competition. Our approach is different from most of studies.

We calibrate the model to match Brazilian moments and analyze the steady state to decompose spread in level. We perform two spread decomposition exercises. In the first exercise, we adapt and apply the ICC accounting decomposition methodology to our model steady state and compare with the shares calculated by BCB in Figure 1.1. This procedure may be thought of as an untargeted moments evaluation except the administrative share which we use as a moment target in calibration. Administrative cost, financial margin, tax and default implied by model shares are 24\%, 21\%, 30\% and 24\%, respectively. Therefore, our model performs reasonably well.

Our main decomposition exercise is the counterfactual analysis which it is performed by altering parameters values to simulate economic policies aiming at spread reduction. Results suggest that fostering competition in credit markets reduces household spread by 3.77 p.p. quarterly or $54 \%$ compared to baseline. Moreover, undermining bank administrative cost decreases firm spread by 1.35 p.p. quarterly or $46 \%$ compared to baseline.

We then compare the components shares calculated by the ICC accounting methodology applied to our model steady state $(\mathrm{m})$ and shares calculated in Figure 1.1 (BCB) with the spread reduction relative to baseline in counterfactual analysis. Average spread tax share represents $30 \%$ implied by model (m) or $22 \%$ calculated by BCB (BCB) while absence of taxation leads to $18.96 \%$ spread reduction in counterfactual analysis. Administrative cost share in accounting exercise is $24 \%(\mathrm{~m})$ or $27 \%$ (BCB), but counterfactual exercise delivers $39.36 \%$ spread decline relative to baseline. Financial margin accounting share represents $21 \%(\mathrm{~m})$ or $20 \%$ (BCB), but no financial margin simulation results in $43.45 \%$ average spread reduction compared to baseline.

Our quantitative findings reveal that household spread reduction is greater when we increase competition in the banking sector. Furthermore, reducing administrative cost is the most effective way of diminishing entrepreneur spread and it is also capable of diminishing household spread in a meaningful way. World Bank (2018) provides empirical evidence regarding the administrative cost as an important component of banking spread. Furthermore, results suggest some careful actions by policy makers only supported by ICC accounting decomposition without an economic model underpinning the analysis. 
In Chapter 2 we briefly discuss the empirical literature on banking spread determinants and studies that directly influence the construction of our model. We note that only Souza-Sobrinho (2010) studies banking spread of Brazilian economy supported by a macroeconomic model with a steady state analysis. Contrasting to our dissertation, his model features different spread components. First, our model does not include an earmarked type of credit, but we include household credit. Second, we model an endogenous default and not only a constant default cost. Third, we incorporate a rich tax structure related to the intermediation of funds in line with the ICC spread decomposition. We see our dissertation as complementary to Souza-Sobrinho (2010) analysis.

We present our DSGE with financial friction model in Chapter 3. It features different agents with respect discount factors, hence patient households are always savers and impatient households and entrepreneurs are always borrowers. Borrowers are subject to a borrowing constraint determining availability of credit and they offer collateral on their debt. Collateral is affected by idiosyncratic shocks giving rise to credit default. Intermediation of funds between savers and borrowers is executed by a banking sector in monopolistic competition. Furthermore, banks face administrative cost to provide credit, reserve requirements, and taxes. After presenting the model, we show steady state interest rates derived from agents optimization problems that provide intuitions about our results.

In Chapter 4, we perform the quantitative analysis which consists of calibrating the model to match Brazilian moments and perform two steady state decompositions. In ICC Accounting Spread Decomposition, we adapt ICC decomposition methodology and apply it to our model steady state, and the process may be thought of as an untargeted moments evaluation. Counterfactual Analysis is the most important decomposition to which we change parameters values to simulate economic policies. We then compare Counterfactual Analysis and ICC Accounting Spread Decomposition in terms of spread reduction.

Finally, the Economic Spread Decomposition which consists of exploring steady state interest rates derived from agents optimal decisions is presented in Appendix A. The propagation of a monetary policy and technology shocks are presented in Appendix F. Alternative credit default modeling and a banking technology structural approach are shown in Appendices H and I, respectively. 


\section{2}

\section{Brief Literature Review}

We study the banking spread of Brazilian economy with the support of a macroeconomic model having in mind the empirical literature on spread determinants and DSGE with financial frictions. Although most studies regarding banking spread focus on trying to find empirical relationships, a few analyze the problem with a model. This dissertation fits into this category.

There is a relatively large empirical literature on the banking spread determinants of Brazilian economy. It is mainly motivated by policy questions since most authors are researchers from Banco Central do Brasil (BCB). The majority of this literature follows Ho and Saunders (1981) methodology that uses bank information and macroeconomic variables in a panel.

We highlight Bignotto and de Souza Rodrigues (2005) and Almeida and Divino (2015) which follow Ho and Saunders (1981) methodology. ${ }^{1}$ Although, studies differ in sample range and data sources both suggest that administrative cost and some measure of risk are the leading factors in explaining the banking spread variations. ${ }^{2}$ The relative importance of banking sector concentration (a proxy for banking competition) is not consistent in both studies. Joaquim et al. (2019) shed light on the question and use banks M\&A episodes as an exogenous variation to study the impact of competition on credit spread and quantity in the Brazilian Economy. Results suggest that less competition leads to higher spread and lower credit, despite possible gains from bank efficiency. Therefore, our model takes into account the most important determinants of banking spread identified by this literature.

Regarding the literature on DSGE with financial frictions, an upsurge of studies emerged after 2008 financial crisis. We only highlight studies that directly influence the construction of our model.

Our core structure model is based on Carvalho et al. (2018) which is a standard DSGE with financial friction and a new ingredient. They add consignado credit ("payroll lending"), whereby creditors are paid straight out of debtors' paychecks and evaluate the credit deepening in Latin America.

We introduce monopolistic competition banking sector in the same spirit

\footnotetext{
${ }^{1}$ Several papers follow the same methodology, we only cite the most important ones.

${ }^{2}$ World Bank (2018) reinforce that these are the main components of spreads.
} 
of Gerali et al. (2010) since it is a tractable modeling. We also incorporate a reduced form banking technology as Curdia and Woodford (2010) which employ final goods in order to produce credit. Their original intent of this modeling device is to capture agency and operational costs not explicitly modeled, but we interpret it as the bank administrative cost. In Appendix I, we present a structural approach of banking technology which is explicitly modeled. We choose the reduced form since it is easier to discipline parameters and intuitions of both approaches are similar.

We include credit default inspired by Elenev et al. (2018) whose issues regarding borrowers liquidity give rise to delinquency. Default is defined by a simple cut-off rule between paying the debt or losing collateral. Carvalho et al. (2014) and Darracq Pariès et al. (2010) also introduce credit default in a DSGE with Gerali et al. (2010) banking sector. ${ }^{3}$ Their modeling is based on Forlati and Lambertini (2011) and consists of a new layer of banks which intermediates funds between final borrowers and imperfect competitively banks. In Appendix $\mathrm{H}$, we show this alternative modeling and present some results. In particular, this modeling approach does not deliver credible results in our counterfactual analysis e.g., default rate skyrockets and can exceed 10 p.p. quarterly.

Finally, Souza-Sobrinho (2010) is the closest study to this dissertation in terms of quantitative analysis procedure. He studies the banking spread of Brazilian economy and also performs a model steady state analysis which he calls medium term analysis. His results suggest that earmarked credit is the main responsible for the high spread of nonearmarked credit. This dissertation is different from Souza-Sobrinho (2010) regarding the model and its main features. First, our model does not include an earmarked type of credit, but we include household credit. Second, we model an endogenous default and not only a constant default cost. Third, we incorporate a rich tax structure related to the intermediation of funds in line with the ICC spread decomposition. We see our dissertation as complementary to Souza-Sobrinho (2010) analysis.

\footnotetext{
${ }^{3}$ Jakab and Kumhof (2018) incorporate credit default in a baking sector resembling Gerali et al. (2010) framework. However, only the deposit market features monopolistic competition while loan market is perfect competitively and model in Costly State Verification fashion.
} 


\section{3}

\section{The Analytical Framework}

The structure of the model is based on Carvalho et al. (2018) incorporating Gerali et al. (2010) monopolistic competition in the banking sector. Banks are subject to subject administrative cost, credit default, and tax structure related to bank intermediation. We consider an economy with three groups of agents that are infinitely-lived: patient households ( $\mathrm{p})$, impatient households (I), and entrepreneurs (e). Each group is composed of a continuum of agents with measure one. Impatient households and entrepreneurs have discount factors lower than patient households (i.e., $\max \left\{\beta^{i}, \beta^{e}\right\}<\beta^{p}$ ), hence, the former two agents have the incentive to borrow from patient households in equilibrium. We focus on the case which patient households are always lenders and impatient households and entrepreneurs are always borrowers.

Inspired by Elenev et al. (2018), we model the credit default arising due to liquidity problem. Borrowers choose between paying last period debt plus interest or losing the collateral (assets and income) that are subject to idiosyncratic shocks. Then a simple default cut-off rule emerges from this decision. Moreover, the heterogeneity among borrowers agents ex-post idiosyncratic shocks is circumvented assuming perfect insurance among agents of each group.

Another important feature of the model is the monopolistic competition banking sector. Banks offer a differentiated product (loans and deposits) and hold market power, so they set interest rates subject to adjustment costs. Products are presented in a Dixit-Stiglitz framework and to save (borrow) one unit of resources agent has to deposit (lend) in every bank $j$ in $[0,1]$. This is a modeling device to capture market power by banks in a tractable manner. We also include administrative cost to provide credit, reserve requirements, and taxes. Government keeps the budget balance across all periods. Figure 3.1 shows the big picture of the model and its main connections.

\section{1}

\section{Patient Households}

Given the higher discount factor of patient agents $\beta^{p}$, we focus on the case which patient households are always lenders. Given the relative price of 


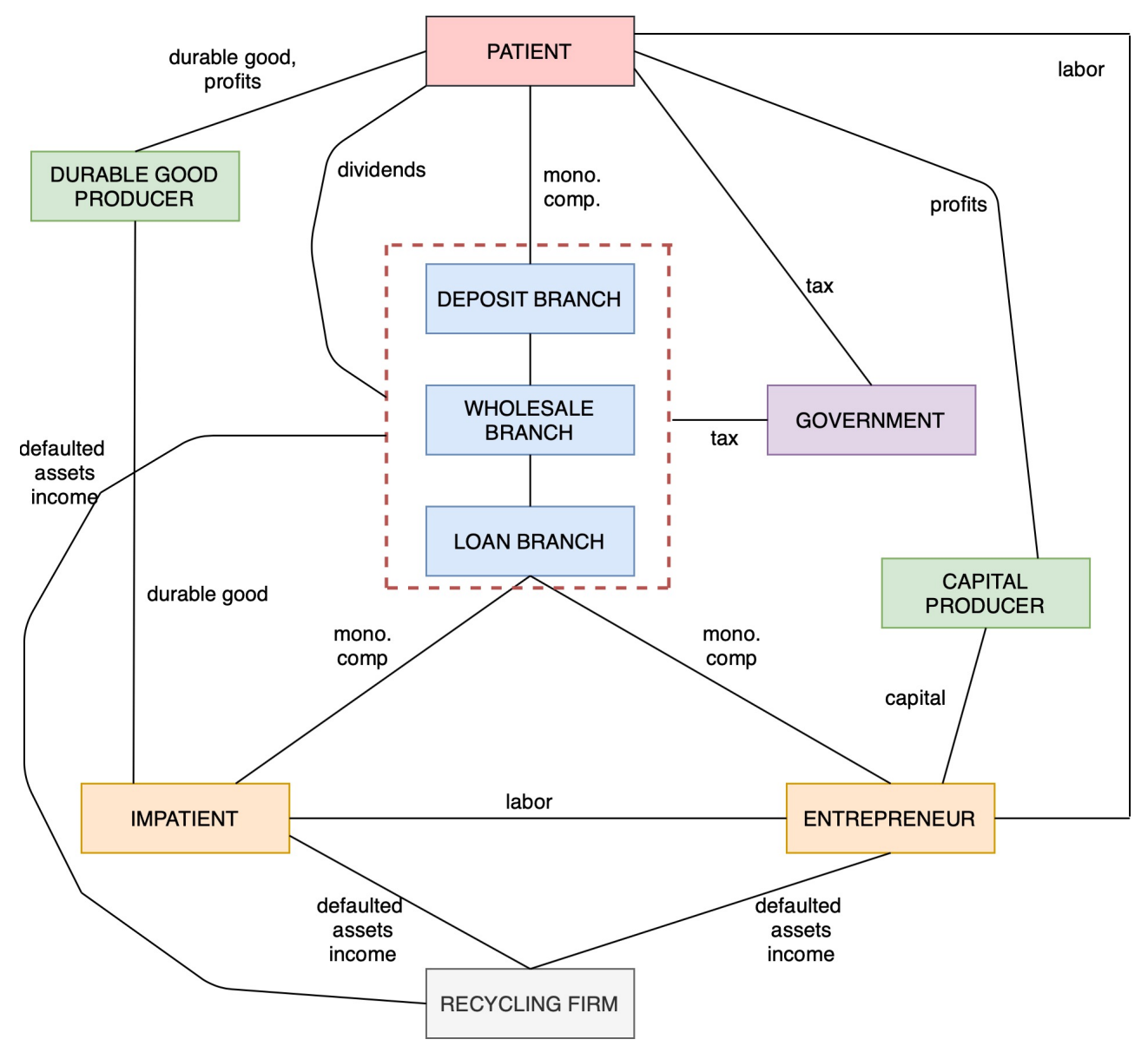

Figure 3.1: The Model - main connections

durable goods in terms of the final goods $q_{t}^{S}$, real wage $W_{t}^{p}$, and the interest on deposits $r_{t}^{d}$, patient households choose a stream of nondurable goods $C_{t}^{p}$, durable goods $S_{t}^{p}$, labor $L_{t}^{p}$, and bank deposits $D_{t}$ in order to maximize

$$
\mathbb{E}_{0} \sum_{t=0}^{\infty}\left(\beta^{p}\right)^{t}\left\{\log \left(\left[\xi\left(C_{t}^{p}\right)^{\sigma}+(1-\xi)\left(S_{t}^{p}\right)^{\sigma}\right]^{\frac{1}{\sigma}}\right)-\frac{\left(L_{t}^{p}\right)^{1+\varphi}}{1+\varphi}\right\}
$$

with $\beta^{p} \in(0,1)$, and $\varphi>0$ subject to the budget constraint

$$
C_{t}^{p}+q_{t}^{S} S_{t}^{p}+D_{t} \leq W_{t}^{p} L_{t}^{p}+q_{t}^{S}\left(1-\delta_{S}\right) S_{t-1}^{p}+\frac{\left(1+r_{t-1}^{d}\left(1-\tau^{p}\right)\right)}{\pi_{t}} D_{t-1}+T_{t}
$$

where $\delta_{S}$ is the depreciation rate of durable goods, $\pi_{t} \equiv \frac{P_{t}}{P_{t-1}}$ is the gross inflation rate, and $\tau^{p}$ is the tax rate on deposit return. $T_{t}$ is composed of banks and firms profits (excluding entrepreneurs). 


\section{2}

\section{Impatient Households}

We focus on the case in which impatient households are always borrowers. They have the same utility of patient households and consume nondurable goods, durable goods, and offer labor to entrepreneurs. Impatient households borrow funds from banks and offer collateral such as assets and labor income which define a borrowing constraint. In particular, labor income in the borrowing constraint captures consignado credit. Furthermore, collateral is subject to idiosyncratic shock in order to generate credit default.

Assets and labor income are offered as collateral and they are subject to idiosyncratic shock $\omega_{t}^{I}$. This is a random variable i.i.d. across time and households that follows a c.d.f. $F^{I}(\omega)$ over non-negative support with mean $1 .^{1}$

The threshold $\bar{\omega}_{t}^{I}$ in the equation below defines the indifference between paying the debt plus interest rate or leaving the collateral for banks (i.e., it defines a default cut-off rule). If $\omega_{t}^{I}<\bar{\omega}_{t}^{I}$, the impatient households default but lose the collateral or if $\omega_{t}^{I}>\bar{\omega}_{t}^{I}$ impatient households pay the debt plus interest and keep collateral. The left-hand side of equation below defines the last period debt plus interest rate and the right-hand side denotes collateral adjusted by idiosyncratic shock whose agent is indifferent compared to default.

$$
\frac{\left(1+r_{t-1}^{f I}\right) B_{t-1}^{I}}{\pi_{t}}=\bar{\omega}_{t}^{I}\left[q_{t}^{s}\left(1-\delta^{s}\right) S_{t-1}^{I}+W_{t}^{I} L_{t}^{I}\right],
$$

where $r_{t-1}^{f I}$ is the last period interest rate on debt, $B_{t-1}^{I}$ is the last period debt, $W_{t}^{I}$ is the impatient real wage rate, $L_{t}^{I}$ is the impatient labor services, and $S_{t}^{I}$ is the stock of durable goods.

We assume perfect insurance among impatient households, so the choices of consumption, labor, credit, and default are the same for all agents. This is a shortcut to circumvent the heterogeneity after idiosyncratic shocks realizations. Therefore, we can deal with a representative impatient household. ${ }^{2}$

The total last period debt payment from the representative impatient household is given by

$$
\int_{\bar{\omega}_{t}^{I}}^{\infty} \frac{\left(1+r_{t-1}^{f I}\right) B_{t-1}^{I}}{\pi_{t}} d F_{t}^{I}(w)+\int_{0}^{\bar{\omega}_{t}^{I}}\left\{\left(1-\delta_{s}\right) q_{t}^{s} S_{t-1}^{I}+W_{t}^{I} L_{t}^{I}\right\} \omega d F_{t}^{I}(\omega)=
$$

\footnotetext{
${ }^{1}$ In particular, $\log \left(\omega_{t}^{I}\right) \sim N\left(-\frac{\sigma^{I}}{2}, \sigma^{I}\right)$.

${ }^{2}$ Alternatively, Carvalho et al. (2014) rule out the possibility of deviation from an optimal decision plan under commitment by threatening to exclude from debt market in the subsequent periods.
} 


$$
=\left(1-F_{t}^{I}\left(\bar{\omega}_{t}^{I}\right)\right) \frac{\left(1+r_{t-1}^{f I}\right) B_{t-1}^{I}}{\pi_{t}}+\left\{\left(1-\delta_{s}\right) q_{t}^{s} S_{t-1}^{I}+W_{t}^{I} L_{t}^{I}\right\} G_{t}^{I}\left(\bar{\omega}_{t}^{I}\right),
$$

where $\int_{0}^{\bar{\omega}_{t}^{I}} \omega d F_{t}^{I}(\omega)=G_{t}^{I}\left(\bar{\omega}_{t}^{I}\right)$. The first component adjusts the debt plus interest from those agents that do not default and the second is the collateral from agents that default.

The representative impatient household chooses a stream of nondurable consumption $C_{t}^{I}$, durable consumption $S_{t}^{I}$, labor services $L_{t}^{I}$, and debt $B_{t}^{I}$ in order to maximize

$$
E_{0} \sum_{0}^{\infty}\left(\beta^{I}\right)^{t}\left\{\log \left(\left[\xi\left(C_{t}^{I}\right)^{\sigma}+(1-\xi)\left(S_{t}^{I}\right)^{\sigma}\right]^{\frac{1}{\sigma}}\right)-\frac{\left(L_{t}^{I}\right)^{1+\varphi}}{1+\varphi}\right\}
$$

with $\varphi>0$, and subject to ${ }^{3}$

$$
\begin{aligned}
C_{t}^{I}+q_{t}^{s} S_{t}^{I}+\left(1-F^{I}\left(\bar{\omega}_{t}^{I}\right)\right) & \frac{\left(1+r_{t-1}^{f I}\right) B_{t-1}^{I}}{\pi_{t}} \leq B_{t}^{I}+ \\
& +\left(1-G^{I}\left(\bar{\omega}_{t}^{I}\right)\right)\left[W_{t}^{I} L_{t}^{I}+q_{t}^{S}\left(1-\delta^{S}\right) S_{t-1}^{I}\right],
\end{aligned}
$$

and the borrowing constraint

$$
\left(1+r_{t}^{f I}\right) B_{t}^{I} \leq E_{t}\left(1-G^{I}\left(\bar{\omega}_{t+1}^{I}\right)\right)\left[\tau^{w l} W_{t}^{I} L_{t}^{I}+\tau^{s} q_{t+1}^{s} \pi_{t+1}\left(1-\delta^{s}\right) S_{t}^{I}\right] .
$$

A fraction of impatient households loan $F_{t}^{I}\left(\bar{\omega}_{t}\right)$ is not repaid to banks. Consequently, the last period debt expenditure (third term of the left-hand side of the budget constraint) considers the default. Similarly, banks seize a fraction $G_{t}^{I}\left(\bar{\omega}_{t}\right)$ of labor income and durable goods due to default.

The second constraint is a borrowing constraint similar to those found in the literature (e.g., Iacoviello (2005), Gerali et al. (2010), Ferreira and Nakane (2018)). Although, we modify it to embrace the future default possibility (term $\left.G^{I}\left(\bar{\omega}_{t+1}^{I}\right)\right)$ and consignado credit in the same spirit as Carvalho et al. (2014) and Carvalho et al. (2018). Consignado credit is captured by the labor income in the borrowing constraint and parameters $\tau^{s}$ and $\tau^{w l}$ are loan-to-value of durable goods assets and labor income, respectively.

\footnotetext{
${ }^{3}$ In the budget constraint, we have to adjust the labor income and assets due to default: $\int_{0}^{\infty}[$ Collateral $] \omega d F_{t}^{I}(\omega)-\int_{0}^{\bar{\omega}_{t}^{I}}[$ Collateral $] \omega d F_{t}^{I}(\omega)=[$ collateral $]\left(1-G_{t}^{I}\left(\bar{\omega}_{t}^{I}\right)\right)$.
} 


\section{3}

\section{Entrepreneurs}

Entrepreneurs are also borrowers and consume final goods. They employ labor services and capital to produce wholesale goods. They also offer capital asset and wholesale goods income as collateral defining a borrowing constraint. Additionally, collateral is subject to idiosyncratic shock in order to generate credit default.

Assets and wholesale goods income are offered as collateral and they are subject to idiosyncratic shock $\omega_{t}^{e}$. This is a random variable i.i.d. across time and agents that follows a c.d.f. $F^{e}(\omega)$ over non-negative support with mean $1{ }^{4}$ Similarly to impatient household problem, an entrepreneur default cut-off rule emerges

$$
\frac{\left(1+r_{t-1}^{f e}\right) B_{t-1}^{e}}{\pi_{t}}=\bar{\omega}_{t}^{e}\left[q_{t}^{k}\left(1-\delta^{k}\right) K_{t-1}+q_{t}^{w} Y_{t}^{e}\right],
$$

where $r_{t-1}^{f e}$ is the last period interest rate on debt, $B_{t-1}^{e}$ is the last period debt, $q_{t}^{w}$ is the relative price of wholesale goods, $Y_{t}^{e}$ are the wholesale goods, and $K_{t}$ is the stock of capital. If $\omega_{t}^{e}<\bar{\omega}_{t}^{e}$ entrepreneur defaults but loses collateral and if $\omega_{t}^{e}>\bar{\omega}_{t}^{e}$ entrepreneur pays the debt plus interest and keeps collateral.

Derivation steps of debt payment are the same as presented in the impatient households problem. ${ }^{5}$ We also suppose an insurance shortcut to deal with the heterogeneity and work with a representative entrepreneur.

The representative entrepreneur chooses a stream of nondurable consumption $C_{t}^{e}$, capital $K_{t}$, input patient labor services $L_{t}^{p}$, input impatient labor services $L_{t}^{I}$, and debt $B_{t}^{e}$ in order to maximize

$$
\mathbb{E}_{0} \sum_{t=0}^{\infty}\left(\beta^{e}\right)^{t} \log \left(C_{t}^{e}\right)
$$

subject to

$$
\begin{gathered}
Y_{t}^{e}=A_{t} K_{t-1}^{\alpha}\left[\left(L_{t}^{p}\right)^{\theta}\left(L_{t}^{I}\right)^{1-\theta}\right]^{1-\alpha}, \\
C_{t}^{e}+q_{t}^{k} K_{t}+W_{t}^{I} L_{t}^{I}+W_{t}^{p} L_{t}^{p}+\left(1-F^{e}\left(\bar{\omega}_{t}^{e}\right)\right) \frac{\left(1+r_{t-1}^{f e}\right) B_{t-1}^{e}}{\pi_{t}} \leq \\
\left(1-G^{e}\left(\bar{\omega}_{t}^{e}\right)\right) q_{t}^{w} Y_{t}^{e}+\left(1-G^{e}\left(\bar{\omega}_{t}^{e}\right)\right) q_{t}^{k}\left(1-\delta^{k}\right) K_{t-1}+B_{t}^{e},
\end{gathered}
$$

and the borrowing constraint

$$
\left(1+r_{t}^{f e}\right) B_{t}^{e} \leq E_{t}\left(1-G^{e}\left(\bar{\omega}_{t+1}^{e}\right)\right)\left[\tau^{y} q_{t}^{w} Y_{t}^{e}+\tau^{k} q_{t+1}^{k} \pi_{t+1}\left(1-\delta^{k}\right) K_{t}\right] .
$$

\footnotetext{
${ }^{4}$ In particular, $\log \left(\omega_{t}^{e}\right) \sim N\left(-\frac{\sigma^{e}}{2}, \sigma^{e}\right)$.

${ }^{5}$ See Appendix G.
} 
The first restriction is a Cobb-Douglas production technology that combines labor services $\left(L_{t}^{p}, L_{t}^{I}\right)$ and capital $K_{t}$ to produce wholesale goods $Y_{t}^{e}$. $A_{t}$ is the level of technology and $\alpha \in(0,1)$ is the capital share. We assume complementarity across labor types, which is governed by the parameter $\theta \in(0,1){ }^{6}$

The second restriction is the budget constraint of the representative entrepreneur. $\delta^{k}$ is the capital depreciation rate, $q_{t}^{k}$ is the capital price relative to the final good, and $q_{t}^{w}$ is the relative price of the wholesale goods. We modify it to embrace the default possibility in the same way of impatient household constraint. A fraction of entrepreneurs loan $F_{t}^{e}\left(\bar{\omega}_{t}^{e}\right)$ is not repaid to banks. Consequently, the last period debt expenditure (fifth term of the left-hand side of the budget constraint) considers the default. Similarly, banks seize a fraction $G_{t}^{e}\left(\bar{\omega}_{t}^{e}\right)$ of wholesale goods income and capital due to default.

The third restriction is a borrowing constraint, but in this case, we have wholesale good income pledged as collateral. ${ }^{7}$ The parameter $\tau^{y}$ is the wholesale good income loan-to-value and $\tau^{k}$ is the capital loan-to-value. It is worth emphasizing that if there is absent uncertainty, borrowing constraints bind in the neighborhood of steady state. We assume that the shocks size are "sufficiently small" so these constraints always bind as Iacoviello (2005) and Gerali et al. (2010).

\section{4}

\section{Loan and Deposit Demand}

Households and entrepreneurs enter into deposit and loan contracts that we assume to be a composite CES basket of differentiated products each supplied by a bank $j \in[0,1]$. Since we are supposing the Dixit-Stiglitz framework, agents need to purchase deposit (loan) contracts from each bank $j$ with the purpose to save (borrow) one unit. As pointed out by Gerali et al. (2010), this assumption is a modeling device to capture banking sector market power in a tractable way. We assume that the elasticity of substitution between deposits is $\varepsilon^{p}<-1$, and the elasticity between households and entrepreneurs loan contracts are $\varepsilon^{I}>1$ and $\varepsilon^{e}>1$, respectively.

The demand by impatient household $i \in[0,1] B_{t}^{I}(i)$ is derived by minimizing total debt repayment for the continuum of banks $j$ i.e., minimizing

\footnotetext{
${ }^{6}$ This complementarity is assumed in some papers (e.g., Gerali et al. (2010), Justiniano et al. (2015), Carvalho et al. (2018)) and it keeps a constant share $\theta$ of labor income that goes to patient households. It is a purely technical assumption, which facilitates the computation of the model. If this is not the case, the labor supply decision of one type of household would change the budget constraint of the other through the labor income share. See Carvalho et al. (2018).

${ }^{7}$ The motivation behind it is purely due to the symmetry of impatient household constraint and quantitatively does not alter significantly the amount of credit even when we raise $\tau^{y}$.
} 
$\int_{0}^{1} r_{t}^{f I}(j) B_{t}^{I}(i, j) d j$ subject to $\left[\int_{0}^{1} B_{t}^{I}(i, j)^{\left(\varepsilon^{I}-1\right) / \varepsilon^{I}} d j\right]^{\varepsilon^{I} /\left(\varepsilon^{I}-1\right)} \geq B_{t}^{I}(i)$. Imposing a symmetric equilibrium and aggregating over households, we get the aggregate demand for loan $B_{t}^{I}(j)$ at bank $j$

$$
B_{t}^{I}(j)=\left(\frac{r_{t}^{f I}(j)}{r_{t}^{f I}}\right)^{-\varepsilon^{I}} B_{t}^{I}, \quad \text { and } \quad r_{t}^{f I} \equiv\left[\int_{0}^{1} r_{t}^{f I}(j)^{1-\varepsilon^{I}} d j\right]^{\frac{1}{1-\varepsilon^{I}}}
$$

where $B_{t}^{I}$ is the total amount of loan to impatient household and $r_{t}^{f I}$ is the Dixit-Stiglitz average interest rate. The same procedure applies to entrepreneurs

$$
B_{t}^{e}(j)=\left(\frac{r_{t}^{f e}(j)}{r_{t}^{f e}}\right)^{-\varepsilon^{e}} B_{t}^{e}, \quad \text { and } \quad r_{t}^{f e} \equiv\left[\int_{0}^{1} r_{t}^{f e}(j)^{1-\varepsilon^{e}} d j\right]^{\frac{1}{1-\varepsilon^{e}}}
$$

The deposit demand of patient household $i \in[0,1] D_{t}(i)$ is derived by maximizing total savings $\int_{0}^{1} r_{t}^{d}(j) D_{t}(i, j) d j$ subject to $\left[\int_{0}^{1} D_{t}(i, j)^{\left(\varepsilon^{p}-1\right) / \varepsilon^{p}} d j\right]^{\varepsilon^{p} /\left(\varepsilon^{p}-1\right)} \leq D_{t}(i)$. Imposing a symmetric equilibrium and aggregating over households, we get the aggregate demand for deposit $D_{t}(j)$ at bank $j$, where $D_{t}$ is the impatient households total deposit amount and $r_{t}^{d}$ is the Dixit-Stiglitz average interest rate.

$$
D_{t}^{p}(j)=\left(\frac{r_{t}^{d}(j)}{r_{t}^{d}}\right)^{-\varepsilon^{p}} D_{t}, \quad \text { and } \quad r_{t}^{d} \equiv\left[\int_{0}^{1} r_{t}^{d}(j)^{1-\varepsilon^{p}} d j\right]^{\frac{1}{1-\varepsilon^{p}}} .
$$

\section{5}

\section{Banking Sector}

The banking sector is composed by monopolistic competition, banks subject to administrative cost, reserve requirements, taxes, and credit default. Moreover, defaulted resources received by banks are Lum-Sum payments i.e., banks do not take into account them when setting interest rates.

There is a continuum of banks $j \in[0,1]$ where each bank is comprised of three branches: two retail branches that offer differentiated loan and deposit contracts (in monopolistic competition) and one wholesale unit managing the capital of the bank group. We separate each bank into three branches to distinguish features of the banking sector and to facilitate exposition. ${ }^{8} \mathrm{We}$ focus on the symmetric equilibrium.

\footnotetext{
${ }^{8}$ Gerali et al. (2010) separating bank approach highlights how the bank capital affects the credit spreads. In our case, we can also highlight the administrative cost in the spread formation.
} 
Banks in monopolistic competition set interest rates subject to adjustment costs. They also obey a balance-sheet identity and there is an optimal leverage with quadratic cost associated with deviations from it. Furthermore, bank capital is accumulated through retained earnings. Hence, a potential feedback loop emerges from the real and financial side of the economy through bank capital.

We include a reduced form banking technology to provide credit using final goods as inputs. This is a modeling device to capture administrative cost faced by banks. ${ }^{9}$ We also add a tax structure related to the intermediation of funds in line with ICC spread decomposition.

We adjust bank revenue for the share of agents that default. When agents default, banks seize the collateral and resell the assets and income to specialized firms (recycling firms), but with a discount that acts as a recovery rate. We model the revenue of selling these assets and income entering as a Lump-Sum profit, but it is a limitation of our model. ${ }^{10}$

\subsection{1}

\section{Wholesale Branch}

Wholesale branch of bank $j$ does not make profit and provides loan $B_{t}(j)$ and keeps reserve requirements $R_{t}$ with remuneration $r_{t}^{r}$. The sources of funds are deposit $D_{t}(j)$ and bank capital $K_{t}^{b}(j)$. Bank capital is accumulated by retained earnings (after tax on profits $\tau$ and dividends payout $d^{b}$ ).

$$
\begin{aligned}
& K_{t}^{b}(j)=\left(1-\delta^{b}\right) \frac{K_{t-1}^{b}(j)}{\pi_{t}}+\left(1-d^{b}\right)(1-\tau)\left[\frac{J_{t-1}^{b}(j)}{\pi_{t}}+\right. \\
& \left.G\left(\bar{\omega}_{t}^{I}\right)\left\{\mu^{I s}\left(1-\delta_{s}\right) q_{t}^{s} S_{t-1}^{I}+\mu^{I w l} W_{t}^{I} L_{t}^{I}\right\}+G\left(\bar{\omega}_{t}^{e}\right)\left\{\mu^{e k}\left(1-\delta_{k}\right) q_{t}^{k} K_{t-1}+\mu^{e y} q_{t}^{w} Y_{t}^{e}\right\}\right]
\end{aligned}
$$

where $\delta^{b}$ is the physical bank capital depreciation, $J_{t-1}^{b}$ is the bank profit from non-defaulted borrowers. The last two terms are profits from defaulted assets and income paid by specialized firms. $\mu^{I s}$ is the durable good recovery rate, $\mu^{I w l}$ labor income recovery rate, $\mu^{e k}$ capital recovery rate, and $\mu^{e y}$ is the wholesale good income recovery rate.

\footnotetext{
${ }^{9}$ See Appendix I for an approach where we explicitly model a banking technology.

${ }^{10}$ We are unable to propose a better approach (e.g., banks taking into account the fact that setting interest rates changes the revenue from defaulted assets). Constant recovery rate is another limitation of our model, Becard and Gauthier (2020) propose a varying approach of the cost to redeploy defaulted assets and estimate using US data. We left for future research to evaluate this mechanism for the Brazilian economy. Anecdotally, the recovery rate, which varies (e.g., depending on the state of the economy), is one of the most important variables when a bank assesses a loan request.
} 
The wholesale bank $j$ chooses $B_{t}(j), D_{t}(j), R_{t}(j)$ in order to maximize discounted sum of cash $^{11}$

$$
\begin{aligned}
E_{0} \sum_{t=0}^{\infty} \lambda_{0, t}^{p} & {\left[\left(1+R_{t}^{b}\right) B_{t}(j)+\left(1+r_{t}^{r}\right) R_{t}(j)-\left(1+r_{t}\right) D_{t}(j)-K_{t}^{b}(j)-\right.} \\
& \left.\frac{\kappa_{K b}}{2}\left(\frac{K_{t}^{b}(j)}{B_{t}(j)+R_{t}(j)}-\nu^{b}\right)^{2} K_{t}^{b}(j)-\eta B_{t}^{\gamma}\right]
\end{aligned}
$$

subject to a balance sheet constraint

$$
B_{t}(j)+R_{t}(j)=D_{t}(j)+K_{t}^{b}(j)
$$

and a reserve requirements constraint

$$
R_{t}(j) \geq \theta^{d} D_{t}(j)
$$

where $\lambda_{0, t}^{P}$ is the patient households discount factor, $R_{t}^{b}$ is the wholesale loan rate, $r_{t}^{r}$ is the remuneration of reserve, $\kappa_{K b}$ is leverage deviation cost parameter, $\nu^{b}$ is the optimal leverage, $\eta$ and $\gamma$ are the administrative cost parameters, and $\theta^{d}$ is the share of deposits as reserve requirements. The first constraint is the balance-sheet identity and the second inequality is the regulatory reserve requirements. The last one is always binding since we assume that reserve remuneration $r_{t}^{r}$ is always lower than the funding cost $r_{t}$.

\subsection{2}

\section{Loan Branch}

The retail loan branch of bank $j$ collects wholesale funds at $R_{t}^{b}$ rate, differentiates at no cost and channels these funds to impatient households and entrepreneurs. Loan branch also pays revenue and loan amount taxes. Loan branch $j$ chooses household interest rate $r_{t}^{f I}(j)$ and entrepreneur interest rate $r_{t}^{f e}(j)$ in order to maximize

$$
\begin{aligned}
& E_{0} \sum_{t=0}^{\infty} \lambda_{0, t}^{P}\left\{\left(1-F\left(\bar{\omega}_{t+1}^{I}\right)\right)\left(1+r_{t}^{f I}(j)\right) B_{t}^{I}(j)-\left(1-F\left(\bar{\omega}_{t+1}^{I}\right)\right) \tau^{p c, I} r_{t}^{f I}(j) B_{t}^{I}(j)-\right. \\
& \tau^{i o f, I} B_{t}^{I}(j)+\left(1-F\left(\bar{\omega}_{t+1}^{e}\right)\right)\left(1+r_{t}^{f e}(j)\right) B_{t}^{e}(j)-\left(1-F\left(\bar{\omega}_{t+1}^{e}\right)\right) \tau^{p c, e} r_{t}^{f e}(j) B_{t}^{e}(j)- \\
& \left.\tau^{i o f, e} B_{t}^{e}(j)-\left(1+R_{t}^{b}\right) B_{t}(j)-\frac{\kappa_{b I}}{2}\left[\frac{r_{t}^{f I}(j)}{r_{t-1}^{f I}(j)}-1\right]^{2} r_{t}^{f I} B_{t}^{I}-\frac{\kappa_{b e}}{2}\left[\frac{r_{t}^{f e}(j)}{r_{t-1}^{f e}(j)}-1\right]^{2} r_{t}^{f e} B_{t}^{e}\right\},
\end{aligned}
$$

\footnotetext{
${ }^{11}$ We assume that banks have unlimited finance at the policy rate $r_{t}$, hence, by arbitrage condition $r_{t}$ is funding cost rate associated with $D_{t}(j)$.
} 
subject to

$$
B_{t}^{I}(j)=\left(\frac{r_{t}^{f I}(j)}{r_{t}^{f I}}\right)^{-\varepsilon_{t}^{I}} B_{t}^{I}, \quad B_{t}^{e}(j)=\left(\frac{r_{t}^{f e}(j)}{r_{t}^{f e}}\right)^{-\varepsilon_{t}^{e}} B_{t}^{e},
$$

and

$$
B_{t}^{I}(j)+B_{t}^{e}(j)=B_{t}(j)
$$

where $\tau^{p c, I}, \tau^{p c, e}$ are parameters associated with revenue tax, $\tau^{i o f, I}, \tau^{i o f, e}$ are the amount taxes parameters. $\kappa_{b I}, \kappa_{b e}$ are parameters associated with adjustment cost of setting interest rates. We can see that revenue is adjusted for default $F\left(\bar{\omega}_{t+1}^{x}\right)$ and restrictions are Dixit-Stiglitz demands for bank $j$ credit.

\subsection{3}

\section{Deposit Branch}

The deposit branch of bank $j$ collects funds from patient households and channels these funds to wholesale unit which remunerates them at $r_{t}$. The deposit branch chooses $r_{t}^{d}(j)$ in order to maximize

$$
E_{0} \sum_{t=0}^{\infty} \lambda_{0, t}^{P}\left[r_{t} D_{t}(j)-r_{t}^{d}(j) D_{t}(j)-\frac{\kappa_{d}}{2}\left(\frac{r_{t}^{d}(j)}{r_{t-1}^{d}(j)}-1\right)^{2} r_{t}^{d} D_{t}\right]
$$

subject to

$$
D_{t}^{p}(j)=\left(\frac{r_{t}^{d}(j)}{r_{t}^{d}}\right)^{-\varepsilon^{p}} D_{t}
$$

where $\kappa_{d}$ is the adjustment cost parameter of deposit rate.

We focus on the symmetric equilibrium and sum profits of all three branches giving rise to total realized non-defaulted profits $J_{t-1}^{b}$ defined by

$$
\begin{aligned}
J_{t-1}^{b} & =B_{t-1}^{I}\left\{\left(1+r_{t-1}^{f I}\right)\left(1-F\left(\bar{\omega}_{t}^{I}\right)\right)-\tau^{p c, I} r_{t-1}^{f I}\left(1-F\left(\bar{\omega}_{t}^{I}\right)\right)-\tau^{i o f, I}-1\right\}+ \\
& B_{t-1}^{e}\left\{\left(1+r_{t-1}^{f e}\right)\left(1-F\left(\bar{\omega}_{t}^{e}\right)\right)-\tau^{p c, e} r_{t-1}^{f e}\left(1-F\left(\bar{\omega}_{t}^{e}\right)\right)-\tau^{i o f, e}-1\right\}+ \\
& r_{t-1}^{r} R_{t-1}-\eta B_{t-1}^{\gamma}-\frac{\kappa_{K b}}{2}\left(\frac{K_{t-1}^{b}}{B_{t-1}+R_{t-1}}-\nu^{b}\right)^{2} K_{t-1}^{b}- \\
& \frac{\kappa_{b I}}{2}\left[\frac{r_{t-1}^{f I}}{r_{t-2}^{f I}}-1\right]^{2} r_{t-1}^{f I} B_{t-1}^{I}-\frac{\kappa_{b e}}{2}\left[\frac{r_{t-1}^{f e}}{r_{t-2}^{f e}}-1\right]^{2} \frac{r_{t-1}^{f e} B_{t-1}^{e}}{\pi_{t}}- \\
& \frac{\kappa_{d}}{2}\left(\frac{r_{t-1}^{d}}{r_{t-2}^{d}}-1\right)^{2} r_{t-1}^{d} D_{t-1} .
\end{aligned}
$$




\section{6}

\section{Recycling Firms}

Recycling firms are a modeling device that prevent asset and income destruction. Banks recover defaulted assets and income and sell them to specialized firms (recycling firms), but with a discount rate i.e., banks face a recovery rate $\mu^{x}$. Banks cannot extract full value of defaulted resources, but its value continue in the economy.

In this case, banks do not know how to use defaulted assets and income but sell them to recycling firms. These collect and resell them according to each borrower and charge the full price. Labor income and durable goods are channeled to impatient households and wholesale good income and capital to entrepreneurs. Borrowers budget constraints remain the same since they acquire and resell these resources. All profits $L_{t}$ are Lump-Sum transfers to patient households.

$$
\begin{aligned}
L_{t}= & G\left(\bar{\omega}_{t}^{I}\right)\left\{\left(1-\mu^{I s}\right)\left(1-\delta_{s}\right) q_{t}^{s} S_{t-1}^{I}+\left(1-\mu^{I w l}\right) W_{t}^{I} L_{t}^{I}\right\}+ \\
& G\left(\bar{\omega}_{t}^{e}\right)\left\{\left(1-\mu^{e k}\right)\left(1-\delta_{k}\right) q_{t}^{k} K_{t-1}+\left(1-\mu^{e y}\right) q_{t}^{w} Y_{t}^{e}\right\} .
\end{aligned}
$$

\section{7}

\section{Capital Producers}

Capital producers behave competitively and buy an amount of final goods $I_{t}^{k}$ from final goods firms and the stock of undepreciated capital $\left(1-\delta^{k}\right) K_{t-1}$ from entrepreneurs at the beginning of each period. The undepreciated capital $\left(1-\delta^{k}\right) K_{t-1}$ stock is transformed into new capital at no cost, but final goods are transformed into new capital subject to quadratic adjustment costs. Finally, the whole stock of new capital $K_{t}$ is sold to entrepreneurs at $q_{t}^{k}$.

Capital producers choose new capital $K_{t}$ in order to maximize

$$
E_{0} \sum_{t=0}^{\infty} \lambda_{0, t}^{P}\left[q_{t}^{K}\left(K_{t}-\left(1-\delta_{K}\right) K_{t-1}\right)-I_{t}^{K}\right]
$$

subject to

$$
K_{t}=\left(1-\delta_{K}\right) K_{t-1}+\left[1-\frac{\kappa_{k}}{2}\left(\frac{I_{t}^{K}}{I_{t-1}^{K}}-1\right)^{2}\right] I_{t}^{K},
$$

where the restriction is the capital law of motion, $\kappa_{k}$ is the adjustment cost parameter, $\lambda_{0, t}^{p}$ is the stochastic discount factor of patient households. Any profits are transferred to patient households. 


\section{8}

\section{Durable Goods Producers}

Durable goods producers behave competitively and buy an amount of final goods $I_{t}^{s}$ from final goods firms and the stock of undepreciated durable goods $\left(1-\delta^{s}\right) S_{t-1}$ from patient and impatient households at the beginning of each period. The undepreciated durable goods $\left(1-\delta^{s}\right) S_{t-1}$ stock are transformed into new durable goods at no cost, but final goods are transformed into new durable goods subject to quadratic adjustment costs. Finally, the whole stock of new durable goods $S_{t}$ is sold to patient and impatient households at $q_{t}^{s}$.

Durable goods producers choose $S_{t}$ in order to maximize

$$
E_{0} \sum_{t=0}^{\infty} \lambda_{0, t}^{P}\left[q_{t}^{s}\left(S_{t}-\left(1-\delta_{s}\right) S_{t-1}\right)-I_{t}^{s}\right],
$$

subject to

$$
S_{t}=\left(1-\delta_{s}\right) S_{t-1}+\left[1-\frac{\kappa_{s}}{2}\left(\frac{I_{t}^{s}}{I_{t-1}^{s}}-1\right)^{2}\right] I_{t}^{s},
$$

where the restriction is the durable good law of motion, $\kappa_{s}$ is the adjustment cost parameter, and $S_{t}=S_{t}^{p}+S_{t}^{I}$. Any profits are transferred to patient households.

\section{9}

\section{Retail Firms and Final Goods Producers}

We assume monopolistic competition among retail firms to implement price rigidities. The retail firms are composed of a continuum of firms $m \in$ $[0,1]$. Each retail firm $m$ acquires the wholesale goods $Y_{t}^{e}$ from entrepreneurs at $P_{t}^{w}$, differentiates it at no cost, and then sells it to final goods firms. The retail firm $m$ set price $P_{t}(m)$ to maximize profits subject to the Dixit-Stiglitz final goods producers demand. Furthermore, retail firms face quadratic price adjustment costs that arise whenever the prices changes by more than weighted average of past inflation and steady state inflation, with relative weights of $\iota$ and $1-\iota$, respectively.

The final good producers behave competitively and aggregate at no cost the continuum of differentiated varieties produced by retailers in a CES basket

$$
Y_{t}=\left[\int_{0}^{1} Y_{t}(m)^{\frac{\varepsilon-1}{\varepsilon}} d m\right]^{\frac{\varepsilon}{\varepsilon-1}},
$$

where $Y(m)$ denote each variety $m, \varepsilon$ is the elasticity of substitution between varieties. 
Therefore, retail firm $m$ chooses $P_{t}(m)$ in order to maximize

$$
E_{0} \sum_{t=0}^{\infty} \frac{P_{0}}{P_{t}} \lambda_{0, t}^{P}\left[P_{t}(m) Y_{t}(m)-P_{t}^{W} Y_{t}(m)-\frac{\kappa_{P}}{2}\left(\frac{P_{t}(m)}{P_{t-1}(m)}-\pi_{t-1}^{\iota} \bar{\pi}^{1-\iota}\right)^{2} P_{t} Y_{t}\right]
$$

subject to

$$
Y_{t}(m)=\left(\frac{P_{t}(m)}{P_{t}}\right)^{-\varepsilon} Y_{t}
$$

where $P_{t}$ is the associated Dixit-Stiglitz average price, $\kappa_{p}$ is the adjustment price cost parameter, $\bar{\pi}$ denotes the steady state inflation, and the restriction is the demand from final good producers. Patient households receive any profits generated from these firms as Lump-Sum transfers.

\subsection{0}

\section{Government}

The government is composed of a fiscal and a monetary (i.e., Central Bank) authorities. The fiscal authority keeps the budget balance across all periods and expenditures (left-hand side) equal revenue (right-hand side) in equation below. In particular, reserve requirements resources appear in the budget equation below since the Central Bank is responsible for it, but transfers the burden to fiscal authority which bears the costs.

$$
\begin{aligned}
G_{t}+\frac{\left(1+r_{t-1}^{r}\right) R_{t-1}}{\pi_{t}}= & R_{t}+\frac{B_{t-1}^{I}}{\pi_{t}}\left[\left(1-F^{I}\left(\bar{\omega}_{t}^{I}\right)\right) \tau^{p c, I} r_{t-1}^{f I}+\tau^{i o f, I}\right]+ \\
& \frac{B_{t-1}^{e}}{\pi_{t}}\left[\left(1-F^{e}\left(\bar{\omega}_{t}^{e}\right)\right) \tau^{p c, e} r_{t-1}^{f e}+\tau^{i o f, e}\right]+\tau^{p} r_{t-1}^{d} \frac{D_{t-1}^{p}}{\pi_{t}}+ \\
& \tau\left[\frac{J_{t-1}^{b}}{\pi_{t}}+\text { defaulted assets banks recovery }\right]
\end{aligned}
$$

The central bank conducts monetary policy setting interest rate according to a Taylor rule ${ }^{12}$

$$
\left(1+r_{t}\right)=(1+\bar{r})^{1-\rho}\left(1+r_{t-1}\right)^{\rho}\left(\frac{\pi_{t}}{\bar{\pi}}\right)^{\phi_{\pi}(1-\rho)}\left(\frac{Y_{t}}{Y_{t-1}}\right)^{\phi_{y}(1-\rho)} e^{\epsilon_{t}^{m}},
$$

where $\bar{r}$ and $\bar{\pi}$ are the steady state levels of policy rate and inflation, respectively. $\phi_{\pi}$ and $\phi_{y}$ are parameters that determine the responses of interest rates to inflation and output stabilization, respectively. $\epsilon_{t}^{m}$ is the monetary policy shock.

\footnotetext{
${ }^{12}$ The same Taylor rule of Carvalho et al. (2018) and Gerali et al. (2010).
} 


\subsection{1}

\section{Market Clearing}

The definition of equilibrium is standard. We assume that capital, wholesale goods, durable goods, both types of labor markets, and recycling defaulted assets and income markets are competitive. The market clearing condition in final good market is

$$
\begin{aligned}
Y_{t}= & C_{t}+I_{t}^{s}+I_{t}^{k}+G_{t}+\frac{\delta^{b} K_{t-1}^{b}}{\pi_{t}}+\frac{\eta B_{t-1}^{\gamma}}{\pi_{t}}+\frac{\kappa_{P}}{2}\left(\pi-\pi_{t-1}^{\iota} \bar{\pi}^{1-\iota}\right)^{2} Y_{t} \\
& \frac{\kappa_{K b}}{2}\left(\frac{K_{t-1}^{b}}{B_{t-1}+R_{t-1}}-\nu^{b}\right)^{2} \frac{K_{t-1}^{b}}{\pi_{t}}+\frac{\kappa_{b I}}{2}\left[\frac{r_{t-1}^{f I}(j)}{r_{t-2}^{f I}(j)}-1\right]^{2} \frac{r_{t-1}^{f I} B_{t-1}^{I}}{\pi_{t}}+ \\
& \frac{\kappa_{b e}}{2}\left[\frac{r_{t-1}^{f e}}{r_{t-2}^{f e}}-1\right]^{2} \frac{r_{t-1}^{f e} B_{t-1}^{e}}{\pi_{t}}+\frac{\kappa_{d}}{2}\left(\frac{r_{t-1}^{d}}{r_{t-2}^{d}}-1\right)^{2} \frac{r_{t-1}^{d} D_{t-1}}{\pi_{t}},
\end{aligned}
$$

where $C_{t}=C_{t}^{p}+C_{t}^{I}+C_{t}^{e}$ is the aggregate consumption, $K_{t}^{b}$ is the aggregate bank capital. GDP is given by

$$
G D P_{t}=C_{t}+I_{t}^{k}+I_{t}^{s}+G_{t}
$$

The mathematical representation of equilibrium with the set of equations is presented in Appendix B.

\subsection{2}

\section{Steady State}

The dissertation analysis is to study the banking spread in level inspired by ICC spread decomposition. Therefore, we focus on the steady state of the economy which is the same approach of Souza-Sobrinho (2010).

The steady state equilibrium of the model is calculated numerically and the whole procedure can be found in Appendix C. Below, we present the interest rates derived from agents optimization problems. These expressions provide intuitions about the mechanisms and are essential to understand the quantitative analysis. ${ }^{13}$

$$
\begin{gathered}
r=\frac{\left(\varepsilon^{p}-1\right)}{\varepsilon^{p}} r^{d} . \quad(3-1) \quad r^{d}=\left[\frac{1}{\beta^{p}}-1\right] \frac{1}{\left(1-\tau^{p}\right)} . \\
R^{b}=\frac{r}{1-\theta^{d}}-\theta^{d} \frac{r^{r}}{1-\theta^{d}}+\eta \gamma B^{\gamma-1} . \\
r^{f I}=\frac{\varepsilon^{I}}{\left(\varepsilon^{I}-1\right)} \frac{1}{\left(1-\tau^{p c, I}\right)\left(1-F^{I}\left(\bar{\omega}^{I}\right)\right)}\left\{R^{b}+\tau^{i o f, I}+F^{I}\left(\bar{\omega}^{I}\right)\right\} .
\end{gathered}
$$

\footnotetext{
${ }^{13}$ Variables without time notation denote its steady state.
} 


$$
r^{f e}=\frac{\varepsilon^{e}}{\left(\varepsilon^{e}-1\right)} \frac{1}{\left(1-\tau^{p c, e}\right)\left(1-F^{e}\left(\bar{\omega}^{e}\right)\right)}\left\{R^{b}+\tau^{i o f, e}+F^{e}\left(\bar{\omega}^{e}\right)\right\} .
$$

Following equations 3-1 and 3-2, Central Bank controls the policy rate $r$ and sets it consistently to zero inflation. Banks take the policy rate as given and set deposit rate $r^{d}$ that takes into account not only the patient households discount factor $\beta^{p}$ and tax on deposit return $\tau^{p}$, but also a markdown associated with banking deposit market power. Deposit branches collect funds from patient households and channel funds to the wholesale units.

In equation 3-3, the wholesale branches provide funds to loan branches at $R^{b}$ interest rate. This includes the opportunity cost of deposit facility at Central Bank $r$ and reserve requirements remuneration $r^{r}$ with both adjusted for reserve requirements itself $\theta^{d} . R^{b}$ also includes the administrative marginal cost to provide loan which captures general equilibrium effects through the credit quantity $B$.

Loan branches channel funds at interest rates $r^{f I}$ and $r^{f e}$ that we see in equations 3-4 and 3-5, respectively. These interest rates take into account a markup associated with credit market power $\varepsilon^{x}$, tax on bank revenue $\tau^{p c, x}$ and on amount of loan $\tau^{i o f, x}$. It also includes the cost to raise funds $R^{b}$, and default rate $F^{x}\left(\bar{\omega}^{x}\right)$. The interest rates expressions provide intuitions about the composition of the marginal credit spreads and how each component affects the spread formation.

The expressions below provide intuitions of how default and both types of credit change along some dimensions. ${ }^{14}$

$$
\begin{gathered}
\bar{\omega}^{I}=\frac{\left(1+r^{f I}\right) B^{I}}{\left[\left(1-\delta^{s}\right) S^{I}+W^{I} L^{I}\right]} . \\
B_{t}^{I}=\left(1-G\left(\bar{\omega}^{I}\right)\right) \frac{\left[\tau^{w l} W^{I} L^{I}+\tau^{s}\left(1-\delta^{s}\right) S^{I}\right]}{\left(1+r^{f I}\right)} . \\
\bar{\omega}^{e}=\frac{\left(1+r^{f e}\right) B^{e}}{\left[\left(1-\delta^{k}\right) K+q^{w} Y^{e}\right]} . \\
B^{e}=\left(1-G\left(\bar{\omega}^{e}\right)\right) \frac{\left[\tau^{y} q^{w} Y^{e}+\tau^{k}\left(1-\delta^{k}\right) K\right]}{\left(1+r^{f e}\right)} .
\end{gathered}
$$

The cut-off rules in 3-6 and 3-8 respond to the amount of credit plus interest and collateral. Higher amount of credit plus interest rate and lower collateral lead to higher default rates ceteris paribus.

\footnotetext{
${ }^{14}$ The intuitions are practically the same when we analyze the model equation, but we present here for completeness. The model equations present other channels (e.g., asset price, debt deflation) that will be discussed in the propagation of shocks.
} 
Equations 3-7 and 3-9 outline the borrowing constraint channel in which the present value of the collateral dictates the level of credit. The lower final bank rates and higher collateral lead to higher amount of credit ceteris paribus. Variations of default also change the amount of credit, i.e., higher default rates lead to stricter borrowing constraints. 


\section{4}

\section{Steady State Quantitative Analysis}

First, we calibrate the model to match Brazilian economy moments and perform two steady state decomposition exercises. The first exercise is a comparison between data and model applying the ICC accounting decomposition methodology. In the second exercise, we perform a counterfactual analysis which consists of changing parameters values to simulate economic policies. We then compare both decompositions in terms of spread reduction.

\section{1}

\section{Calibration}

We divide the calibration into four approaches and Table 4.1 summarizes the procedure. Whenever we set a parameter to match a given moment for the Brazilian economy, the data range interval is an average between 2011-2019. Although, it can be shorter for some variables due to data availability. See Appendix J for details. The time period is set to one quarter.

Literature.-In this parameter block, we follow references in the literature. We set entrepreneur discount factor $\beta^{e}=0.95$ which is the same used by Ferreira and Nakane (2018) and Iacoviello (2005). The inverse of Frisch elasticity is set $\varphi=1$ which is within the range commonly used in the literature specifically the same used in Carvalho et al. (2018).

Furthermore, we also set the capital share in production function $\alpha=$ 0.44 and elasticity of substitution between final goods $\varepsilon=6$ to the same values used in Carvalho et al. (2018).

Direct sample mean.-We directly calibrate parameters of this block. The optimal bank leverage $\nu^{b}$ is set to match the average of the regulatory capital to risk-weighted assets 0.17 which is close to the value of 0.16 used in Ferreira and Nakane (2018). The dividend pay-out $d^{b}$ is set to match dividend payout of publicly traded financial institutions.

In the data, the share of deposit as reserve requirements $\theta^{d}$ depends on the type of deposit. According to Banco Central do Brasil (2019a), the share of each type of deposit as reserve requirements varies between 0.21 and 0.31 , so we set $\theta^{d}=0.25$. 
The recovery rates of defaulted assets $\mu s$ are set to match the recovery rate calculated by World Bank Group (2020) which is approximately 0.2. It is worth noting two aspects. First, the World Bank Group (2020) recovery rate calculates how many cents on the dollar secured creditors recover from an insolvent firm at the end of insolvency proceedings which is different from our model recovery rate. Second, the recovery rate depends on the type of loan, but in the absence of such detailed information we set all of them equal to the World Bank Group (2020) estimate.

We set the tax rates to match specific taxes related to the banking intermediation of funds. The tax rates on the amount of loan $\tau^{i o f} s$ are set to 0.0038 , which is only the fixed rate of imposto sobre operações financeiras (IOF). We do not include the daily additional tax rate since it depends on installment. The tax rates on loan revenue $\tau^{p c} s$ are set to match the rates of programa de integração social (PIS) and contribuição para financiamento da seguridade social (Cofins). The tax rate on deposit return $\tau^{p}$ is set to 0.175 which is the rate associated with the average term of certificado de depósito bancário (CDB). Lastly, the tax rate on bank profit $\tau=0.45$ is set to match the sum of tax rates contribuição social sobre lucro líquido (CSLL) and imposto de renda das pessoas jurídicas (IRPJ). ${ }^{1}$

Internal calibration.-We set parameters of this block using an internal calibration approach to match Brazilian economy moments. The patient household discount factor $\beta^{p}=0.994$ is set to match the real return on certificado de depósito de crédito (CDB). According to Banco Central do Brasil (2019a), the reserve requirements remuneration is the same of the funding, then we set $r^{r}=r^{d}=0.0075$. We also set $r_{t}^{r}=r_{t}^{d} \forall t$ to guarantee that the reserve requirements constraint in the wholesale branch problem is always binding.

Regarding impatient household discount factor, we set $\beta^{I}=0.925$ to match the nonearmarked household credit-to-GDP. The household borrowing constraint does not bind when we analyze the propagation of shocks with higher values.

The weight of nondurable goods in the utility function $\xi=0.5$ and the share of patient household in the production function $\theta=0.5$ are set to match the nonearmarked household credit-to-GDP.

The capital depreciation parameter $\delta^{k}=0.0295$ is set to match the investment-to-GDP. In the absence of similar information regarding the production of durable goods, we set $\delta^{s}=\delta^{k}$.

\footnotetext{
${ }^{1}$ Likewise administrative cost parametrization, another possibility is to match expenditures with these accounts from the financial institution balance sheets (COSIF). However, we have no access to the detail accounts level required.
} 
Table 4.1: Calibration

\begin{tabular}{|c|c|c|c|}
\hline Description & & Value & Target/Source \\
\hline \multicolumn{4}{|l|}{1 - Literature } \\
\hline Entrepreneur discount factor & $\beta^{e}$ & 0.95 & Iacoviello (2005) \\
\hline Inverse of Frisch elasticity & $\varphi$ & 1 & Carvalho et al. (2018) \\
\hline Elasticity between durable and nondurable goods $\frac{1}{1-\sigma}$ & $\sigma$ & 0 & Carvalho et al. (2018) \\
\hline Capital share in production function & $\alpha$ & 0.44 & Carvalho et al. (2018) \\
\hline Elasticity of substitution - final good & $\varepsilon$ & 6 & Carvalho et al. (2018) \\
\hline \multicolumn{4}{|l|}{2 - Direct sample mean } \\
\hline Optimal bank leverage & $\nu^{b}$ & 0.17 & Regulatory leverage \\
\hline Dividend pay-out & $d^{b}$ & 0.4648 & Payout - Bloomberg \\
\hline Share of deposit as reserve requirement & $\theta^{d}$ & 0.25 & Banco Central do Brasil (2019a) \\
\hline Labor income and durable good recovery rate & $\mu^{I w l} ; \mu^{I s}$ & 0.2 & World Bank Group (2020) \\
\hline Intermediate good income and capital recovery rate & $\mu^{e y} ; \mu^{e k}$ & 0.2 & World Bank Group (2020) \\
\hline Tax rate on impatient and entrepreneur loan & $\tau^{i o f, I}, \tau^{i o f, e}$ & 0.0038 & $\mathrm{IOF}$ \\
\hline Tax rate on loan revenue & $\tau^{p c, I}, \tau^{p c, e}$ & 0.0465 & PIS/Cofins \\
\hline Tax rate on return of deposit & $\tau^{p}$ & 0.175 & IR \\
\hline Tax rate on bank profit & $\tau$ & 0.45 & CSLL/IRPJ \\
\hline \multicolumn{4}{|l|}{3 - Internal calibration } \\
\hline Patient discount factor & $\beta^{p}$ & 0.994 & $r^{d}(\mathrm{CDB})$ \\
\hline Reserve requirements remuneration & $r^{r}$ & 0.0075 & $r^{d}$ \\
\hline Impatient discount factor & $\beta^{I}$ & 0.925 & $\frac{B^{I}}{4 G D P}$ \\
\hline Weight of the nondurable good in the Utility Function & $\xi$ & 0.5 & $\frac{B^{I}}{4 G D P}$ \\
\hline Share of patient in the production function & $\theta$ & 0.5 & $\frac{B^{I}}{4 G D P}$ \\
\hline Capital depreciation & $\delta^{k}$ & 0.0295 & $\frac{I^{k}}{G D P}$ \\
\hline Durable good depreciation & $\delta^{s}$ & 0.0295 & $\delta^{k}$ \\
\hline Impatient idiosyncratic shock - standard deviation & $\sigma^{I}$ & 0.562 & $F^{I}\left(\bar{\omega}^{I}\right)$ \\
\hline Entrepreneur idiosyncratic shock - standard deviation & $\sigma^{e}$ & 0.921 & $F^{e}\left(\bar{\omega}^{e}\right)$ \\
\hline Elasticity of substitution - impatient loan & $\varepsilon^{I}$ & 2.17 & $r^{f I}(I C C)$ \\
\hline Elasticity of substitution - entrepreneur loan & $\varepsilon^{e}$ & 25 & $r^{f e}$ (ICC); REB adm. cost \\
\hline Elasticity of substitution - deposit & $\varepsilon^{p}$ & -3.95 & $r-r^{d}:$ Deposit markdown \\
\hline Scale of administrative cost function & $\eta$ & 0.0123 & $r^{f e}(\mathrm{ICC}) ; \mathrm{REB}$ adm. cost \\
\hline Convexity of administrative cost function & $\gamma$ & 1.005 & $r^{f e}(\mathrm{ICC}) ; \mathrm{REB}$ adm. cost \\
\hline Loan-to-value of labor income & $\tau^{W L}$ & 0.414 & $\frac{B^{I}}{4 G D P}$ \\
\hline Loan-to-value of durable good & $\tau^{S}$ & 0.224 & $\frac{B^{I}}{4 G D P}$ \\
\hline Loan-to-value of wholesale income & $\tau^{Y}$ & 0.01 & $\frac{B^{e}}{4 G D P}$ \\
\hline Loan-to-value capital & $\tau^{K}$ & 0.086 & $\frac{B^{e}}{4 G D P}$ \\
\hline \multicolumn{4}{|l|}{4 - Dynamics } \\
\hline Deposit rate adjustment cost & $\kappa_{d}$ & 3.5 & Gerali et al. (2010) \\
\hline Household rate adjustment cost & $\kappa_{b H}$ & 0.16 & Ferreira and Nakane (2018) \\
\hline Entrepreneur rate adjustment cost & $\kappa_{b e}$ & 0.28 & Ferreira and Nakane (2018) \\
\hline Banks leverage cost & $\kappa_{K b}$ & 22.96 & Ferreira and Nakane (2018) \\
\hline Adjustment cost - capital and durable good & $\kappa_{k}, \kappa_{s}$ & 2.53 & Carvalho et al. (2018) \\
\hline Price adjustment cost - final good & $\kappa_{P}$ & 50 & Carvalho et al. (2018) \\
\hline Interest smoothing parameter & $\rho$ & 0.79 & Carvalho et al. (2018) \\
\hline Steady state inflation weight - indexation & $\iota$ & 0.158 & Carvalho et al. (2018) \\
\hline Response to output in Taylor rule & $\phi_{y}$ & 0.16 & Carvalho et al. (2018) \\
\hline Response to inflation in Taylor rule & $\phi_{\pi}$ & 2.43 & Carvalho et al. (2018) \\
\hline $\operatorname{AR}(1)$ technology autocor. coeficient & $\rho_{a}$ & 0.91 & Carvalho et al. (2018) \\
\hline
\end{tabular}

Notes: See Appendix J for details. 
Regarding the parameters associated with the distribution of the idiosyncratic shocks, we set $\sigma^{I}=0.562$ and $\sigma^{e}=0.921$ to match default rates of each type of nonearmarked credit-to-GDP.

Deposit market elasticity $\varepsilon^{p}=-3.95$ is set to match the deposit markdown with respect the policy rate. Regarding the entrepreneur loan market elasticity $\varepsilon^{e}=20$ and administrative cost parameters $\eta=0.013 ; \gamma=$ 1.05, they are set jointly to match nonearmarked corporate ICC and ICC administrative cost share spread in Banco Central do Brasil (2019b). We adopt this procedure since entrepreneur credit rate $r^{f e}$ is sensitive to administrative cost parameters. The elasticity of household loan market $\varepsilon^{I}=2.17$ is set to match nonearmarked household ICC.

We set the loan-to-value of durable good $\tau^{s}=0.224$ and labor income $\tau^{w l}=0.414$ to match nonearmarked household credit-to-GDP. ${ }^{2}$ Correspondingly, the loan-to-value of capital $\tau^{k}=0.086$ and wholesale income $\tau^{y}=0.01$ are set to match nonearmarked corporate credit-to-GDP. We cannot match credit linked with durable goods/capital and other types of credit individually as in Carvalho et al. (2018). In our model, most of credit is link to durable goods/capital. ${ }^{3}$

Dynamics.-Finally, the calibration approach of the last block is the same of the literature group, but we separate it since these parameters only matter when analyzing the propagation of shocks in Appendix F.

Table 4.2 shows a comparison between data and model moments. ${ }^{4}$ The model moments are quite close to the data counterpart with two exceptions: entrepreneur credit rate $r^{f e}$ and ICC administrative cost share. When we improve the first moment, the other gets worse and vice versa.

The second block of Table 4.2 displays spreads and banking depreciation not explicitly targeted in calibration. Nonearmarked ICC spreads are close to the credit spreads implied by model, but differences arise due to funding rate $r$. We use the SELIC rate and BCB the swap DIxPre rate.

The banking physical depreciation $\delta^{b}$ is not a free setting parameter. It is implied by the model when we set banking optimal leverage $\nu^{b}$. The quarterly rate of 3.39 is high, but we are not able to improve this result. ${ }^{5}$

\footnotetext{
${ }^{2}$ Souza-Sobrinho (2010) faced the same problem of matching such high bank rates with "high" credit-to-GDP ratios, but his priority is to match the quantity ratios and let the spread be one-third lower than in the data.

${ }^{3}$ Carvalho et al. (2018) used nonearmarked corporate credit even though their firm borrowing constraint has only capital. In our framework, we add wholesale income in the borrowing constraint, but with a low $\tau^{y}$ value (it has negligible impact even if set higher values).

${ }^{4}$ We compare our model only with non-earmarked credit i.e., financing and loans in which rates and destination are freely negotiated between financial institutions and borrowers.

${ }^{5}$ In Gerali et al. (2010), $\delta^{b}=0.1049$ measures resources used up in managing bank capital
} 
Table 4.2: Steady State Properties - Model vs Data

\begin{tabular}{|c|c|c|c|}
\hline Steady State Variables & & Model & Data \\
\hline Nonearmarked corporate credit-to-GDP (entrep.) & $\frac{B^{e}}{4 G D P}$ & 12.40 & 12.40 \\
\hline Nonearmarked household credit-to-GDP (imp.) & $\frac{B^{I}}{4 G D P}$ & 13.28 & 13.28 \\
\hline Investment-to-GDP & $\frac{I^{k}}{G D P}$ & 17.85 & 17.85 \\
\hline Deposit spread & $r-r^{d}$ & 0.19 & 0.19 \\
\hline Nonearmarked corporate ICC (entrep.) & $r^{f e}$ & 3.88 & 3.64 \\
\hline Nonearmarked household ICC (imp.) & $r^{f I}$ & 7.95 & 7.95 \\
\hline Nonearmarked corporate default (entrep.) & $F^{e}\left(\bar{\omega}^{e}\right)$ & 0.89 & 0.89 \\
\hline Nonearmarked household default (imp.) & $F^{I}\left(\bar{\omega}^{I}\right)$ & 1.41 & 1.41 \\
\hline REB administrative cost share of ICC spread & $\frac{\frac{\eta B^{\gamma}}{B}}{\frac{r^{f I} B^{I}+r f^{f e} B^{e}}{B}-r}$ & 24.48 & 27 \\
\hline \multicolumn{4}{|l|}{ Untargeted moments and not free setting parameter } \\
\hline Nonearmarked corporate ICC spread (entrep.) & $r^{f e}-r$ & 2.91 & 2.91 \\
\hline Nonearmarked household ICC spread (imp.) & $r^{f I}-r$ & 6.94 & 7.7 \\
\hline Banking physical depreciation & $\delta^{b}$ & 3.39 & \\
\hline
\end{tabular}

Notes: Spreads, rates, and default in percentage points (quarterly). Ratios in percent.

\section{2}

\section{ICC Accounting Spread Decomposition}

In this exercise, we adapt and apply the Banco Central do Brasil (2017) ICC accounting methodology to decompose banking spread and compare model with Brazilian economy. This analysis can be thought of as an untargeted moments evaluation except for the administrative cost share since we used it as a moment target in calibration. It is like a "picture" of the baseline equilibrium.

Banco Central do Brasil (2017) proposes a methodology to decompose ICC from accounting information of financial institutions. The ICC decomposition separates and measures each component share size (funding, default, tax, administrative, and costs related to bank market power/financial margin) from financial intermediaries balance sheet i.e., an accounting methodology. We adapt the ICC spread decomposition methodology and apply it to our model steady state. ${ }^{6}$ Administrative cost share is already used in the calibration step as a moment target, then we assess the rest of shares.

Figures 4.1 and 4.2 display implied decomposition by model and Banco

and includes administrative costs that we explicitly separated and modeled.

${ }^{6}$ See Appendix D for procedure details. Fundo Garantidor de Crédito (FGC) is not considered since it represents less than $1 \%$ of credit spread share. 
Central do Brasil (2019b) decomposition, respectively. Overall, the model performs relatively well, and the financial margin shares are practically the same.

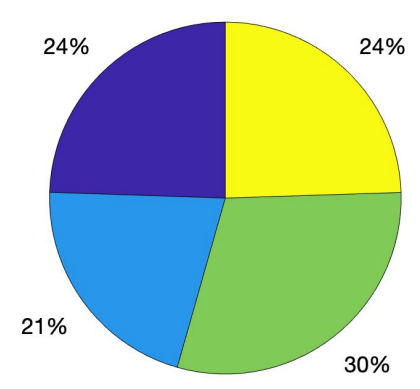

Figure 4.1: Model

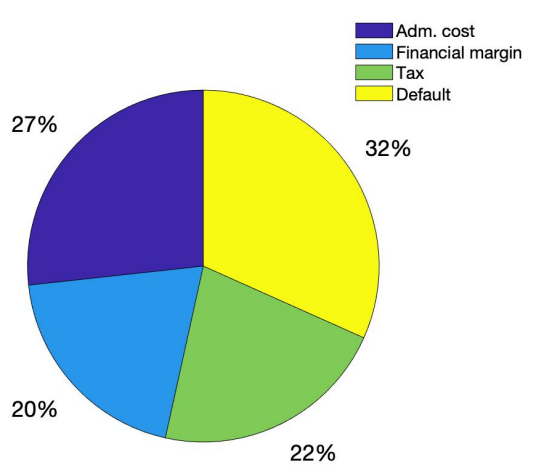

Figure 4.2: Banco Central do Brasil (2019b) - nonearmarked credit

We can see that the major sources of discrepancy between the two pie charts are the tax and default shares. General limitations can be the cause behind these differences: limitations of adapting the methodology to a steady state, and only one type of credit to each borrower (BCB considers many types of credit). Regarding specific limitations of adapting the tax share, we can point out the different calculation bases for each tax that is difficult to replicate in our model.

\section{3}

\section{Counterfactual Analysis}

In Counterfactual Analysis, we simulate economic policies aiming at banking spread reduction through parameter alterations and evaluate the new steady state compared to baseline. It is like a comparison between two "pictures". 7 Then, we compare accounting and counterfactual decompositions in terms of spread reduction, but it is worth emphasizing that the former assesses spread formation in baseline and the latter evaluates steady state changes.

Counterfactual results suggest that reducing administrative cost is the most effective way of diminishing entrepreneur spread (1.35 p.p. quarterly or $46 \%$ decrease compared to baseline). The household spread reduction is greater when we increase competition in the banking sector (3.77 p.p. quarterly or $54 \%$ decrease compared to baseline). Furthermore, results also suggest some careful

\footnotetext{
${ }^{7}$ We leave for future research to investigate the transition between steady states.
} 
actions by policy makers only supported by ICC accounting decomposition without an economic model underpinning the analysis.

Table 4.3 summarizes the cases in which we turn off features of banking spreads individually. ${ }^{8}$ Each column represents a new equilibrium with the baseline in the first one and macroeconomic variables characterizing the equilibrium are presented in the lines. Furthermore, we indicate agents welfare changes relative to baseline. Steady state expressions 3-1 to 3-9 provide intuitions behind the results.

Table 4.3 column 3 shows the absence of taxation case (No tax) which we set $\forall \tau^{x}=0$. It is the only case that decreases deposit return $r^{d}$ by 0.13 p.p. due to $\tau^{p}=0$. Revenue and quantity taxes directly increase final borrowers interest rates and zero bank profit tax induces a patient household dividends increase and higher banking depreciation. ${ }^{9}$ Overall, spreads decrease, credits increase, and the default impacts are almost zero. This is the only case where all households and entrepreneurs are better off since more resources are available for private consumption and less labor is required.

Table 4.3 column 4 shows the absence of financial margin case (No fin. margin) in which we set $\forall \varepsilon^{x}= \pm \infty$. Impatient household spread reduction of 3.77 p.p. is more than half of baseline while entrepreneur spread decline of 0.22 p.p. is less significant. In this case, the markup amplification due to bank market power on final credit rates is undone, especially the household interest rate $r^{f I} . r^{f I}$ reduction is behind the $15 \%$ household credit-to-GDP expansion as denoted by the borrowing constraint. Entrepreneur credit-to-GDP is almost the same.

Table 4.3 column 5 presents the case in which banks are not subject to administrative cost (No adm. cost) with $\eta=0$. Wholesale interest rate $R^{b}$ declines and it further reduces final bank rates $r^{f e}$ and $r^{f I}$ since markups amplifications of financial margin are undone. It suggests that reducing administrative cost is the most effective way of cutting entrepreneur final bank rate (1.36 p.p.) and spread (1.35 p.p.). However, it is not possible to meaningfully increase both types of credit-to-GDP and generate default variations. Interestingly, the absence of administrative cost and taxation do not improve the banking sector profits. Lower final bank rates are not compensated for lower costs and higher credit quantities.

Table 4.3 columns 2 (No remun.) and 3 (No reserve) display lower impacts on credit spreads. Furthermore, 100\% recovery on column 7 reveals our default modeling limitations as interest rates changes are negligible since defaulted

\footnotetext{
${ }^{8}$ See Appendix E for combinations of it.

${ }^{9}$ Zero profit tax leads to higher dividends and retained bank capital. Therefore, bank depreciation rise to keep the optimal leverage $\nu^{b}$.
} 


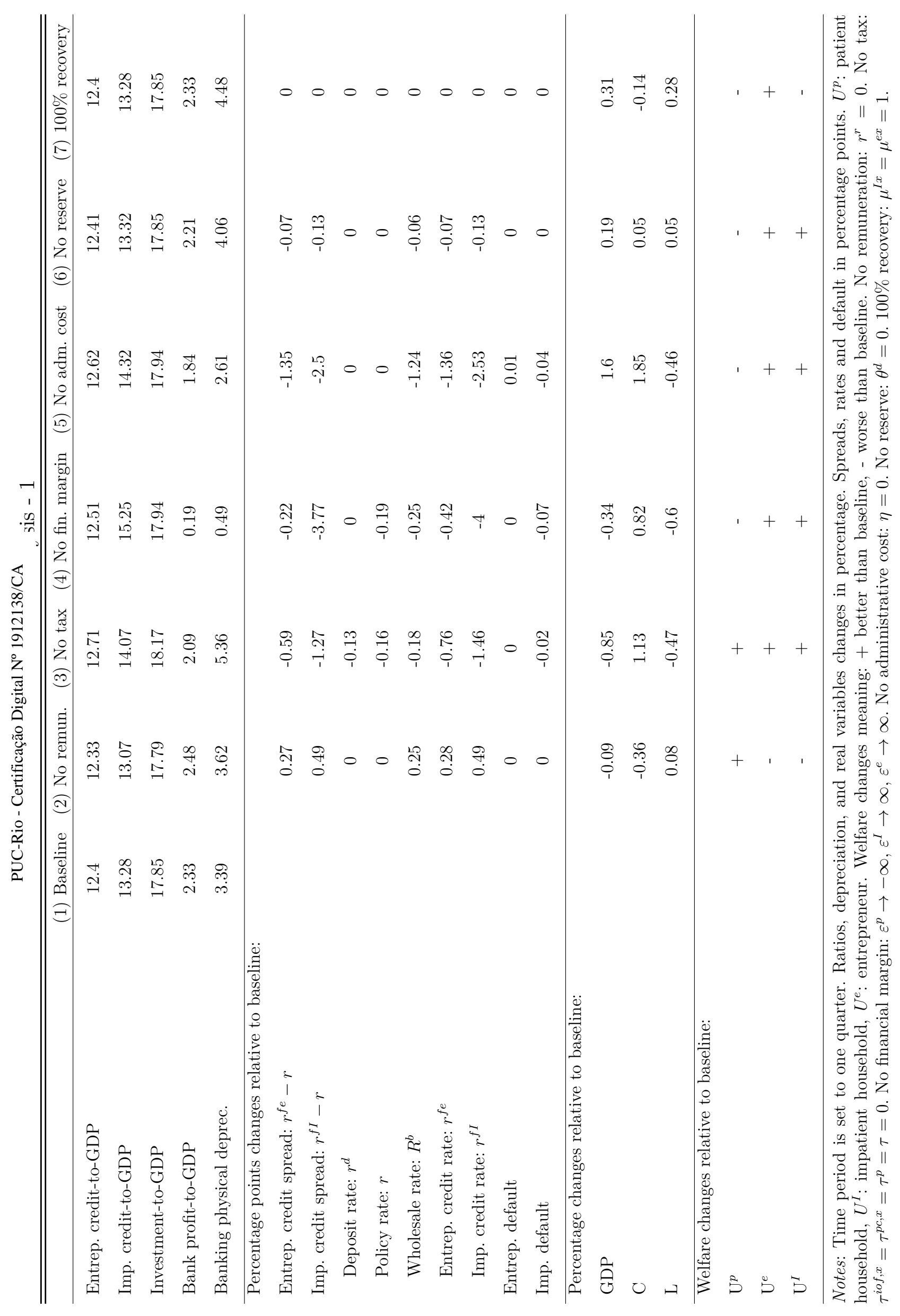


resourced are Lump-Sum profits. See Appendix H for an alternative default modelling approach following Carvalho et al. (2014) and Darracq Pariès et al. (2010).

Table 4.3 suggests that household spread reduction is greater when we increase competition in the banking sector. Furthermore, reducing administrative cost is the most effective way of diminishing entrepreneur spread and it is also capable of diminishing household spread in a meaningful way. World Bank (2018) provides empirical evidence behind our results. In that analysis, they point administrative cost (overhead cost) as one of the leading components of the banking spread (net interest margin). For instance, administrative cost accounts for $4.3 \%$ of total assets in Brazil, compared to a median of $2.9 \%$ in peer countries.

A comparison between decompositions is presented in Table 4.4. We compare both decompositions in terms of spread reduction specifically the accounting shares implied by model and calculated by BCB with the spread reduction compared to baseline in counterfactual. We note that the tax component in accounting exercises is overestimated when we compared to counterfactual. On the other hand, administrative cost and financial margin are underrated with the latter presenting a meaningful difference. These results suggest some careful actions by policy makers only supported by ICC accounting decomposition without an economic model underpinning the analysis.

Table 4.4: Accounting vs Counterfactual

\begin{tabular}{lcccc}
\hline \hline & \multicolumn{2}{c}{ Accounting } & & Counterfactual \\
\cline { 2 - 3 } \cline { 5 - 5 } & BCB & Model & & \\
\hline Tax & 22 & 30 & & 19 \\
Adm. cost & 27 & 24 & & 39 \\
Financial margin & 20 & 21 & & 43 \\
\hline
\end{tabular}

Notes: \% shares and \% spread decrease compared to baseline

Following the quantitative results, we highlight limitations and patterns in our theoretical framework. It is suggested in all decompositions exercises that administrative cost is an important ingredient of the spread formation and it is relevant to reduce banking spreads. However, the marginal administrative cost to provide credit does not play a significant role as evidenced by wholesale rate $R^{b}$ direction changes. ${ }^{10}$ Following Equation $3-3$ and administrative cost

\footnotetext{
${ }^{10}$ In a preliminary version of the model, we explicitly develop a banking technology using
} 
parameters values $(\eta>0$ and $\gamma>1)$, a given credit quantity $B$ rise leads to higher administrative marginal cost and higher $R^{b}$. Excluding Table 4.3 second column, $R^{b}$ decreases despite credit $B$ rise. Therefore, other channels prevails on abating $R^{b}$ against the upward effect through the administrative marginal cost.

Another pattern of the counterfactual decomposition is somewhat related to the findings of Carvalho et al. (2018) using the same model core structure. Labor of impatient and patient households move in opposite ways in most of exercises. Hence, impatient households better financial conditions permit higher consumption and lower labor, meanwhile patient households labor increases, despite higher durable and non-durable goods consumption of both households.

The model is not capable of generating higher ratios of credit-to-GDP, especially entrepreneur credit. The smaller entrepreneur credit rate $r^{f e}$ reductions have less impact in the borrowing constraint (Equation 3-9). Therefore, entrepreneur credit expansions are limited comparing with household credit. The other minor reason behind this limitation is GDP and credit moving in the same direction which prevents the ratio alterations.

A theoretical framework limitation is the negligible impact on defaults that pervade counterfactual analysis, despite our modeling attempts. ${ }^{11}$ Equations 3-6 to 3-9 provide intuition about two effects behind the result. The default cut-off rules 3-6 and 3-8 numerators terms credit bank rates and credit move in opposite ways through the asset pricing channel underpinning by borrowing constraints (equations 3-7 and 3-9). This first numerator effect presents credit quantities changes that dominate bank rates changes. The second effect of cut-off rules concerns the denominator (collateral) moving in the same direction of numerator (credit plus interest) since more collateral expands the borrowing capacity. Overall, default cut-offs $\bar{\omega}^{I}$ and $\bar{\omega}^{e}$ exhibit muted variations since more debt (credit plus interest) encourages more default, but higher collateral disincentivizes it. In the case of households spread reductions, the second effect dominates (default decreases), but the other way round for entrepreneurs (default increases).

capital and labor as inputs. The intuitions behind the counterfactual results are similar to our reduced form administrative cost. See Appendix I.

${ }^{11}$ See Appendix H. 


\section{5}

\section{Conclusion}

In this dissertation we study and decompose the banking spread according to the ICC decomposition with the support of a structural macroeconomic model. We utilize a DSGE with financial friction characterized by endogenous default, administrative cost, tax, and monopolistic competition. Our approach is different from most of studies.

Our quantitative findings reveal that reducing administrative cost is the most effective way of diminishing firms spread while households spread reduction is greater when banking sector competition is increased. Furthermore, results suggest some careful actions by policy makers only supported by ICC accounting decomposition without an economic model underpinning the analysis. Nevertheless, our study still leaves room for further research questions.

We deal with heterogeneity ex-post idiosyncratic shocks imposing a short cut and working with representative agents. A possible research path is studying banking spread with real heterogeneous agents which could deliver new insights and answers to different questions.

A limitation to our model is the recovery of defaulted resources by banks as Lump-Sum profits. Therefore, banks do not take into account recovery of defaulted resources when setting interest rates. A potential improvement of our model could be the recovery rate by banks directly influencing their interest rates.

Another important line of investigation refers to propagation of shocks, but with a model including sticky wages, habit formation, and variable capital utilization as Gerali et al. (2010). 


\section{Bibliography}

Almeida, F. D. and Divino, J. A. (2015). Determinants of the banking spread in the brazilian economy: The role of micro and macroeconomic factors. International Review of Economics \& Finance, 40:29-39.

Banco Central do Brasil (2017). Relatório de economia bancária. Technical report, Banco Central do Brasil.

Banco Central do Brasil (2018). Nota técnica do banco central do brasil 45 indicador de custo de crédito (nota metodológica). Technical report, Banco Central do Brasil.

Banco Central do Brasil (2019a). Discussão sobre as funções dos recolhimentos compulsórios. Technical report, Banco Central do Brasil.

Banco Central do Brasil (2019b). Relatório de economia bancária. Technical report, Banco Central do Brasil.

Becard, Y. and Gauthier, D. (2020). Collateral shocks. American Economic Journal: Macroeconomics.

Bignotto, F. G. and de Souza Rodrigues, E. A. (2005). Iv-fatores de risco e o spread bancário no brasil. Relatório de Economia Bancária e Crédito, page 45.

Carvalho, C., Pasca, N., Souza, L., and Zilberman, E. (2018). Macroeconomic effects of credit deepening in latin america. Available at SSRN 2503755.

Carvalho, F. A., Castro, M. R., and Costa, S. (2014). Traditional and matter-offact financial frictions in a dsge model for brazil: the role of macroprudential instruments and monetary policy.

Curdia, V. and Woodford, M. (2010). Credit spreads and monetary policy. Journal of Money, credit and Banking, 42:3-35.

Darracq Pariès, M., Kok, C., and Rodriguez-Palenzuela, D. (2010). Macroeconomic propagation under different regulatory regimes: Evidence from an estimated dsge model for the euro area. 
De Castro, M. R., Gouvea, S. N., Minella, A., Santos, R., and Souza-Sobrinho, N. F. (2015). Samba: Stochastic analytical model with a bayesian approach. Brazilian Review of Econometrics, 35(2):103-170.

Elenev, V., Landvoigt, T., and Van Nieuwerburgh, S. (2018). A macroeconomic model with financially constrained producers and intermediaries. Technical report, National Bureau of Economic Research.

Ferreira, L. N. and Nakane, M. I. (2018). Macroprudential policy in a dsge model: anchoring the countercyclical capital buffer". Economics Bulletin, 38(4):23452352.

Forlati, C. and Lambertini, L. (2011). Risky mortgages in a dsge model. Technical report.

Gerali, A., Neri, S., Sessa, L., and Signoretti, F. M. (2010). Credit and banking in a dsge model of the euro area. Journal of Money, Credit and Banking, 42:107-141.

Ho, T. S. and Saunders, A. (1981). The determinants of bank interest margins: theory and empirical evidence. Journal of Financial and Quantitative analysis, pages $581-600$.

lacoviello, M. (2005). House prices, borrowing constraints, and monetary policy in the business cycle. American economic review, 95(3):739-764.

Jakab, Z. and Kumhof, M. (2018). Banks are not intermediaries of loanable funds-facts, theory and evidence.

Joaquim, G., Van Doornik, B., and Ornelas, J. R. (2019). Bank competition, cost of credit and economic activity: evidence from brazil. Technical report.

Justiniano, A., Primiceri, G. E., and Tambalotti, A. (2015). Household leveraging and deleveraging. Review of Economic Dynamics, 18(1):3-20.

Souza-Sobrinho, N. F. (2010). Macroeconomics of bank interest spreads: Evidence from brazil. Annals of Finance, 6(1):1.

World Bank (2018). Brazil - improving the efficiency in credit markets. Technical report, World Bank.

World Bank Group (2020). Doing business brazil- economy profile of brazil. Technical report, World Bank Group. 
A

\section{Economic Spread Decomposition}

In this exercise, we evaluate the composition of banking spread in baseline calibration with the direct support of the steady state expressions 3-1 to 3-5. We use interest rates from agents optimal decisions to decompose spread into outside and inside shares. Inside share considers components that internally arise in the banking sector and includes administrative cost, reserve requirements, and the remuneration associated with it. Outside share contains taxes, banking market power (financial margin), and default. In this decomposition, we focus on the steady state of baseline calibration and it is like a "picture" of the equilibrium. Expressions below show how we calculate each share.

$$
\begin{aligned}
\text { Inside share } & =\frac{R^{b}-r}{r^{f x}-r} . \\
\text { Outside share } & =\frac{\left[r^{f x}-R^{b}\right]}{r^{f x}-r} .
\end{aligned}
$$

We calculate and display each share for impatient household spread in Figure A.1, entrepreneur spread in Figure A.2, and average spread weighted by credit in Figure A.3. Folowing Equation 3-3, we calculate components in $R^{b}$ and conclude that the bulk of inside share is the (marginal) administrative cost.

Regarding the spread composition of the two types of credit, the inside share of household spread (19\%) represents less than half of entrepreneur spread (44\%). This indicates that (marginal) administrative cost share is one of the most important components of entrepreneur spread, but not so representative for household spread in the baseline equilibrium. 

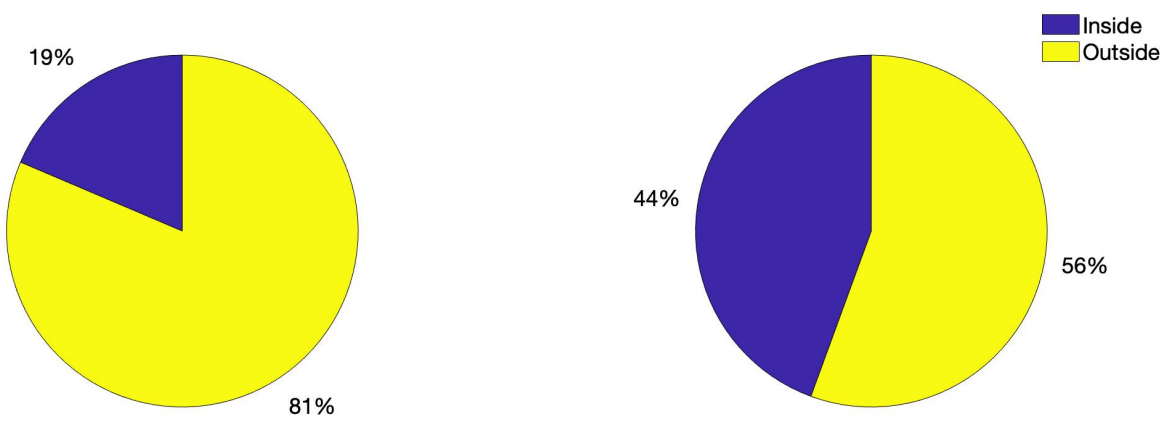

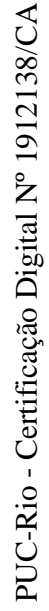

Figure A.1: Impatient household

Figure A.2: Entrepreneur

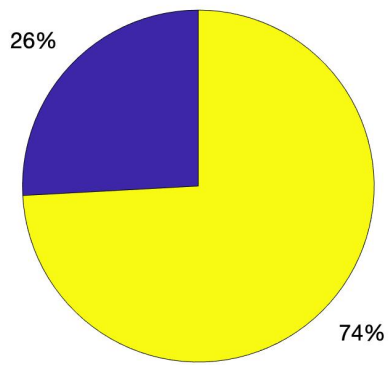

Figure A.3: Total 
B

\section{Equilibrium Equations}

\section{B.1}

\section{Patient Households}

$$
\begin{gathered}
\frac{\xi\left(C_{t}^{p}\right)^{\sigma-1}}{\xi\left(C_{t}^{p}\right)^{\sigma}+(1-\xi)\left(S_{t}^{p}\right)^{\sigma}}=E_{t} \beta^{p} \frac{\xi\left(C_{t+1}^{p}\right)^{\sigma-1}}{\xi\left(C_{t+1}^{p}\right)^{\sigma}+(1-\xi)\left(S_{t+1}^{p}\right)^{\sigma}} \frac{\left(1+r_{t}^{d}\left(1-\tau^{p}\right)\right)}{\pi_{t+1}} \\
\frac{\left(L_{t}^{p}\right)^{\varphi}}{W_{t}^{p}}=\frac{\xi\left(C_{t}^{p}\right)^{\sigma-1}}{\xi\left(C_{t}^{p}\right)^{\sigma}+(1-\xi)\left(S_{t}^{p}\right)^{\sigma}}
\end{gathered}
$$

$\mho_{\infty}^{\varangle} \quad \frac{(1-\xi)\left(S_{t}^{p}\right)^{\sigma-1}}{\xi\left(C_{t}^{p}\right)^{\sigma}+(1-\xi)\left(S_{t}^{p}\right)^{\sigma}}+E_{t} \beta^{p} \frac{\xi\left(C_{t+1}^{p}\right)^{\sigma-1} q_{t+1}^{s}\left(1-\delta^{s}\right)}{\xi\left(C_{t+1}^{p}\right)^{\sigma}+(1-\xi)\left(S_{t+1}^{p}\right)^{\sigma}}=\frac{\xi\left(C_{t}^{p}\right)^{\sigma-1}}{\xi\left(C_{t}^{p}\right)^{\sigma}+(1-\xi)\left(S_{t}^{p}\right)^{\sigma}} q_{t}^{s}$

\section{B.2}

\section{Impatient Households}

$\Lambda_{t}^{I}$ is the Lagrange multiplier associated to the impatient households borrowing constraints

$$
\begin{gathered}
\frac{\xi\left(C_{t}^{I}\right)^{\sigma-1}}{\xi\left(C_{t}^{I}\right)^{\sigma}+(1-\xi)\left(S_{t}^{I}\right)^{\sigma}}=E_{t} \beta^{I} \frac{\xi\left(C_{t+1}^{I}\right)^{\sigma-1}}{\xi\left(C_{t+1}^{I}\right)^{\sigma}+(1-\xi)\left(S_{t+1}^{I}\right)^{\sigma}} \frac{\left(1-F\left(\bar{\omega}_{t+1}^{I}\right)\right)\left(1+r_{t}^{f I}\right)}{\pi_{t+1}}+ \\
+\left(1+r_{t}^{f I}\right) \Lambda_{t}^{I} \\
\frac{\left(L_{t}^{I}\right)^{\varphi}}{W_{t}^{I}}=\frac{\xi\left(C_{t}^{I}\right)^{\sigma-1}\left[1-G\left(\bar{\omega}_{t}^{I}\right)\right]}{\xi\left(C_{t}^{I}\right)^{\sigma}+(1-\xi)\left(S_{t}^{I}\right)^{\sigma}}+\Lambda_{t}^{I} \tau^{w l} E_{t}\left[1-G\left(\bar{\omega}_{t+1}^{I}\right)\right] \\
q_{t}^{s}=\frac{(1-\xi)}{\xi} \frac{\left(S_{t}^{I}\right)^{\sigma-1}}{\left(C_{t}^{I}\right)^{\sigma-1}}+\beta^{I} E_{t} \frac{\frac{\xi\left(C_{t+1}^{I}\right)^{\sigma-1}}{\frac{\xi\left(C_{t+1}^{I}\right)^{\sigma}+(1-\xi)\left(S_{t+1}^{I}\right)^{\sigma}}{\left.\xi\left(C_{t}^{I}\right)^{\sigma-1}\right)}}}{\frac{\xi\left(C_{t}^{I^{\prime}}\right)^{\sigma}+(1-\xi)\left(S_{t}^{I}\right)^{\sigma}}{(B)}}\left[1-G\left(\bar{\omega}_{t+1}^{I}\right)\right] q_{t+1}^{s}\left(1-\delta^{s}\right)+ \\
+E_{t} \Lambda_{t}^{I} \tau^{s} \frac{\left[1-G\left(\bar{\omega}_{t+1}^{I}\right)\right] q_{t+1}^{s} \pi_{t+1}\left(1-\delta^{s}\right)}{\frac{\xi\left(C_{t}^{I}\right)^{\sigma-1}}{\xi\left(C_{t}^{I}\right)^{\sigma}+(1-\xi)\left(S_{t}^{I}\right)^{\sigma}}} \\
\left(1+r_{t-1}^{f I}\right) \frac{B_{t-1}^{I}}{\pi_{t}}=\bar{\omega}_{t}^{I}\left[q_{t}^{s}\left(1-\delta^{s}\right) S_{t-1}^{I}+W_{t}^{I} L_{t}^{I}\right]
\end{gathered}
$$




$$
\begin{aligned}
\left(1+r_{t}^{f I}\right) B_{t}^{I}=E_{t}\left(1-G\left(\bar{\omega}_{t+1}^{I}\right)\right)\left[\tau^{w l} W_{t}^{I} L_{t}^{I}+\tau^{s} q_{t+1}^{s} \pi_{t+1}\left(1-\delta^{s}\right) S_{t}^{I}\right] \\
C_{t}^{I}+q_{t}^{s} S_{t}^{I}+\left(1-F\left(\bar{\omega}_{t}^{I}\right)\right) \frac{\left(1+r_{t-1}^{f I}\right) B_{t-1}^{I}}{\pi_{t}}=B_{t}^{I}+ \\
+\left(1-G\left(\bar{\omega}_{t}^{I}\right)\right)\left[W_{t}^{I} L_{t}^{I}+q_{t}^{S}\left(1-\delta^{S}\right) S_{t-1}^{I}\right]
\end{aligned}
$$

\section{B.3}

\section{Entrepreneur}

$$
\begin{gathered}
1=E_{t} \beta^{e} \frac{C_{t}^{e}}{C_{t+1}^{e}}\left(1-F^{e}\left(\bar{\omega}_{t+1}^{e}\right)\right) \frac{\left(1+r_{t}^{f e}\right)}{\pi_{t+1}}+\Lambda_{t}^{e} C_{t}^{e}\left(1+r_{t}^{f e}\right) \\
W_{t}^{p}=\left(1-G\left(\bar{\omega}_{t}^{e}\right)\right) q_{t}^{w}(1-\alpha) \theta \frac{Y_{t}^{e}}{L_{t}^{p}}+\Lambda_{t}^{e} C_{t}^{e} E_{t}\left(1-G\left(\bar{\omega}_{t+1}^{e}\right)\right) \tau^{y} q_{t}^{w}(1-\alpha) \theta \frac{Y_{t}^{e}}{L_{t}^{p}}
\end{gathered}
$$

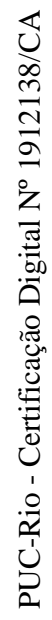

$$
W_{t}^{I}=\left(1-G\left(\bar{\omega}_{t}^{e}\right)\right) q_{t}^{w}(1-\alpha)(1-\theta) \frac{Y_{t}^{e}}{L_{t}^{I}}+\Lambda_{t}^{e} C_{t}^{e} E_{t}\left(1-G\left(\bar{\omega}_{t+1}^{e}\right)\right) \tau^{y} q_{t}^{w}(1-\alpha)(1-\theta) \frac{Y_{t}^{e}}{L_{t}^{I}}
$$

$$
\begin{aligned}
& q_{t}^{k}=\beta^{e} E_{t} q_{t+1}^{w} \alpha \frac{Y_{t}^{e}}{K_{t}}\left[\left(1-G\left(\bar{\omega}_{t+1}^{e}\right)\right) \frac{C_{t}^{e}}{C_{t+1}^{e}}+\Lambda_{t}^{e} C_{t}^{e} \tau^{y}\right]+ \\
& +\beta^{e} E_{t} \frac{C_{t}^{e}}{C_{t+1}^{e}}\left(1-G\left(\bar{\omega}_{t+1}^{e}\right)\right)\left(1-\delta^{k}\right) q_{t+1}^{k}+\Lambda_{t}^{e} C_{t}^{e} \tau^{k} E_{t}\left[\pi_{t+1}\left(1-G\left(\bar{\omega}_{t+1}^{e}\right)\right)\left(1-\delta^{k}\right) q_{t+1}^{k}\right]
\end{aligned}
$$

$$
\begin{gathered}
C_{t}^{e}+q_{t}^{k} K_{t}+W_{t}^{I} L_{t}^{I}+W_{t}^{p} L_{t}^{p}+\left(1-F\left(\bar{\omega}_{t}^{e}\right)\right) \frac{\left(1+r_{t-1}^{f e}\right) B_{t-1}^{e}}{\pi_{t}}= \\
\left(1-G\left(\bar{\omega}_{t}^{e}\right)\right) q_{t}^{w} Y_{t}^{e}+\left(1-G\left(\bar{\omega}_{t}^{e}\right)\right) q_{t}^{k}\left(1-\delta^{k}\right) K_{t-1}+B_{t}^{e} \\
\left(1+r_{t}^{f e}\right) B_{t}^{e}=E_{t}\left(1-G\left(\bar{\omega}_{t+1}^{e}\right)\right)\left[\tau^{y} q_{t}^{w} Y_{t}^{e}+\tau^{k} q_{t+1}^{k} \pi_{t+1}\left(1-\delta^{k}\right) K_{t}\right] \\
Y_{t}^{e}=A_{t} K_{t-1}^{\alpha}\left[\left(L_{t}^{p}\right)^{\theta}\left(L_{t}^{I}\right)^{1-\theta}\right]^{1-\alpha}
\end{gathered}
$$




\section{B.4}

\section{Banking Sector}

$$
\begin{aligned}
& B_{t}+R_{t}=D_{t}+K_{t}^{b} \\
& R_{t}=\theta^{d} D_{t} \\
& K_{t}^{b}=\left(1-\delta^{b}\right) \frac{K_{t-1}^{b}}{\pi_{t}}+\left(1-d^{b}\right)(1-\tau)\left[\frac{J_{t-1}^{b}}{\pi_{t}}+\right. \\
& \left.G\left(\bar{\omega}_{t}^{I}\right)\left\{\mu^{I s}\left(1-\delta_{s}\right) q_{t}^{s} S_{t-1}^{I}+\mu^{I w l} W_{t}^{I} L_{t}^{I}\right\}+G\left(\bar{\omega}_{t}^{e}\right)\left\{\mu^{e k}\left(1-\delta_{k}\right) q_{t}^{k} K_{t-1}+\mu^{e y} q_{t}^{w} Y_{t}^{e}\right\}\right] \\
& R_{t}^{b}=\frac{r_{t}}{\left(1-\theta^{d}\right)}-\theta^{d} \frac{r_{t}^{r}}{\left(1-\theta^{d}\right)}-\kappa_{k b}\left(\frac{K_{t}^{b}}{B_{t}+R_{t}}-\nu^{b}\right)\left(\frac{K_{t}^{b}}{B_{t}+R_{t}}\right)^{2} \frac{1}{\left(1-\theta^{d}\right)}+\eta \gamma B_{t}^{\gamma-1} \\
& -1+\varepsilon_{t}^{p}-\varepsilon_{t}^{p} \frac{r_{t}}{r_{t}^{d}}-\kappa_{d}\left(\frac{r_{t}^{d}}{r_{t-1}^{d}}-1\right) \frac{r_{t}^{d}}{r_{t-1}^{d}}+\beta_{P} E_{t}\left\{\frac{\lambda_{0, t+1}^{P}}{\lambda_{0, t}^{P}} \kappa_{d}\left(\frac{r_{t+1}^{d}}{r_{t}^{d}}-1\right)\left(\frac{r_{t+1}^{d}}{r_{t}^{d}}\right)^{2} \frac{D_{t+1}}{D_{t}}\right\}=0 \\
& \left.\left(1-\varepsilon_{t}^{I}\right)\left[E_{t}\left(1-F\left(\bar{\omega}_{t+1}^{I}\right)\right)\right)\left(1-\tau^{p c, I}\right)\right]+\frac{\varepsilon_{t}^{I}}{r_{t}^{f I}}\left[\tau^{i o f, I}-E_{t}\left(1-F\left(\bar{\omega}_{t+1}^{I}\right)\right)+\left(1+R_{t}^{b}\right)\right]- \\
& \kappa_{b I}\left(\frac{r_{t}^{f I}}{r_{t-1}^{f I}}-1\right) \frac{r_{t}^{f I}}{r_{t-1}^{f I}}+\beta_{P} E_{t}\left\{\frac{\lambda_{0, t+1}^{P}}{\lambda_{0, t}^{P}} \kappa_{b I}\left(\frac{r_{t+1}^{f I}}{r_{t}^{f I}}-1\right)\left(\frac{r_{t+1}^{f I}}{r_{t}^{f I}}\right)^{2} \frac{B_{t+1}^{I}}{B_{t}^{I}}\right\}=0
\end{aligned}
$$

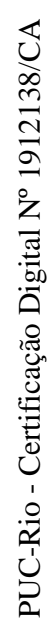

$$
\begin{aligned}
& \left.\left(1-\varepsilon_{t}^{e}\right)\left[E_{t}\left(1-F\left(\bar{\omega}_{t+1}^{e}\right)\right)\right)\left(1-\tau^{p c, e}\right)\right]+\frac{\varepsilon_{t}^{e}}{r_{t}^{f e}}\left[\tau^{i o f, e}-E_{t}\left(1-F\left(\bar{\omega}_{t+1}^{e}\right)\right)+\left(1+R_{t}^{b}\right)\right]- \\
& \kappa_{b e}\left(\frac{r_{t}^{f e}}{r_{t-1}^{f e}}-1\right) \frac{r_{t}^{f e}}{r_{t-1}^{f e}}+\beta_{P} E_{t}\left\{\frac{\lambda_{0, t+1}^{P}}{\lambda_{0, t}^{P}} \kappa_{b e}\left(\frac{r_{t+1}^{f e}}{r_{t}^{f e}}-1\right)\left(\frac{r_{t+1}^{f e}}{r_{t}^{f e}}\right)^{2} \frac{B_{t+1}^{e}}{B_{t}^{e}}\right\}=0
\end{aligned}
$$

$$
\begin{aligned}
J_{t-1}^{b} & =B_{t-1}^{I}\left\{\left(1+r_{t-1}^{f I}\right)\left(1-F\left(\bar{\omega}_{t}^{I}\right)\right)-\tau^{p c, I} r_{t-1}^{f I}\left(1-F\left(\bar{\omega}_{t}^{I}\right)\right)-\tau^{i o f, I}-1\right\}+ \\
& +B_{t-1}^{e}\left\{\left(1+r_{t-1}^{f e}\right)\left(1-F\left(\bar{\omega}_{t}^{e}\right)\right)-\tau^{p c, e} r_{t-1}^{f e}\left(1-F\left(\bar{\omega}_{t}^{e}\right)\right)-\tau^{i o f, e}-1\right\}+ \\
& +r_{t-1}^{r} R_{t-1}-\eta B_{t-1}^{\gamma}-4 \text { adjusment costs }
\end{aligned}
$$

$$
B_{t}=B_{t}^{I}+B_{t}^{e}
$$




$$
r_{t}^{d}=r_{t}^{r}
$$

\section{B.5}

\section{Capital and Durable Good Producer}

$$
\begin{gathered}
q_{t}^{k}\left[1-\kappa_{k}\left(\frac{I_{t}^{k}}{I_{t-1}^{k}}-1\right) \frac{I_{t}^{k}}{I_{t-1}^{k}}-\frac{\kappa_{k}}{2}\left(\frac{I_{t}^{k}}{I_{t-1}^{k}}-1\right)^{2}\right]+E_{t} q_{t+1}^{k} \kappa_{k}\left(\frac{I_{t+1}^{k}}{I_{t}^{k}}-1\right)\left(\frac{I_{t+1}^{k}}{I_{t}^{k}}\right)^{2} \beta^{p} \frac{\lambda_{0, t+1}^{P}}{\lambda_{0, t}^{P}}=1 \\
K_{t}=\left(1-\delta^{k}\right) K_{t-1}+\left[1-\frac{\kappa_{k}}{2}\left(\frac{I_{t}^{k}}{I_{t-1}^{k}}-1\right)^{2}\right] I_{t}^{k} \quad(\mathrm{~B}-29) \\
q_{t}^{s}\left[1-\kappa_{s}\left(\frac{I_{t}^{s}}{I_{t-1}^{s}}-1\right) \frac{I_{t}^{s}}{I_{t-1}^{s}}-\frac{\kappa_{s}}{2}\left(\frac{I_{t}^{s}}{I_{t-1}^{s}}-1\right)^{2}\right]+E_{t} q_{t+1}^{s} \kappa_{s}\left(\frac{I_{t+1}^{s}}{I_{t}^{s}}-1\right)\left(\frac{I_{t+1}^{s}}{I_{t}^{s}}\right)^{2} \beta^{p} \frac{\lambda_{0, t+1}^{P}}{\lambda_{0, t}^{P}}=1 \\
S_{t}=\left(1-\delta^{s}\right) S_{t-1}+\left[1-\frac{\kappa_{s}}{2}\left(\frac{I_{t}^{s}}{I_{t-1}^{s}}-1\right)^{2}\right] I_{t}^{s}
\end{gathered}
$$

\section{B.6}

\section{Retail Firms}

$$
(1-\varepsilon)+\varepsilon q_{t}^{w}-\kappa_{p}\left(\pi_{t}-\pi_{t-1}^{\iota} \bar{\pi}^{1-\iota}\right) \pi_{t}+\beta^{p} E_{t}\left[\frac{\lambda_{0, t+1}^{P}}{\lambda_{0, t}^{P}} \pi_{t+1}\left(\pi_{t+1}-\pi_{t}^{\iota} \bar{\pi}^{1-\iota}\right) \frac{Y_{t+1}}{Y_{t}}\right]
$$

\section{B.7}

\section{Government}

$$
\begin{aligned}
G_{t}+\frac{\left(1+r_{t-1}^{r}\right) R_{t-1}}{\pi_{t}}= & R_{t}+\frac{B_{t-1}^{I}}{\pi_{t}}\left[\left(1-F^{I}\left(\bar{\omega}_{t}^{I}\right)\right) \tau^{p c, I} r_{t-1}^{f I}+\tau^{i o f, I}\right]+ \\
& \frac{B_{t-1}^{e}}{\pi_{t}}\left[\left(1-F^{e}\left(\bar{\omega}_{t}^{e}\right)\right) \tau^{p c, e} r_{t-1}^{f e}+\tau^{i o f, e}\right]+\tau^{p} r_{t-1}^{d} \frac{D_{t-1}^{p}}{\pi_{t}}+ \\
& \tau\left[\frac{J_{t-1}^{b}}{\pi_{t}}+\text { defaulted assets banks recovery }\right]
\end{aligned}
$$$$
\left(1+r_{t}\right)=(1+\bar{r})^{1-\rho}\left(1+r_{t-1}\right)^{\rho}\left(\frac{\pi_{t}}{\bar{\pi}}\right)^{\phi_{\pi}(1-\rho)}\left(\frac{Y_{t}}{Y_{t-1}}\right)^{\phi_{y}(1-\rho)} e^{\epsilon_{t}^{m}}
$$ 


\section{B.8}

Recycling Firms

$$
\begin{aligned}
L_{t}= & G\left(\bar{\omega}_{t}^{I}\right)\left\{\left(1-\mu^{I s}\right)\left(1-\delta_{s}\right) q_{t}^{s} S_{t-1}^{I}+\left(1-\mu^{I w l}\right) W_{t}^{I} L_{t}^{I}\right\}+ \\
& +G\left(\bar{\omega}_{t}^{e}\right)\left\{\left(1-\mu^{e k}\right)\left(1-\delta_{k}\right) q_{t}^{k} K_{t-1}+\left(1-\mu^{e y}\right) q_{t}^{w} Y_{t}^{e}\right\}
\end{aligned}
$$

\section{B.9}

\section{Market Clearing and Exogenous Process}

$$
\begin{gathered}
Y_{t}=C_{t}+I_{t}^{s}+I_{t}^{k}+G_{t}+\frac{\delta^{b} K_{t-1}^{b}}{\pi_{t}}+\frac{\eta B_{t-1}^{\gamma}}{\pi_{t}}+\frac{\kappa_{P}}{2}\left(\pi-\pi_{t-1}^{\iota} \bar{\pi}^{1-\iota}\right)^{2} Y_{t} \\
\frac{\kappa_{K b}}{2}\left(\frac{K_{t-1}^{b}}{B_{t-1}+R_{t-1}}-\nu^{b}\right)^{2} \frac{K_{t-1}^{b}}{\pi_{t}}+\frac{\kappa_{b I}}{2}\left[\frac{r_{t-1}^{f I}(j)}{r_{t-2}^{f I}(j)}-1\right]^{2} \frac{r_{t-1}^{f I} B_{t-1}^{I}}{\pi_{t}}+ \\
\frac{\kappa_{b e}}{2}\left[\frac{r_{t-1}^{f e}}{r_{t-2}^{f e}}-1\right]^{2} \frac{r_{t-1}^{f e} B_{t-1}^{e}}{\pi_{t}}+\frac{\kappa_{d}}{2}\left(\frac{r_{t-1}^{d}}{r_{t-2}^{d}}-1\right)^{2} \frac{r_{t-1}^{d} D_{t-1}}{\pi_{t}} \\
S_{t}=S_{t}^{p}+S_{t}^{I} \\
C_{t}=C_{t}^{p}+C_{t}^{I}+C_{t}^{e} \\
G D P_{t}=C_{t}+I_{t}^{k}+I_{t}^{s}+G_{t} \\
A_{t}=\rho_{a} A_{t-1}+\epsilon_{t}^{a}
\end{gathered}
$$




\section{C}

\section{Steady State}

The steady state of the model is calculated numerically ${ }^{1}$.

$$
\begin{gathered}
A=1, \quad \pi=1, \quad q^{s}=1, \quad q^{k}=1, \quad q^{w}=\frac{(\varepsilon-1)}{\varepsilon} \\
r^{d}=\left[\frac{1}{\beta^{p}}-1\right] \frac{1}{\left(1-\tau^{p}\right)}, \quad r=\frac{\left(\varepsilon^{p}-1\right)}{\varepsilon^{p}} r^{d}
\end{gathered}
$$

First Step: Guess both types of credit $B_{\text {guess }}=B_{\text {guess }}^{I}+B_{\text {guess }}^{e}$

$$
R^{b}=\frac{r}{1-\theta^{d}}-\theta^{d} \frac{r^{r}}{1-\theta^{d}}+\eta \gamma B_{\text {guess }}^{\gamma-1}
$$

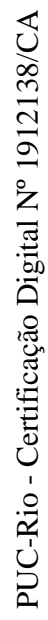

Second Step: Given the first guess, guess both cut-offs $\bar{\omega}_{\text {guess }}^{I}, \bar{\omega}_{\text {guess }}^{e}$

$$
\begin{gathered}
r^{f I}=\frac{\varepsilon^{I}}{\left(\varepsilon^{I}-1\right)} \frac{1}{\left(1-\tau^{p c, I}\right)\left(1-F^{I}\left(\bar{\omega}_{\text {guess }}^{I}\right)\right)}\left\{R^{b}+\tau^{\text {iof }, I}+F^{I}\left(\bar{\omega}_{\text {guess }}^{I}\right)\right\} \\
r^{f e}=\frac{\varepsilon^{e}}{\left(\varepsilon^{e}-1\right)} \frac{1}{\left(1-\tau^{p c, e}\right)\left(1-F^{e}\left(\bar{\omega}_{\text {guess }}^{e}\right)\right.}\left\{R^{b}+\tau^{\text {iof,e }}+F^{e}\left(\bar{\omega}_{\text {guess }}^{e}\right)\right\} \\
\frac{Y}{K}=\frac{1-\beta^{e}\left(1-G^{e}\left(\bar{\omega}_{\text {guess }}^{e}\right)\right)\left(1-\delta^{k}\right)-A^{e} \tau^{k}\left(1-G^{e}\left(\bar{\omega}_{\text {guess }}^{e}\right)\right)\left(1-\delta^{k}\right)}{1+r^{e} q^{w} \alpha\left[\left(1-G^{e}\left(\bar{\omega}_{\text {guess }}^{e}\right)\right)+\tau^{y} A^{e}\right.}-\frac{1}{A^{e}}\left(1-F^{e}\left(\bar{\omega}_{\text {guess }}^{e}\right)\right) \\
\frac{K}{L}=\left(\frac{Y}{A K}\right)^{\frac{1}{\alpha-1}}, \frac{Y}{L}=A\left(\frac{K}{L}\right)^{\alpha}, \quad \frac{I^{k}}{L}=\delta^{k} \frac{K}{L} \\
\frac{B^{e}}{L}=\frac{\left(1-G^{e}\left(\bar{\omega}_{\text {guess }}^{e}\right)\right)}{1+r^{f e}}\left[\tau^{k}\left(1-\delta^{k}\right) \frac{K}{L}+\tau^{y} q^{w} \frac{Y}{L}\right] \\
X^{p}=\frac{W^{p} L^{p}}{L}=\left(1-G^{e}\left(\bar{\omega}_{\text {guess }}^{e}\right)\right) q^{w}(1-\alpha) \theta \frac{Y}{L}+A^{e}\left(1-G^{e}\left(\bar{\omega}_{\text {guess }}^{e}\right)\right) \tau^{y} q^{w}(1-\alpha) \theta \frac{Y}{L}
\end{gathered}
$$

\footnotetext{
${ }^{1}$ Variable without time notation means steady state.
} 


$$
\begin{aligned}
& X^{I}=\frac{W^{I} L^{I}}{L}=\left(1-G^{e}\left(\bar{\omega}_{\text {guess }}^{e}\right)\right) q^{w}(1-\alpha)(1-\theta) \frac{Y}{L}+A^{e}\left(1-G^{e}\left(\bar{\omega}_{\text {guess }}^{e}\right)\right) \tau^{y} q^{w}(1-\alpha)(1-\theta) \frac{Y}{L} \\
& \frac{C^{e}}{L}=\frac{B^{e}}{L}+\left(1-G^{e}\left(\bar{\omega}_{\text {guess }}^{e}\right)\right) q^{w} \frac{Y}{L}+\left(1-G^{e}\left(\bar{\omega}_{\text {guess }}^{e}\right)\right)\left(1-\delta^{k}\right) \frac{K}{L}-\frac{K}{L}- \\
& -X^{I}-X^{p}-\left(1-F^{e}\left(\bar{\omega}_{\text {guess }}^{e}\right)\right)\left(1+r^{f e}\right) \frac{B^{e}}{L} \\
& A^{I}=\frac{\Lambda^{I}}{\frac{\xi\left(C^{p}\right) \sigma-1}{\xi\left(C^{p}\right)^{\sigma}+(1-\xi)\left(S^{p}\right)^{\sigma}}}=\frac{1}{\left(1+r^{f I}\right)}-\beta^{I}\left(1-F^{I}\left(\bar{\omega}_{\text {guess }}^{I}\right)\right) \\
& \frac{C^{I}}{L}=\frac{X^{I}\left(1-G^{I}\left(\bar{\omega}_{\text {guess }}^{I}\right)\right)\left[1-\frac{\tau^{w l}\left(\left(1-F^{I}\left(\bar{\omega}_{\text {guess }}^{I}\right)\right)\left(1+r^{F I}-1\right)\right.}{1+r^{f I}}\right]}{1+\left[\frac{\xi}{1-\xi}\left(1-\beta^{I}\left(1-G^{I}\left(\bar{\omega}_{\text {guess }}^{I}\right)\right)\left(1-\delta^{s}\right)-\tau^{s} A^{I}\left(1-G^{I}\left(\bar{\omega}_{\text {guess }}^{I}\right)\right)\left(1-\delta^{s}\right)\right)\right]^{\frac{1}{\sigma-1}}} \\
& \frac{1}{1-\left(1-G^{I}\left(\bar{\omega}_{\text {guess }}^{I}\right)\right)+\tau^{s}\left(1-\delta^{s}\right) \frac{\left(1-G^{I}\left(\bar{\omega}_{\text {guess }}^{I}\right)\right)}{1+r^{f I}}\left(\left(1-F^{I}\left(\bar{\omega}_{\text {guess }}^{I}\right)\right)\left(1+r^{f I}\right)-1\right)} \\
& \frac{S^{I}}{L}=\frac{C^{I}}{L}\left[\frac{\xi}{1-\xi}\left(1-\beta^{I}\left(1-G^{I}\left(\bar{\omega}_{\text {guess }}^{I}\right)\right)\left(1-\delta^{s}\right)-\tau^{s} A^{I}\left(1-G^{I}\left(\bar{\omega}_{\text {guess }}^{I}\right)\right)\left(1-\delta^{s}\right)\right)\right]^{\frac{1}{1-\sigma}} \\
& \frac{B^{I}}{L}=\frac{\left(1-G^{I}\left(\bar{\omega}_{\text {guess }}^{I}\right)\right)}{1+r^{f I}}\left[\tau^{w l} X^{I}+\tau^{s}\left(1-\delta^{s}\right) \frac{S^{I}}{L}\right] \\
& \bar{\omega}_{\text {implicit }}^{I}=\frac{\left(1+r^{f I}\right) B^{I} / L}{\left(1-\delta^{s}\right) S^{I} / L+X^{I}}
\end{aligned}
$$

Third Step: Verify if $\bar{\omega}_{\text {implicit }}^{I}=\bar{\omega}_{\text {guess }}^{I}$ and $\bar{\omega}_{\text {implicit }}^{e}=\bar{\omega}_{\text {guess }}^{e}$. Continue if conditions are satisfied or return to the second step if at least one is invalid.

$$
\begin{aligned}
& \bar{\omega}^{I}=\bar{\omega}_{\text {implicit }}^{I}=\bar{\omega}_{\text {guess }}^{I} \\
& \bar{\omega}^{e}=\bar{\omega}_{\text {implicit }}^{e}=\bar{\omega}_{\text {guess }}^{e}
\end{aligned}
$$

Calculating $\delta^{b}$ requires defining the collateral in terms of credit guesses due to the non-linearity of the administrative cost.

$$
\begin{gathered}
T_{1}=\left(1-\delta^{s}\right) S^{I}=\frac{\left(1+r^{f I}\right) B_{\text {guess }}^{I}\left[\bar{\omega}^{I}-\left(1-G^{I}\left(\bar{\omega}^{I}\right)\right) \tau^{w l}\right]}{\bar{\omega}^{I}\left(1-G^{I}\left(\bar{\omega}^{I}\right)\right)\left(\tau^{s}-\tau^{w l}\right)} \\
T_{2}=W^{I} L^{I}=\frac{\left(1+r^{f I}\right) B_{\text {guess }}^{I}\left[\left(1-G^{I}\left(\bar{\omega}^{I}\right)\right) \tau^{s}-\bar{\omega}^{I}\right]}{\bar{\omega}^{I}\left(1-G^{I}\left(\bar{\omega}^{I}\right)\right)\left(\tau^{s}-\tau^{w l}\right)} \\
T_{3}=\left(1-\delta^{k}\right) K=\frac{\left(1+r^{f e}\right) B_{\text {guess }}^{e}\left[\bar{\omega}^{e}-\left(1-G^{e}\left(\bar{\omega}^{e}\right)\right) \tau^{y}\right]}{\bar{\omega}^{e}\left(1-G^{e}\left(\bar{\omega}^{e}\right)\right)\left(\tau^{k}-\tau^{y}\right)} \\
T_{4}=q^{w} Y=\frac{\left(1+r^{f e}\right) B_{\text {guess }}^{e}\left[\left(1-G^{e}\left(\bar{\omega}^{e}\right)\right) \tau^{k}-\bar{\omega}^{e}\right]}{\left.\bar{\omega}^{e}\left(1-G^{e} \bar{\omega}^{e}\right)\right)\left(\tau^{k}-\tau^{y}\right)}
\end{gathered}
$$




$$
\begin{aligned}
\delta^{b}= & \frac{\left(1-d^{b}\right)(1-\tau)}{\nu^{b} B_{\text {guess }}\left(1+\frac{\theta^{d}\left(1-\nu^{b}\right)}{1-\theta^{d}+\nu^{b} \theta^{d}}\right)}\{ \\
& B_{\text {guess }}^{I}\left[\left(1+r^{f I}\right)\left(1-F^{I}\left(\bar{\omega}^{I}\right)\right)-\tau^{p c, I} r^{f I}\left(1-F^{I}\left(\bar{\omega}^{I}\right)\right)-\tau^{i o f, I}-1\right]+ \\
& +B_{\text {guess }}^{e}\left[\left(1+r^{f e}\right)\left(1-F^{e}\left(\bar{\omega}^{e}\right)\right)-\tau^{p c, e} r^{f e}\left(1-F^{e}\left(\bar{\omega}^{e}\right)\right)-\tau^{i o f, e}-1\right]+ \\
& +r^{r} \frac{\theta^{d}\left(1-\nu^{b}\right)}{1-\theta^{d}+\nu^{b} \theta^{d}} B_{g u e s s}-\eta B_{\text {guess }}^{\gamma}-r^{d} \frac{\left(1-\nu^{b}\right) B_{\text {guess }}}{1-\theta^{d}+\nu^{b} \theta^{d}}+ \\
& \left.+G^{I}\left(\bar{\omega}^{I}\right)\left(\mu^{I s} T_{1}+\mu^{I w l} T_{2}\right)+G^{e}\left(\bar{\omega}^{e}\right)\left(\mu^{e k} T_{3}+\mu^{e y} T_{4}\right)\right\} \\
& \frac{D}{L}=\frac{\left(1-\nu^{b}\right)}{1-\theta^{d}+\nu^{b} \theta^{d}} \frac{B}{L} \quad \frac{R}{L}=\theta^{d} \frac{D}{L} \\
& \frac{J^{b}}{L}=\frac{\delta^{b}}{\left(1-\theta^{d}\right)(1-\tau)} \frac{K^{b}}{L}-\nu^{I}\left(\frac{B}{L}+\frac{R}{L}\right) \\
& \quad-G^{e}\left(\bar{\omega}^{e}\right)\left(\mu^{e k}\left(1-\mu^{k}\right) \frac{K}{L}+\mu^{e y} \frac{q^{w} Y}{L}\right)
\end{aligned}
$$

$$
\begin{aligned}
\frac{\eta B^{\gamma}}{L}= & \frac{B^{I}}{L}\left[\left(1+r^{f I}\right)\left(1-F^{I}\left(\bar{\omega}^{I}\right)\right)-\tau^{p c, I} r^{f I}\left(1-F^{I}\left(\bar{\omega}^{I}\right)\right)-\tau^{i o f, I}-1\right]+ \\
& +\frac{B^{e}}{L}\left[\left(1+r^{f e}\right)\left(1-F^{e}\left(\bar{\omega}^{e}\right)\right)-\tau^{p c, e} r^{f e}\left(1-F^{e}\left(\bar{\omega}^{e}\right)\right)-\tau^{i o f, e}-1\right]+ \\
& +r^{r} \frac{R}{L}-r^{d} \frac{D}{L}-\frac{J^{b}}{L} \\
\frac{G}{L}=- & \frac{r^{r} R}{L}+\frac{B^{I}}{L}\left[\left(1-F^{I}\left(\bar{\omega}^{I}\right)\right) \tau^{p c, I} r^{f I}+\tau^{i o f, I}\right]+\frac{B^{e}}{L}\left[\left(1-F^{e}\left(\bar{\omega}^{e}\right)\right) \tau^{p c, e} r^{f e}+\tau^{i o f, e}\right]
\end{aligned}
$$$$
+\tau^{p} r^{d} \frac{D^{p}}{L}+\tau\left[\frac{J^{b}}{L}+G^{I}\left(\bar{\omega}^{I}\right)\left(\mu^{I s}\left(1-\delta^{s} \frac{S^{I}}{L}+\mu^{I w l} X^{I}\right)-\right.\right.
$$$$
\left.-G^{e}\left(\bar{\omega}^{e}\right)\left(\mu^{e k}\left(1-\delta^{k}\right) \frac{K}{L}+\mu^{e y} \frac{q^{w} Y}{L}\right)\right]
$$$$
\frac{C^{p}}{L}=\frac{1}{\left[1+\delta^{s}\left(\frac{\xi}{1-\xi}\left(1-\beta^{p}\left(1-\delta^{s}\right)\right)^{\frac{1}{\sigma-1}}\right]\right.}\left\{\frac{Y}{L}-\frac{C^{I}}{L}-\frac{C^{e}}{L}-\delta^{s} \frac{S^{I}}{L}-\right.
$$$$
\left.-\frac{G}{L}-\frac{I^{k}}{L}-\delta^{b} \frac{K^{b}}{L}\right\}
$$$$
\frac{S^{p}}{L}=\frac{C^{p}}{L}\left[\frac{\xi}{1-\xi}\left(1-\beta^{p}\left(1-\delta^{s}\right)\right)\right]^{\frac{1}{\sigma-1}}
$$$$
L^{p}=\left\{\frac{X^{p}}{\frac{C^{p}}{L}\left[1+\frac{1-\xi}{\xi}\left(\frac{S^{p} / L}{C^{p} / L}\right)^{\sigma}\right]}\right\}^{\frac{1}{1+\varphi}} \quad L^{I}=\left\{\frac{X^{I}\left(1-G^{I}\left(\bar{\omega}^{I}\right)\right)\left[1+A^{I} \tau^{w l}\right]}{\frac{C^{I}}{L}\left[1+\frac{1-\xi}{\xi}\left(\frac{S^{I} / L}{C^{I} / L}\right)^{\sigma}\right]}\right\}^{\frac{1}{1+\varphi}}
$$ 


$$
L=\left(L^{p}\right)^{\theta}\left(L^{I}\right)^{1-\theta}
$$

Forth Step: Verify if $B_{\text {guess }}^{I}=\frac{B^{I}}{L} L$ and $B_{\text {guess }}^{e}=\frac{B^{e}}{L} L$. Calculate all variables multiplying ratios by $L$ if conditions are satisfied or return to the first step if at least one is invalid. 
D

\section{BCB Accounting Decomposition - Adapted}

The ICC and its spread decomposition methodologies can be found in Banco Central do Brasil (2018) and Banco Central do Brasil (2017), respectively. We adapt these methodologies with respect to our steady state analysis.

$$
\begin{aligned}
\text { Interest expenses } & =r^{f I} B^{I}+r^{f e} B^{e} . \\
\text { Total credit } & =B^{I}+B^{e} . \\
\text { ICC } & =\frac{\text { Interest expenses }}{\text { Total credit }} .
\end{aligned}
$$

ICC total spread $=\mathrm{ICC}-r$.

$$
\begin{aligned}
& \text { ICC default }=\frac{\left(1+r^{f I}\right) F^{I}\left(\bar{\omega}^{I}\right) B^{I}+\left(1+r^{f e}\right) F^{e}\left(\bar{\omega}^{e}\right) B^{e}}{\text { Total Credit }} . \\
& \text { ICC adm cost }=\frac{\eta B^{\gamma}}{\text { Total Credit } .} \\
& \text { IOF rate }=\text { ICC }-\frac{\text { Interest expenses }- \text { IOF expenditure }}{\text { Total credit }} \\
& \text { PIS } / \text { Cofins rate }=0.0465(\mathrm{ICC}-\mathrm{IOF} \text { rate })\left[\left(1-F^{e}\right) \frac{B^{e}}{B}+\left(1-F^{I}\right) \frac{B^{I}}{B}\right] . \\
& \text { CSLL/IRPJ rate }=0.45[\text { ICC total spread }- \text { IOF rate- } \\
& \qquad \text { PIS } / \text { Cofins rate }- \text { ICC adm cost }- \text { ICC default }] . \\
& \text { ICC tax }=\text { IOF rate }+ \text { PIS } / \text { Cofins rate }+ \text { CSLL/IRPJ rate. }
\end{aligned}
$$

ICC financial margin = ICC total spread - ICC default - ICC adm cost - ICC tax.

Divide each ICC component by ICC total spread to get the ICC component share. 
E

\section{Counterfactual Analysis - Combinations}

We present combinations of parameters alterations following individual cases in the Counterfactual Analysis - Section 4.3.

Table E.1: Counterfactual Analysis - 2

\begin{tabular}{|c|c|c|c|c|c|c|c|}
\hline & (1) Baseline & $\begin{array}{c}\text { (2) No tax } \\
\text { Banking comp. }\end{array}$ & $\begin{array}{l}\text { (3) No tax } \\
\text { No adm. cost }\end{array}$ & $\begin{array}{c}\text { (4) No tax } \\
100 \% \text { recovery }\end{array}$ & $\begin{array}{l}\text { (5) Banking comp. } \\
\text { No adm. cost }\end{array}$ & $\begin{array}{l}\text { (6) Banking comp } \\
100 \% \text { recovery }\end{array}$ & $\begin{array}{l}\text { (7) No adm. cost } \\
100 \% \text { recovery }\end{array}$ \\
\hline Entrep. credit-to-GDP & 12.4 & 12.73 & 12.9 & 12.75 & 12.72 & 12.51 & 12.62 \\
\hline Imp. credit-to-GDP & 13.28 & 15.72 & 15.14 & 14.1 & 15.89 & 15.24 & 14.31 \\
\hline Investment-to-GDP & 17.85 & 18.13 & 18.21 & 18.22 & 18.01 & 17.94 & 17.93 \\
\hline Bank profit-to-GDP & 2.33 & 0.16 & 1.54 & 2.1 & 0.18 & 0.19 & 1.84 \\
\hline Banking physical deprec. & 3.39 & 0.82 & 3.91 & 7.32 & 0.48 & 1.54 & 3.67 \\
\hline \multicolumn{8}{|c|}{ Percentage points changes relative to baseline: } \\
\hline Entrep. credit spread: $r^{f e}-r$ & & -0.76 & -1.88 & -0.59 & -1.52 & -0.22 & -1.35 \\
\hline Imp. credit spread: $r^{f I}-r$ & & -4.34 & -3.66 & -1.27 & -5.1 & -3.77 & -2.5 \\
\hline Deposit rate: $r^{d}$ & & -0.13 & -0.13 & -0.13 & 0 & 0 & 0 \\
\hline Policy rate: $r$ & & -0.32 & -0.16 & -0.16 & -0.19 & -0.19 & 0 \\
\hline Wholesale rate: $R^{b}$ & & -0.38 & -1.42 & -0.18 & -1.49 & -0.25 & -1.24 \\
\hline Entrep. credit rate: $r^{f e}$ & & -1.1 & -2.06 & -0.76 & -1.73 & -0.42 & -1.36 \\
\hline Imp. credit rate: $r^{f I}$ & & -4.71 & -3.86 & -1.46 & -5.34 & -4 & -2.53 \\
\hline Entrep. default & & 0 & 0.01 & 0 & 0.01 & 0 & 0.01 \\
\hline Imp. default & & -0.08 & -0.06 & -0.02 & -0.09 & -0.07 & -0.04 \\
\hline \multicolumn{8}{|c|}{ Percentage changes relative to baseline: } \\
\hline GDP & & -0.34 & 0.96 & -0.89 & 1.4 & -0.02 & 1.93 \\
\hline C & & 1.72 & 2.94 & 1.03 & 2.56 & 0.68 & 1.71 \\
\hline $\mathrm{L}$ & & -0.81 & -0.9 & -0.27 & -0.95 & -0.31 & -0.18 \\
\hline
\end{tabular}

$\mathrm{U}^{p}$

$\mathrm{U}^{e}$

Notes: Time period is set to one quarter. Ratios, depreciation, and real variables changes in percentage. Spreads, rates and default in percentage points. $U^{p}$ : patient household $U^{I}$ : impatient household, $U^{e}$ : entrepreneur. Welfare changes meaning: + better than baseline, - worse than baseline. No remuneration: $r^{r}=0$. No tax: $\tau^{i o f, x}=\tau^{p c, x}=\tau^{p}=\tau=0$ No financial margin: $\varepsilon^{p} \rightarrow-\infty, \varepsilon^{I} \rightarrow \infty, \varepsilon^{e} \rightarrow \infty$. No administrative cost: $\eta=0$. No reserve: $\theta^{d}=0.100 \%$ recovery: $\mu^{I x}=\mu^{e x}=1$.

Table E.1 summarizes pairwise combinations of policy changes/parameters alterations, but we omit no remuneration and no reserve. The first one raises credit spreads and the last one delivers an insignificant impact on equilibrium changes.

Combination of no financial margin with no administrative cost generates better result in terms of household spread reduction (5.1 p.p.). On the other hand, the combination of no tax and no administrative cost is the most effective in cutting entrepreneur spread (1.88 p.p.). Both new equilibria are in line with individuals counterfactual in table 4.3 .

Entrepreneur credit-to-GDP variations remain small, but for household variations it can increase $19.65 \%$ in the absence of financial margin and administrative cost. Regarding both defaults, none of simulations are able to generate meaningful changes similar to individual counterfactual. 
The third column simulation is the only table E.1 exercise which all agents are better relative to baseline. This steams from no tax since zero government expenditure enables more private consumption and less labor is required.

We can compare two shares of BCB accounting decomposition and table E.1 results. Tax and financial margin represent $51 \%(\mathrm{~m})$ or $42 \%$ (REB) of spread while no tax and no financial margin simulation results $54.81 \%$ average spread reduction relative to baseline. Tax and administrative cost shares account for $54 \%(\mathrm{~m})$ or $49 \%$ (REB) of spread composition in line with the $53 \%$ average spread decrease in counterfactual. Financial margin and administrative cost account for $45 \%$ (m) or $47 \%$ (REB) of spread, but no financial margin and no administrative cost counterfactual result in $70.2 \%$ average spread reduction relative to baseline.

Table E.2: Counterfactual Analysis - 3

\begin{tabular}{|c|c|c|c|c|c|c|}
\hline & (1) Baseline & $\begin{array}{l}\text { (2) No tax } \\
\text { No fin. margin } \\
\text { No adm. cost }\end{array}$ & $\begin{array}{c}\text { (3) No tax } \\
\text { No fin. margin } \\
100 \% \text { recovery }\end{array}$ & $\begin{array}{l}\text { (4) No fin. margin } \\
\text { No adm. cost } \\
100 \% \text { recovery }\end{array}$ & $\begin{array}{c}\text { (5) No tax } \\
\text { No adm. cost } \\
100 \% \text { recovery }\end{array}$ & $\begin{array}{c}\text { (6) No tax } \\
\text { No fin. margin } \\
\text { No adm. cost } \\
\text { No reserve } \\
100 \% \text { recovery }\end{array}$ \\
\hline Entrep. credit-to-GDP & 12.4 & 12.92 & 12.76 & 12.71 & 12.93 & 12.94 \\
\hline Imp. credit-to-GDP & 13.28 & 16.36 & 15.76 & 15.89 & 15.18 & 16.39 \\
\hline Investment-to-GDP & 17.85 & 18.19 & 18.18 & 18 & 18.26 & 18.21 \\
\hline Bank profit-to-GDP & 2.33 & 0.16 & 0.16 & 0.18 & 1.55 & 0.12 \\
\hline Banking physical deprec. & 3.39 & 0.8 & 2.71 & 1.51 & 5.81 & 3.26 \\
\hline \multicolumn{7}{|c|}{ Percentage points changes relative to baseline: } \\
\hline Entrep. credit spread: $r^{f e}-r$ & & -2 & -0.76 & -1.52 & -1.88 & -2 \\
\hline Imp. credit spread: $r^{f I}-r$ & & -5.62 & -4.34 & -5.1 & -3.66 & -5.62 \\
\hline Deposit rate: $r^{d}$ & & -0.13 & -0.13 & 0 & -0.13 & -0.13 \\
\hline Policy rate: $r$ & & -0.32 & -0.32 & -0.19 & -0.16 & -0.32 \\
\hline Wholesale rate: $R^{b}$ & & -1.63 & -0.38 & -1.49 & -1.42 & -1.63 \\
\hline Entrep. credit rate: $r^{f e}$ & & -2.34 & -1.1 & -1.73 & -2.06 & -2.34 \\
\hline Imp. credit rate: $r^{f I}$ & & -5.99 & -4.71 & -5.34 & -3.86 & -5.99 \\
\hline Entrep. default & & 0.01 & 0 & 0.01 & 0.01 & 0.01 \\
\hline Imp. default & & -0.1 & -0.08 & -0.09 & -0.06 & -0.1 \\
\hline \multicolumn{7}{|c|}{ Percentage changes relative to baseline: } \\
\hline GDP & & 1.4 & -0.38 & 1.74 & 0.92 & 1.54 \\
\hline $\mathrm{C}$ & & 3.43 & 1.62 & 2.42 & 2.84 & 3.3 \\
\hline $\mathrm{L}$ & & -1.16 & -0.61 & -0.66 & -0.69 & -0.87 \\
\hline \multicolumn{7}{|c|}{ Welfare changes relative to baseline: } \\
\hline$U^{p}$ & & - & - & - & - & - \\
\hline$U^{e}$ & & + & + & + & + & + \\
\hline$U^{I}$ & & + & + & + & + & + \\
\hline
\end{tabular}

Table E.2 displays combinations "turning off" three features per column with the last one leaving only the default possibility. The second and the last columns present the most powerful combinations in terms of cutting both types of banking spreads. Impatient and entrepreneur spreads decrease 5.62 p.p. and 
2 p.p., respectively. The same magnitudes of interest rates changes are observed in both columns, but the credit-to-GDP changes are higher in the last.

Likewise simulations before, both default variations are small in all table E.2 columns. Entrepreneur credit-to-GDP changes are larger than other counterfactual, but they remain small. Impatient credit-to-GDP can reach $16.39 \%$ (23.42\% increase compared to baseline) in last column.

We can perform the same comparison between accounting decomposition and counterfactual spread reduction. Tax, financial margin, and administrative cost account for $76 \%(\mathrm{~m})$ or $68 \%$ (REB) average spread in accounting decomposition. In the counterfactual, the absence of these ingredients results in $80.5 \%$ average spread reduction relative to baseline. Although the values are close, the advantage of the counterfactual exercise is to map how other important variables change. 


\section{F \\ Propagation of Shocks}

In this Chapter, we analyze the propagation of a monetary policy and technology shocks. We compare the impulse response functions of our model (Baseline) and a financial friction model with fewer ingredients (FF) resembling Gerali et al. (2010). The differences between the two models are credit default, administrative cost, reserve requirements, and taxes. We use the same calibration of Chapter 4 and time period is quarterly. It is important to emphasizing that both models do not incorporate stick wages, habit formation, and variable capital utilization as Gerali et al. (2010), so they are not able to reproduce similar dynamics to the paper.

Each model is log-linearized around the respective steady state using Dynare routines (interest rates and defaults are linearized). We do not take into account possible nonlinearities, and the supposition of always binding borrowing constraints remain.

\section{F.1 \\ Monetary Policy Shock}

Monetary policy shocks are assumed to be i.i.d. with a standard deviation of $0.01 .^{1}$ In the FF model, several transmission channels already discussed in the literature are at play. Iacoviello (2005) model already highlighted three channels. First, the traditional interest channel with heterogeneous agents concerning impatience degree. Second, the borrowing constraint channel that present value changes of the collateral affect credit. Third, the nominal debt channel - debt in nominal terms changes the ex-post distribution of resources due to inflation.

Additionally, wedges between the policy rate and interest rates relevant for each agent emerge due to the credit market power and bank capital as proposed by Gerali et al. (2010). We add new ingredients to baseline model that increase the interest rates wedges. The default cost passes through bank rates and changes the borrowing constraint, assets, and income for consumption. The administrative cost and reserve requirements raise the spread due to higher

\footnotetext{
${ }^{1}$ Estimate of Ferreira and Nakane (2018).
} 
cost to provide credit. Taxes act the same way but also change the retained earnings and bank capital that, in its turn, affects the final bank rates.
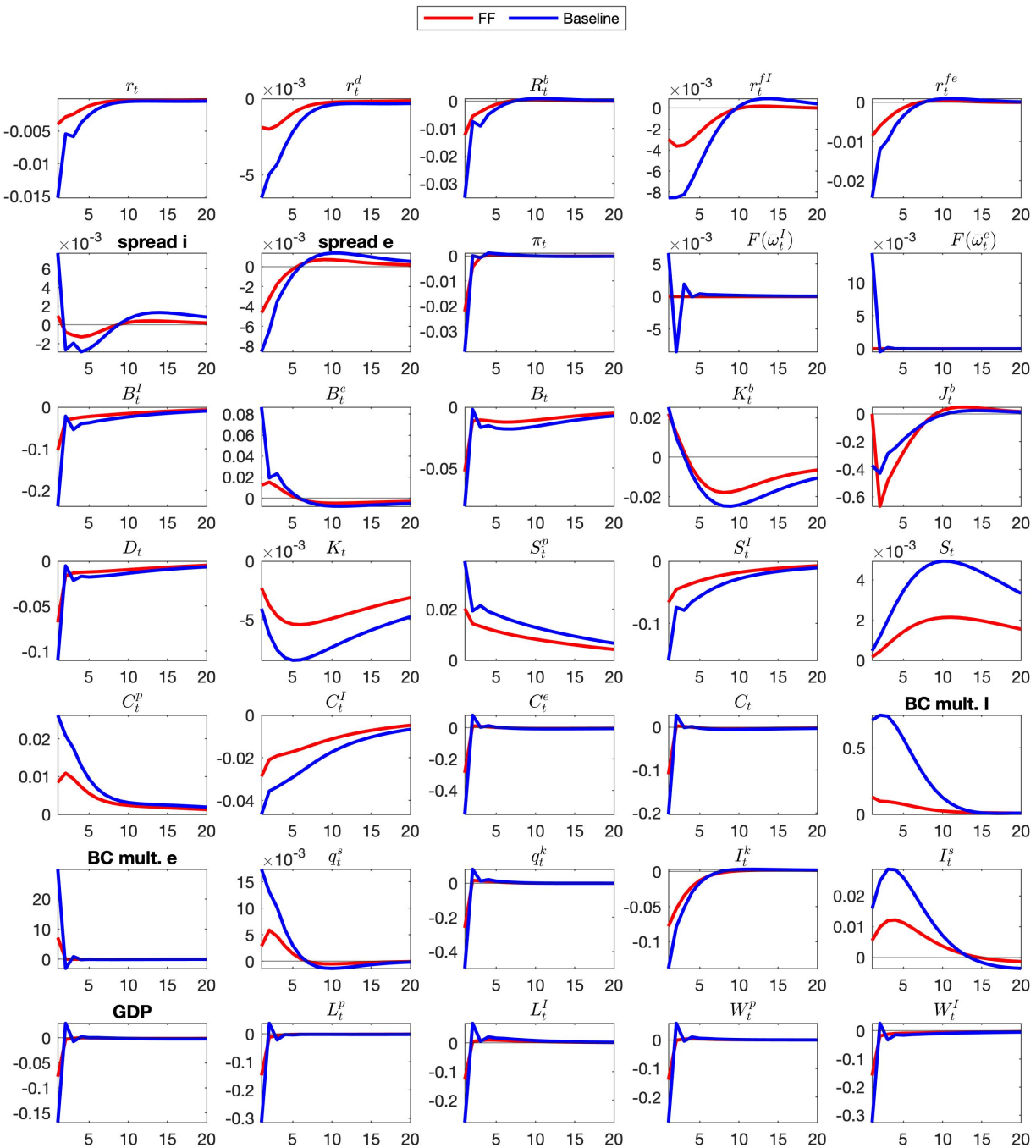

Figure F.1: Monetary Policy Shock

Figure F.1 shows a positive monetary shock of one standard deviation, and overall, new channels tend to amplify variable dynamics. The initial raise of the policy rate passes to the final bank rates. Both models present an initial severe recession driven by entrepreneurs consumption postpone

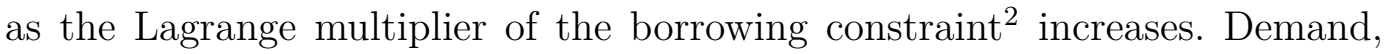
output, and its inputs demands capital and labor decrease. Central Bank (CB) responds cutting interest rates. Impatient also reduces consumption due to lower labor income and higher debt repayment of deflationary effect.

\footnotetext{
${ }^{2}$ The Lagrange multiplier of borrowing constraint is the shadow value (in utils) of easing the borrowing constraint.
} 
As the impact is deflationary, $\mathrm{CB}$ reacts cutting interest aggressively. Higher default and taxes put upward pressure on final bank rates, but the policy rate declining with imperfect competitive banks, more capitalized banks (due to initial deflation), and lower administrative cost push down bank rates.

Household credit decreases even though impatient lower interest rate and higher durable goods price. Household credit follows her durable goods dynamics which diminish as patient agents increase spending. This borrowing constraint and financial accelerator channel stimulate higher entrepreneur credit, but do not compensate the lower household loan as total credit diminishes.

The baseline model generates unstable default rates dynamics since variables related to the cut-off rule move abruptly. ${ }^{3}$

\section{F.2}

\section{Technology Shock}

Technology shocks follows an AR(1) process with the same autocorrelation coefficient 0.91 of De Castro et al. (2015). The impulse response functions of baseline and FF are closer than a monetary policy shock, but the initial impact is more powerful in baseline. Figure F.2 displays the impulse response functions of both models. The increase in productivity is contractionary on impact for output (before going up). This is similar to the dynamics of Iacoviello (2005) model.

Higher productivity diminishes the marginal cost of firms which tends to put deflationary pressure. CB reacts reducing interest rates. Shadow value/Lagrange multiplier of easing the borrowing constraint skyrocket, then entrepreneurs cut consumption substantially. Demand and output contract boosting further policy rate reductions.

Baseline final bank rates decrease more aggressively because of $\mathrm{CB}$ response, and higher default costs include in these rates do not compensate. Initially, lower administrative cost and more capitalize banks reinforce the decrease of bank rates but the opposite effect rises bank rates after some periods.

The impatient credit is mainly driven by the reduction of durable goods despite the lower interest rate and higher durable goods price are pushed up by patient agents demand. Lower deposit rates discourage savings and stimulate patient households consumption. Asset price (future capital price rise) and borrowing constraint channel (lower interest rate) drive the entrepreneur credit

\footnotetext{
${ }^{3} \mathrm{We}$ left for future research to evaluate our Baseline model with stick wages, habit formation, and variable capital utilization as Gerali et al. (2010).
} 

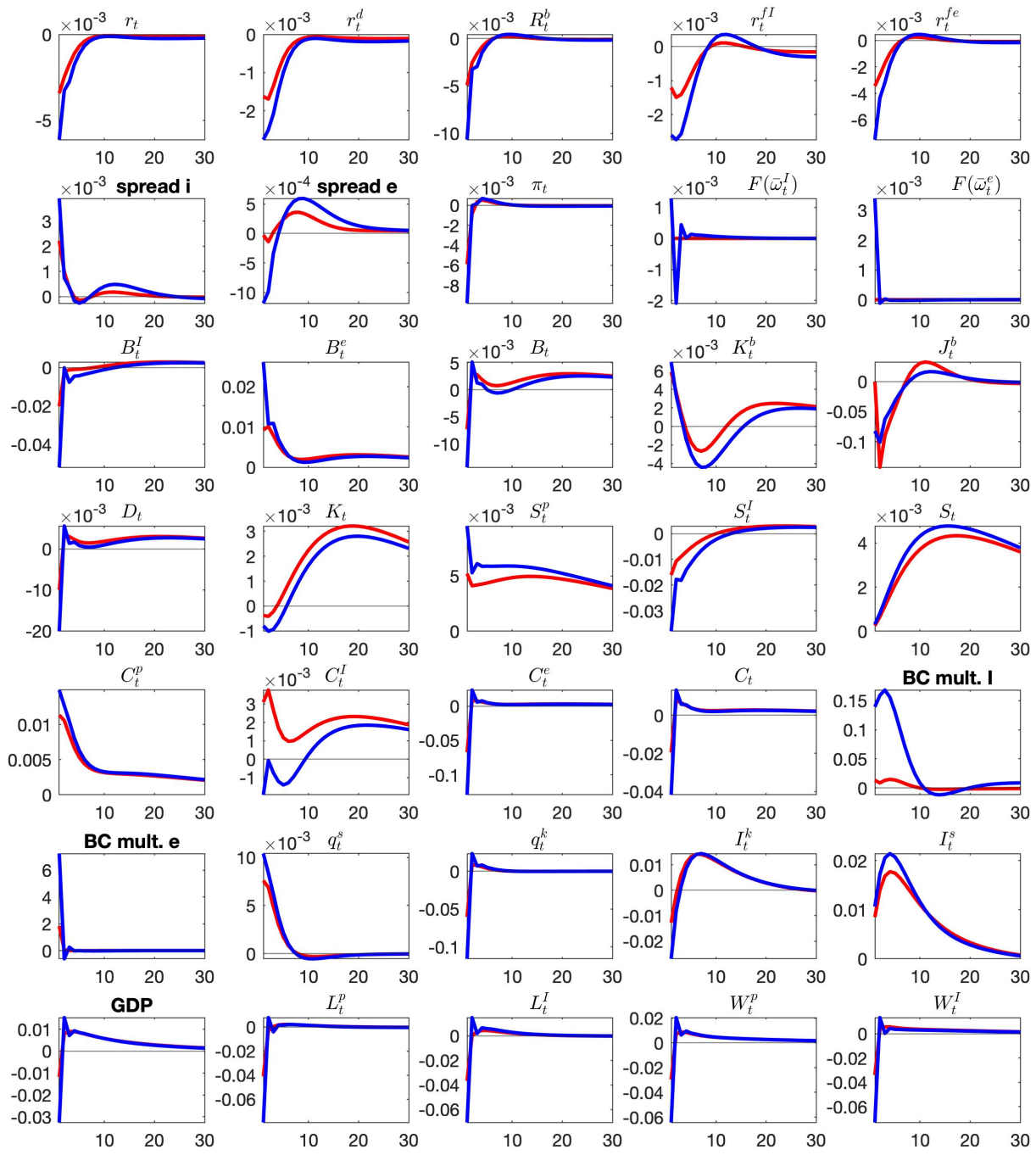

Figure F.2: Technology Shock

dynamics. Accumulation of capital occurs after the initial decrease and helps to slack the borrowing constraint.

The baseline model also generates unstable default rates dynamics since variables related to the cut-off rule move abruptly (e.g., household loan and household bank rate). 
G

Steps of debt payment from the Representative Entrepreneur

The total debt payment from the representative entrepreneur is given by

$$
\begin{gathered}
\int_{\bar{\omega}_{t}^{I}}^{\infty} \frac{\left(1+r_{t-1}^{f e}\right) B_{t-1}^{e}}{\pi_{t}} d F_{t}^{e}(w)+\int_{0}^{\bar{\omega}_{t}^{e}}\left\{\left(1-\delta_{k}\right) q_{t}^{k} K_{t-1}+q_{t}^{w} Y_{t}^{e}\right\} \omega d F_{t}^{e}(\omega)= \\
\quad=\left(1-F_{t}^{e}\left(\bar{\omega}_{t}^{e}\right)\right) \frac{\left(1+r_{t-1}^{f e}\right) B_{t-1}^{e}}{\pi_{t}}+\left\{\left(1-\delta_{k}\right) q_{t}^{k} K_{t-1}+q_{t}^{w} Y_{t}^{e}\right\} G_{t}^{e}\left(\bar{\omega}_{t}^{e}\right)
\end{gathered}
$$

where $\int_{0}^{\bar{\omega}_{t}^{e}} \omega d F_{t}^{e}(\omega)=G_{t}^{e}\left(\bar{\omega}_{t}^{e}\right)$. The first component adjusts the debt plus interest from those agents who did not default and the second is the collateral from agents who default. 


\section{H \\ Default Modelling Approaches - Alternative Model 1}

The modelling challenge is to incorporate credit default in a framework with banking sector imperfect competition. Carvalho et al. (2014) and Darracq Pariès et al. (2010) have similar approaches inspired by the strategic default of Forlati and Lambertini (2011) that is different from our liquidity default.

Basically, their approach consists of including an additional layer of banks (Commercial) which intermediate funds between final borrowers and monopolistic banking sector. Recycling firms modelling device is not required since commercial banks seize defaulted collateral by themselves. This new layer of banks behave competitively and simply adjust final borrowers rates to account for default. Borrowers internalize the zero profit conditions of the new layer of banks when optimizing their utilities and these restrictions replace the borrowing constraint in baseline approach.

Steady state counterfactual analysis delivers doubtful results since defaults skyrocket as a response of borrowers optimal decisions. In some counterfactual, impatient default rise above 10 p.p. quarterly. Figure H.1 shows model main connections.

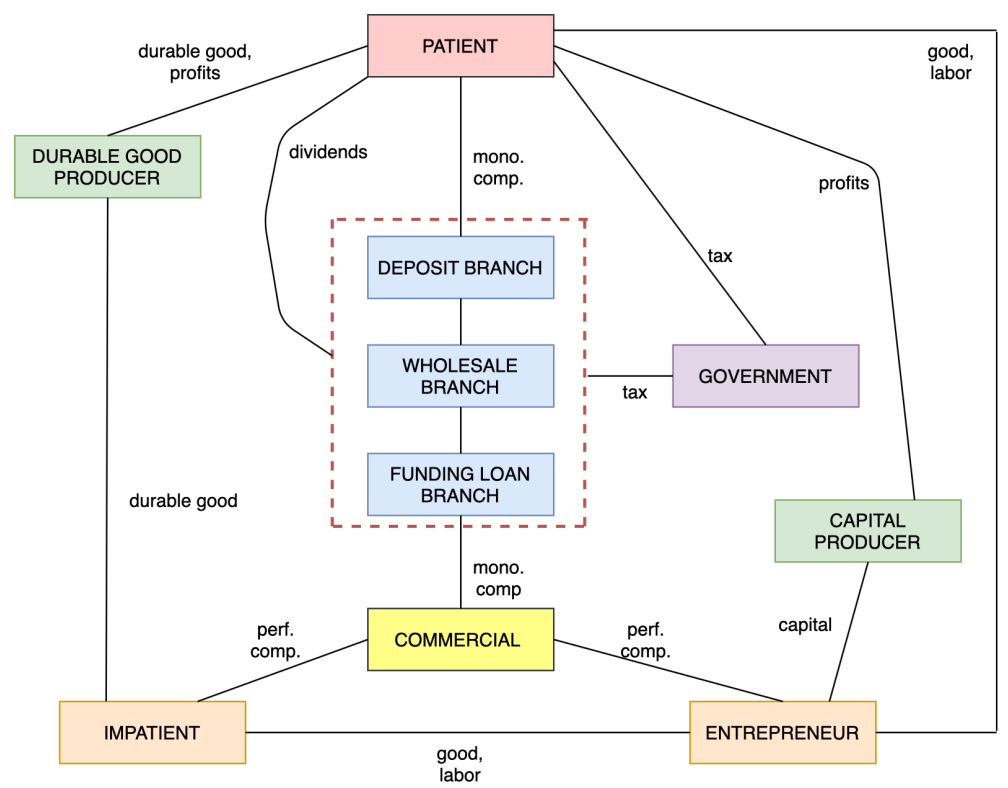

Figure H.1: Model with strategic default - main connections 
Regarding the model, patient agents, capital producers, durable goods producers, retail and final goods producers remain the same. We simplify the tax structure related to banking intermediation and government collects taxes from imperfect competitive banks.

\section{H.1}

\section{Banking Sector - Alternative Model 1}

Deposit and loan Dixit-Stiglitz framework continue the same, but they are commercial banks demands. We do not include reserve requirements.

\section{H.1.1}

\section{Wholesale Branch - Alternative Model 1}

The capital law of motion is given by

$$
\pi_{t} K_{t}^{b}(j)=\left(1-\delta^{b}\right) K_{t-1}^{b}(j)+\left(1-d^{b}\right)(1-\tau) J_{t-1}^{b}(j)
$$

Wholesale branch of bank $j$ chooses $B_{t}(j)$ and $D_{t}(j)$ in order to maximize

$$
E_{0} \sum_{t=0}^{\infty} \lambda_{0, t}^{p}\left[R_{t}^{b} B_{t}(j)-r_{t} D_{t}(j)-\frac{\kappa_{K b}}{2}\left(\frac{K_{t}^{b}(j)}{B_{t}(j)}-\nu^{b}\right)^{2} K_{t}^{b}(j)-\eta B_{t}(j)^{\gamma}\right]
$$

s.t.

$$
B_{t}(j)=D_{t}(j)+K_{t}^{b}(j)
$$

\section{H.1.2}

\section{Funding Loan Branch}

This branch is the equivalent of loan branch in baseline model, but it channels funds to commercial banks.

They obtain wholesale loan $B(j)$ at the rate $R_{t}^{b}$, differentiate at no cost and resell it to commercial loan banks (of impatient and entrepreneur) applying mark-ups.

Funding branch of bank $j$ chooses $r_{t}^{f I}(j)$ and $r_{t}^{f e}(j)$ in order to maximize

$$
E_{0} \sum_{t=0}^{\infty} \lambda_{0, t}^{P}\left\{\left(1-\tau^{I}\right) r_{t}^{f I}(j) B_{t}^{I}(j)+\left(1-\tau^{e}\right) r_{t}^{f e}(j) B_{t}^{e}(j)-R_{t}^{b} B_{t}(j)\right\},
$$

s.t. ${ }^{1}$

$$
\begin{gathered}
B_{t}^{I}(j)=\left(\frac{r_{t}^{f I}(j)}{r_{t}^{f I}}\right)^{-\varepsilon_{t}^{I}} B_{t}^{I}, \quad B_{t}^{e}(j)=\left(\frac{r_{t}^{f e}(j)}{r_{t}^{f e}}\right)^{-\varepsilon_{t}^{e}} B_{t}^{e}, \\
B_{t}^{I}(j)+B_{t}^{e}(j)=B_{t}(j) .
\end{gathered}
$$

\footnotetext{
${ }^{1}$ Commercial bank loan demand.
} 


\section{H.1.3}

\section{Deposit Branch - Alternative Model 1}

Deposit branch collects deposits from patient household and channels funds to the wholesale unit which remunerates them at $r_{t}(j)$.

Deposit branch of bank $j$ chooses $r_{t}^{d}(j)$ in order to maximize

$$
E_{0} \sum_{t=0}^{\infty} \lambda_{0, t}^{P}\left[r_{t}(j) D_{t}(j)-r_{t}^{d}(j) D_{t}^{p}(j)\right]
$$

s.t.,

$$
D_{t}^{p}(j)=\left(\frac{r_{t}^{d}(j)}{r_{t}^{d}}\right)^{-\varepsilon_{t}^{p}} D_{t}^{p}, \quad D_{t}^{p}(j)=D_{t}(j) .
$$

Summing all parts of bank $j$, total profit is given by

$$
\begin{aligned}
J_{t}^{b}(j)= & (1-\tau) r_{t}^{f I}(j) B_{t}^{I}(j)+(1-\tau) r_{t}^{f e}(j) B_{t}^{e}(j)-(1+\tau) r_{t}^{d}(j) D_{t}(j)- \\
& \frac{\kappa_{K b}}{2}\left(\frac{K_{t}^{b}(j)}{B_{t}(j)}-\nu^{b}\right)^{2} K_{t}^{b}(j)-\eta B_{t}(j)^{\gamma} .
\end{aligned}
$$

\section{H.2}

\section{Commercial banks - impatient households}

Impatient household durable good price and labor income are subject to idiosyncratic shock (i.i.d. across agents, time, and the distribution is given by $F_{t}^{I}$ with mean one): $\omega_{i, t}^{I}\left(P_{t}^{s}\left(1-\delta^{s}\right) S_{t-1}^{I}+W_{t}^{I, n} L_{t}^{I}\right)$.

$\bar{\omega}_{t}^{I}$ defines the indifference between repaying or not the loan contracted in the previous period: ${ }^{2}$

$$
\bar{\omega}_{t}^{I}\left(q_{t}^{s}\left(1-\delta^{s}\right) S_{t-1}^{I}+W_{t}^{I} L_{t}^{I}\right)=\left(1+r_{t}^{b I}\right) \frac{B_{t-1}^{I}}{\pi_{t}},
$$

where left hand side is the loan collateral and right hand side is the repayment of the loan contracted at $t-1$. If $\omega^{I}>\bar{\omega}^{I}$ impatient repays the loan and keeps $\omega^{I}\left(q_{t}^{s}\left(1-\delta^{s}\right) S_{t-1}^{I}+W_{t}^{I} L_{t}^{I}\right)-\left(1+r_{t}^{b I}\right) \frac{B_{t-1}^{I}}{\pi_{t}}$ while loan branch $\left(1+r_{t}^{b I}\right) \frac{B_{t-1}^{I}}{\pi_{t}}$. If $\omega^{I}<\bar{\omega}^{I}$ impatient does not repay the loan and loses the collateral, but loan branch receives $\omega^{I}\left(1-\mu^{I}\right)\left(q_{t}^{s}\left(1-\delta^{s}\right) S_{t-1}^{I}+W_{t}^{I} L_{t}^{I}\right)$ where $\mu^{I}$ is the monitoring cost. The parameter interpretation contrasts with baseline which is the recovery rate (opposite interpretation).

After the idiosyncratic shock, impatient households pool assets and labor income from each agent and guarantee perfect insurance so the allocation across agents of impatient households is ex-post equal. Agents of impatient

\footnotetext{
${ }^{2} r^{b I}$ is the interest rate which takes into account default. It is different from $r^{f I}$. In the baseline model, the last already incorporate credit risk.
} 
households are ex-post identical so we can assess the problem from a representative impatient household perspective.

Total repayment receive by commercial bank is given by the fraction that repay the loan and the fraction that default and collateral is seized with monitoring cost discount.

$$
\begin{gathered}
\int_{\bar{\omega}_{t}^{I}}^{\infty} \frac{\left(1+r_{t}^{b I}\right) B_{t-1}^{I} d F_{t}^{I}(w)+\int_{0}^{\bar{\omega}_{t}^{I}}\left(1-\mu^{I}\right)\left[q_{t}^{s}\left(1-\delta^{s}\right) S_{t-1}^{I}+W_{t}^{I} L_{t}^{I}\right] \omega d F_{t}^{I}(\omega)=}{=} \\
=\underbrace{\left\{\left(1-F_{t}^{I}\left(\bar{\omega}_{t}^{I}\right)\right)+\left(1-\mu^{I}\right) \int_{0}^{\bar{\omega}_{t}^{I}} \omega d F_{t}^{I}(\omega)\right\}}_{\Gamma_{t}^{I}\left(\bar{\omega}_{t}^{I}\right)}\left[q_{t}^{s}\left(1-\delta^{s}\right) S_{t-1}^{I}+W_{t}^{I} L_{t}^{I}\right] .
\end{gathered}
$$

The cost of acquire funds is given by $\frac{\left(1+r_{t-1}^{f I}\right) B_{t-1}^{I}}{\pi_{t}}$ where the interest rate $r_{t-1}^{f I}$ is set according to a monopolistic competitive market. Since commercial bank operates in perfect competition, zero profit condition is

$$
\Gamma_{t}^{I}\left(\bar{\omega}_{t}^{I}\right)\left[q_{t}^{s}\left(1-\delta^{s}\right) S_{t-1}^{I}+W_{t}^{I} L_{t}^{I}\right]=\frac{\left(1+r_{t-1}^{f I}\right) B_{t-1}^{I}}{\pi_{t}}
$$

where the left-hand side is the amount received by the commercial bank from impatient household and the right-hand side is the cost to acquire funds.

\section{H.3}

\section{Impatient households - Alternative Model 1}

Impatient households maximize utility subject to commercial bank zero profit condition and a budget constraint. First, we have to adjust the budget constraint due to default, since part of last period debt is not repaid and a fraction of collateral is seized by commercial bank.

Total repayment of the representative impatient household is given by the fraction that can repay the loan and the fraction that defaults and loses collateral.

$$
\begin{gathered}
\int_{\bar{\omega}_{t}^{I}}^{\infty} \frac{\left(1+r_{t}^{b I}\right) B_{t-1}^{I} d F_{t}^{I}(w)+\int_{0}^{\bar{\omega}_{t}^{I}}\left[q_{t}^{s}\left(1-\delta^{s}\right) S_{t-1}^{I}+W_{t}^{I} L_{t}^{I}\right] \omega d F_{t}^{I}(\omega)=}{=\underbrace{\left\{\left(1-F_{t}^{I}\left(\bar{\omega}_{t}^{I}\right)\right)+\int_{0}^{\bar{\omega}_{t}^{I}} \omega d F_{t}^{I}(\omega)\right\}}_{\Xi_{t}^{I}\left(\bar{\omega}_{t}^{I}\right)}\left[q_{t}^{s}\left(1-\delta^{s}\right) S_{t-1}^{I}+W_{t}^{I} L_{t}^{I}\right] .}
\end{gathered}
$$

Impatient households choose a stream of $C_{t}^{I}, S_{t}^{I}, L_{t}^{I}, B_{t}^{I}, \bar{\omega}_{t}^{I}$ in order to 
maximize

$$
E_{0} \sum_{0}^{\infty}\left(\beta^{I}\right)^{t}\left\{\log \left(\left[\xi\left(C_{t}^{I}\right)^{\sigma}+(1-\xi)\left(S_{t}^{I}\right)^{\sigma}\right]^{\frac{1}{\sigma}}\right)-\frac{\left(L_{t}^{I}\right)^{1+\varphi}}{1+\varphi}\right\}
$$

s.t.

$$
\begin{gathered}
C_{t}^{I}+q_{t}^{s} S_{t}^{I}+\Xi_{t}^{I}\left(\bar{\omega}_{t}^{I}\right)\left[q_{t}^{s}\left(1-\delta^{s}\right) S_{t-1}^{I}+W_{t}^{I} L_{t}^{I}\right] \leq W_{t}^{I} L_{t}^{I}+q_{t}^{S}\left(1-\delta^{S}\right) S_{t-1}^{I}+B_{t}^{I}, \\
\Gamma_{t}^{I}\left(\bar{\omega}_{t}^{I}\right)\left[q_{t}^{s}\left(1-\delta^{s}\right) S_{t-1}^{I}+W_{t}^{I} L_{t}^{I}\right]=\frac{\left(1+r_{t-1}^{f I}\right) B_{t-1}^{I}}{\pi_{t}} .
\end{gathered}
$$

\section{H.4}

\section{Entrepreneurs - Alternative Model 1}

Entrepreneurs are subject to idiosyncratic shock that affects price capital $\omega^{e} q_{t}^{k} K_{t-1}$. Derivation follows the same steps already shown for impatient household.

The entrepreneurs choose a stream of $C_{t}^{e}, K_{t}, L_{t}^{I}, L_{t}^{p}, B_{t}^{e}, \bar{\omega}_{t}^{e}$ in order to maximize

$$
E_{0} \sum_{t=0}^{\infty}\left(\beta^{e}\right)^{t} \log \left(C_{t}^{e}\right)
$$

s.t.

$$
\begin{gathered}
Y_{t}^{e}=A_{t} K_{t-1}^{\alpha}\left[\left(L_{t}^{p}\right)^{\theta}\left(L_{t}^{I}\right)^{1-\theta}\right]^{1-\alpha} \\
C_{t}^{e}+q_{t}^{k} K_{t}+W_{t}^{I} L_{t}^{I}+W_{t}^{p} L_{t}^{p}+\Xi_{t}^{e}\left(\bar{\omega}_{t}^{e}\right)\left(1-\delta^{k}\right) q_{t}^{k} K_{t-1} \leq q_{t}^{w} Y_{t}^{e}+B_{t}^{e}+q_{t}^{k}\left(1-\delta^{k}\right) K_{t-1}, \\
\Gamma_{t}^{e}\left(\bar{\omega}_{t}^{e}\right)\left(1-\delta^{k}\right) q_{t}^{k} K_{t-1}=\frac{\left(1+r_{t-1}^{f e}\right) B_{t-1}^{e}}{\pi_{t}} .
\end{gathered}
$$

\section{H.5}

\section{Government - Alternative Model 1}

Government keeps budget balance across all periods:

$$
G_{t}=\frac{\tau^{I} r_{t-1}^{f I} B_{t-1}^{I}}{\pi_{t}}+\frac{\tau^{e} r_{t-1}^{f e} B_{t-1}^{e}}{\pi_{t}}+\frac{\tau J_{t-1}^{b}}{\pi_{t}}
$$

\section{H.6}

\section{Steady State - Alternative Model 1}

Steady state is calculated numerically resembling baseline approach. Calculation of cut-offs $\bar{\omega}^{I}$ and $\bar{\omega}^{e}$ are defined implicitly by borrowers Euler equations. 
Guess values of $B^{I, g u e s s}$ and $B^{e, g u e s s}$, calculate all variables, and then check if the guesses were correct.

$$
\begin{gathered}
\pi=1, \quad q^{s}=1, \quad q^{k}=1 . \\
r=\frac{\left(\varepsilon^{p}-1\right)}{\varepsilon^{p}} r^{d}, \quad r^{d}=\left[\frac{1}{\beta^{p}}-1\right] \frac{1}{\left(1-d^{b}(1-\tau)\right)} . \\
R^{b}=r+\eta \gamma\left(B^{I, \text { guess }}+B^{e, g u e s s}\right)^{\gamma-1} . \\
\left.r^{f I}=\frac{\varepsilon^{I}}{\left(\varepsilon^{I}-1\right)} \frac{1}{\left(1-\tau^{b I}\right)} R^{b}, \quad r^{f e}=\frac{\varepsilon^{e}}{\left(\varepsilon^{e}-1\right.}\right) \frac{1}{\left(1-\tau^{b e}\right)} R^{b} .
\end{gathered}
$$

Find implicit $\bar{\omega}^{\prime} s$

$$
1=\beta^{I} \frac{\Xi^{\prime I}\left(\bar{\omega}^{I}\right)}{\Gamma^{\prime I}\left(\bar{\omega}^{I}\right)}\left(1+r^{f I}\right), \quad 1=\beta^{e} \frac{\Xi^{\prime e}\left(\bar{\omega}^{e}\right)}{\Gamma^{\prime e}\left(\bar{\omega}^{e}\right)}\left(1+r^{f e}\right),
$$

then calculate final borrowers rates.

$$
r^{b I}=\frac{\bar{\omega}^{I}}{\Gamma^{I}\left(\bar{\omega}^{I}\right)}\left(1+r^{f I}\right)-1, \quad \quad r^{b e}=\frac{\bar{\omega}^{1}}{\Gamma^{1}\left(\bar{\omega}^{1}\right)}\left(1+r^{f e}\right)-1 .
$$

The rest of procedure is the same of baseline.

\section{H.7 \\ Counterfactual Analysis - Alternative Model 1}

We need to point out some differences between baseline and alternative model counterfactual. Alternative model spread is defined as the difference between $r^{b x}$ and $r^{d}$, but baseline definition is relative $r$. Results change little quantitatively.

Costless default exercise is achieved by setting $\mu^{x}=0.3$, i.e., monitoring cost equals $30 \%$ of defaulted resources which is equivalent to a recovery rate of $70 \%{ }^{3}$ Calibration is slightly different from baseline model.

Tables H.1 and H.2 display counterfactual exercises with the same approach of changing parameters to simulate economic policies.

Both defaults increase across all columns comparing with baseline 1 . They reach the peak of 13.62 p.p. quaterly for households and 6.38 p.p. for entrepreneurs in no friction. Results are not reliable since the difference from baseline 1 is huge. We depart from this strategic default modeling and adopt the baseline liquidity default.

\footnotetext{
${ }^{3}$ Average recovery rate of OECD countries.
} 
Table H.1: Counterfactual Analysis 1 - Alternative Model 1

\begin{tabular}{lccccc}
\hline \hline & Baseline 1 & No tax & No fin. margin & No adm. cost & Costless Default \\
\hline Entrep. credit-to-GDP & 12.46 & 13.83 & 13.45 & 15.7 & 18.61 \\
Imp. credit-to-GDP & 8.94 & 9.81 & 12.83 & 11.16 & 11.5 \\
Investment-to-GDP & 17.85 & 18.67 & 17.69 & 18 & 18.41 \\
Entrep. default & 0.89 & 1.17 & 1.06 & 1.64 & 2.73 \\
Imp. default & 1.8 & 2.24 & 3.6 & 2.95 & 5.64 \\
Entrep. credit spread: $r^{b e}-r d$ & 2.9 & 2.87 & 2.65 & 1.88 & 3.48 \\
Imp. credit spread: $r^{b I}-r d$ & 9.46 & 8.69 & 4.91 & 6.49 & 10.55 \\
Banking physical deprec. & 3.89 & 6.21 & 0.45 & 2.64 & 3.64 \\
\hline
\end{tabular}

Notes: Time period is to one quarter. Ratios, depreciation, and real variables in percentage. Spreads, rates and default in percentage points. No tax: $\tau^{f I}=\tau^{f e}=0$. No financial margin: $\varepsilon^{p} \rightarrow-\infty, \varepsilon^{I} \rightarrow \infty, \varepsilon^{e} \rightarrow \infty$. No administrative cost: $\eta=0$. Costless default: $\mu^{I}=\mu^{e}=0.3$.

Table H.2: Counterfactual Analysis 2 - Alternative Model 1

\begin{tabular}{lccccc}
\hline \hline & $\begin{array}{c}\text { No tax } \\
\text { Costless default }\end{array}$ & $\begin{array}{c}\text { No fin. margin } \\
\text { No adm cost }\end{array}$ & $\begin{array}{c}\text { No fin.margin } \\
\text { Costless default }\end{array}$ & $\begin{array}{c}\text { No adm. cost } \\
\text { Costless default }\end{array}$ & No friction \\
\hline Entrep. credit-to-GDP & 21.15 & 16.48 & 20.52 & 24.72 & 28.26 \\
Imp. credit-to-GDP & 12.85 & 14.02 & 17.78 & 14.96 & 20.72 \\
Investment-to-GDP & 19.57 & 17.85 & 18.3 & 18.74 & 19 \\
Entrep. default & 3.61 & 1.81 & 3.28 & 5.13 & 6.38 \\
Imp. default & 7.04 & 4.11 & 11.47 & 9.36 & 13.62 \\
Entrep. credit spread: $r^{b e}-r d$ & 3.66 & 1.67 & 3.36 & 3.06 & 3.27 \\
Imp. credit spread: $r^{b I}-r d$ & 10.09 & 3.7 & 7.33 & 8.41 & 6.67 \\
Banking physical deprec. & 5.78 & 0.45 & 0.45 & 2.47 & 0.68 \\
\hline
\end{tabular}

Notes: Time period is to one quarter. Ratios, depreciation, and real variables in percentage. Spreads, rates and default in percentage points. No tax: $\tau^{f I}=\tau^{f e}=0$. No financial margin: $\varepsilon^{p} \rightarrow-\infty, \varepsilon^{I} \rightarrow \infty, \varepsilon^{e} \rightarrow \infty$. No administrative cost: $\eta=0$. Costless default: $\mu^{I}=\mu^{e}=0.3$. No friction: only default. 


\section{I}

\section{Model with Banking Technology - Alternative Model 2}

A potential drawback of baseline model is the administrative cost reduced form and someone could question our counterfactual analysis results. We address this problem modeling a banking technology explicitly.

The central difference from baseline model is a Cobb-Douglass credit production function with labor and capital as inputs. We also assume sector specific factors: there are a final goods and another loan sector demanding production factors without mobility.

Results suggest that administrative cost reduced form captures mechanism similar to the structural approach. Reduced form banking employs final goods to produce credit, but final goods producers already combine capital and labor in their production. In the structural approach, capital and labor are employed by banks directly. We choose the reduced form approach in baseline since it is easier to discipline parameters.

Regarding model alterations, we include capital producers of capital that is employed in banking technology and allow labor supply by patient and impatient households. New utility function is

$$
\left\{\log \left(\left[\xi\left(C_{t}^{x}\right)^{\sigma}+(1-\xi)\left(S_{t}^{x}\right)^{\sigma}\right]^{\frac{1}{\sigma}}\right)-\frac{w l 1\left(L_{1, t}^{x}\right)^{1+\varphi}}{1+\varphi}-\frac{w l 2\left(L_{2, t}^{x}\right)^{1+\varphi}}{1+\varphi}\right\} .
$$

We also include $\frac{W_{2, t-1}^{x} L_{2, t-1}^{x}}{\pi_{t}}$ in the budget constraints as a source of funds. ${ }^{1}$

The major alteration is the wholesale bank $j$ problem which chooses a stream of $B_{t}(j), D_{t}(j), R_{t}(j), K_{2, t}(j), L_{2, t}^{p}(j)$ and $L_{2, t}^{I}(j)$ in order to maximize

$$
\begin{aligned}
E_{0} \sum_{t=0}^{\infty} \lambda_{0, t}^{p}\left[\left(1+R_{t}^{b}\right) B_{t}(j)+\left(1+r_{t}^{r}\right) R_{t}(j)-\left(1+R_{t}^{d}\right) D_{t}(j)-K_{t}^{b}(j)-\right. \\
\quad \frac{\kappa_{K b}}{2}\left(\frac{K_{t}^{b}(j)}{B_{t}(j)+R_{t}(j)}-\nu^{b}\right)^{2} K_{t}^{b}(j)-W_{2, t}^{p} L_{2, t}^{p}(j)-W_{2, t}^{I} L_{2, t}^{I}(j)- \\
\left.q_{t}^{k_{2}} K_{2, t}(j)+q_{t}^{k_{2}}\left(1-\delta^{K_{2}}\right) K_{2, t-1}(j)\right],
\end{aligned}
$$

\footnotetext{
${ }^{1}$ Banking sector expenditures of a given period is paid only next period as Gerali et al. (2010).
} 
s.t.

$$
\begin{aligned}
B_{t}(j)+R_{t}(j) & =D_{t}(j)+K_{t}^{b}(j), \\
R_{t}(j) & \geq \theta^{d} D_{t}(j), \\
B_{t}(j) & =A_{2, t} K_{2, t-1}^{\alpha_{2}}(j)\left[\left(L_{2, t}^{p}(j)\right)^{\theta_{2}}\left(L_{2, t}^{I}(j)\right)^{1-\theta_{2}}\right]^{1-\alpha_{2}} .
\end{aligned}
$$

The computation of model steady state is slightly different from baseline approach. Guess $R^{b}$ and verify if loan demand equals supply. 


\section{Data Sources}

\section{J.1}

Nonearmarked credit operations outstanding - Total

Outstanding balance of credit operations portfolio in the end of a period, with interest rates established under market conditions. It excludes operations with regulated rates, operations with funds from the National Bank for Economic and Social Development (BNDES) or any operations with government funds or funds with mandatory destination. Periodicity: Monthly; Range: 01/2011-12/2019; Source: Banco Central do Brasil - Departamento de Estatísticas/ Data code: 20542.

\section{J.2}

Nonearmarked credit operations outstanding - Non-financial corporations - Total

J.1 definition, but credit only to non-financial corporations. Periodicity: Monthly; Range: 01/2011-12/2019; Source: Banco Central do Brasil - Departamento de Estatísticas/ Data code: 20543.

\section{J.3}

Nonearmarked credit operations outstanding - Households - Total

J.1 definition, but credit only to households. Periodicity: Monthly; Range: 01/2011-12/2019; Source: Banco Central do Brasil - Departamento de Estatísticas/ Data code: 20570.

\section{J.4}

Percent of 90 days past due loans of nonearmarked credit operations outstanding - Non-financial corporations - Total

Share of National Financial System portfolio of nonearmarked credit operations in which there is at least one payment in arrears for over 90 days. It excludes operations with regulated rates, operations with funds from the National Bank for Economic and Social Development (BNDES) or any operations with government funds or funds with mandatory destination. Credit only to Non-financial corporations. Periodicity: Monthly; Range: 01/2011- 
12/2019; Source: Banco Central do Brasil - Departamento de Estatísticas/ Data code: 21086.

\section{$\mathrm{J} .5$}

90 days past due loans - Nonearmarked credit outstanding - Households - Total

J.4 definition, but credit to households. Periodicity: Monthly; Range: 01/2011-12/2019; Source: Banco Central do Brasil - Departamento de Estatísticas/ Data code: 21112.

\section{J.6}

\section{Regulatory Capital to Risk-Weighted Assets}

This indicator measures the capital adequacy of financial institutions and is based on the definitions used in the Basel Capital Accord. Scope of entities: Commercial banks, universal banks, investment banks, savings banks or any financial conglomerate comprising any of these entities. Periodicity: Monthly; Range: 01/2011-12/2019; Source: Banco Central do Brasil/ Data code: 21424.

\section{J.7}

ICC Spread - Nonearmarked - Non-financial corporations - Total

Difference between average cost of outstanding loans (ICC) and its average funding cost of non-financial corporations credit. Periodicity: Monthly; Range: 01/2013-12/2019; Source:Banco Central do Brasil - Departamento de Estatísticas/ Data code: 27447.

\section{J.8}

\section{ICC Spread - Nonearmarked - Households - Total}

Difference between average cost of outstanding loans (ICC) and its average funding cost of households credit. Periodicity: Monthly; Range: 01/201312/2019; Source:Banco Central do Brasil - Departamento de Estatísticas/ Data code: 27448.

\section{J.9}

\section{GDP at current prices in $\mathrm{R} \$$}

Current price GDP measures the total value of goods and services for final use obtained during the year before deducting consumption of fixed capital. Periodicity: Annually ; Range: 2011-2019; Source: IBGE/ SGS Data code: 1207. 


\section{J.10 \\ GDP - investment rate - current prices}

The relationship between gross fixed capital formation (GFCF) and gross domestic product (GDP), both at current prices, that is, in the year in which that the products were produced and marketed. GFCF corresponds to the value of durable goods purchased on the market or produced on their own and intended for use, in production units, for a period exceeding one year. Periodicity: Annually ; Range: 2011-2018; Source: IBGE/Data code: SCN10_FBKFPIBV10.

\section{J.11}

Payout

Ratio of shareholders total remuneration and earnings from 18 publicly traded companies (BOVESPA) that provide financial services. Periodicity: Annually ; Range: 2011-2019; Source: Bloomberg.

\section{J.12 \\ IPCA}

Indice nacional de preços ao consumidor-amplo is an inflation measure of a set of products and services sold at retail related to household consumption. Its coverage represents $90 \%$ of household living in an urban area. Periodicity: Monthly; Range: 2011-2019; Source: IBGE/ SGS Data code: 433.

\section{J.13}

CDB

Real return of certificado de depósito de crédito (CDB) and recibos de depósitos bancários (RDB) for households. Financial firms use these time deposits from household to fund their activities. We use the average rate of all time deposits to household and discount the inflation rate (IPCA). First, we calculate the time deposit real rate yearly, and then take the average. Periodicity: Monthly; Range: 2011-2019; Source: Sisbacen PESP300/ Data code: 28585. 